KEURRIE CIPRIANO GOES

\title{
UM MODELO PARA PREVISÃO DE VIDA À FADIGA DE JUNTAS SOLDADAS SUBMETIDAS A CARREGAMENTOS COMBINADOS
}

Dissertação apresentada à Escola

Politécnica da Universidade de

São Paulo para a obtenção do

Título de Mestre em Engenharia Mecânica

São Paulo 
KEURRIE CIPRIANO GOES

\title{
UM MODELO PARA PREVISÃO DE VIDA À FADIGA DE JUNTAS SOLDADAS SUBMETIDAS A CARREGAMENTOS COMBINADOS
}

\author{
Dissertação apresentada à Escola \\ Politécnica da Universidade de \\ São Paulo para a obtenção do \\ Título de Mestre em Engenharia Mecânica
}

Área de concentração:

Engenharia Mecânica de Projeto de

Fabricação

Professor Orientador:

Prof. Dr. Gilmar Ferreira Batalha

São Paulo 
Este exemplar foi revisado e alterado em relação à versão original, sob responsabilidade única do autor e com a anuência de seu orientador.

São Paulo, 07 de maio de 2010.

Assinatura do autor

Assinatura do orientador

FICHA CATALOGRÁFICA

Goes, Keurrie Cipriano

Um modelo para previsão de vida à fadiga de juntas solda das submetidas a carregamentos combinados / K.C. Goes. -ed.rev. -- São Paulo, 2010.

99 p.

Dissertação (Mestrado) - Escola Politécnica da Universidade de São Paulo. Departamento de Engenharia Mecatrônica e de Sistemas Mecânicos.

1. Fadiga dos materiais (Análise) 2. Juntas soldadas 3 . Tensão dos materiais 4 . Integridade estrutural 5 . Método dos elementos finitos I. Universidade de São Paulo. Escola Politécnica. Departamento de Engenharia Mecatrônica e de Sistemas Mecânicos II. t. 


\section{DEDICATÓRIA}

Dedico este trabalho as duas Anitas da minha vida:

Minha filha e minha vovó (in memoriam)

E ao meu grande amigo e mentor Arnaldo Camarão 


\section{AGRADECIMENTOS}

A minha filha, meu amorzinho, que tanto me apóia e entende (ou pelo menos tenta) a ausência da mãe, que durante meus estudos em casa me trazia chazinho e água e pedia para as amiguinhas não fazerem muito barulho, pois a mãe estava estudando. A minha mamãe Josani e minha irmã Kryslei, pelo apoio, paciência, carinho e por sempre acreditarem em mim. Ao meu vovô José Cipriano, que me recebe com um delicioso abraço, mesmo sabendo que perderá seu sofá e seu sossego durante o final de semana. A Rose, meu braço direito e esquerdo, que cuidou de tudo enquanto eu estudava e bagunçava (muito).

Ao meu orientador Prof. Dr. Gilmar Ferreira Batalha, pelo apoio, ensinamentos, incentivo e confiança que depositou no meu trabalho.

Ao meu co-orientador e amigo Arnaldo Freitas Camarão, que com muita paciência me ajudou com seus ensinamentos sobre elementos finitos, fadiga e sobre a vida. Uma pessoa fantástica, iluminada e amiga, um verdadeiro exemplo a ser seguido. Alguém com quem sempre vale a pena tomar um café quer seja no Otavio, na Colombo, ou na padoca da esquina e que ao final sempre se leva um ensinamento para o resto da vida.

A Luis Augusto lba, meu compadre e grande amigo. Paidrinho da Anita, que fez as vezes desta mãe, quando nos feriados eu ficava estudando e ele ia viajar com a Anita.

Aos meus amigos que me fizeram fugir um pouco do projeto, para retomar um ar e recomeçar tudo de novo, em especial a Julio Cezar (meu compadre e excelente atacante, isso dito por ele), Larissa (não poderia escolher melhor madrinha para a Anita), Fabíola (a nova ex-solteira, amiga de infância), Mary (anos e anos de uma grande amizade), Dennis (pelos sorvetes que eu estou devendo), as amigas de Santos: Bruna, Alexsandra, Ivane, Carla e Marly, pela delicadeza com a qual 
acolheram essa intrusa Paulistana, apesar de ser Santista de nascimento e ao Daniel (saudade dos nossos papos nos corredores da ArM).

Aos amigos da primeira turma de engenharia mecânica noturno da Unesp de Guaratinguetá, em especial a Anchieta, Siqueira, Fernando e Anderson, o presente trabalho não seria possível sem uma boa base, conseguida através de uma boa faculdade e de excelentes companheiros de turma.

A Maria Esther, que sempre acreditou que eu podia e que eu posso conseguir tudo o que eu quiser inclusive terminar esta dissertação.

Aos amigos da ArvinMeritor, que tanto me apoiaram nesta aventura que foi fazer um trabalho de mestrado, especialmente ao meu amigo Egídio Correia, por prorrogar os prazos de entrega dos meus projetos enquanto era meu chefe e me auxiliar na reta final deste trabalho, sendo imprescindível para a conclusão desta dissertação. Ao grande amigo Juliano Rodrigues, por fazer todas as versões dos desenhos 3D tendo muita paciência com a autora. Ao amigo José Roberto dos Santos, uma pessoa maravilhosa, que me presenteou com seus desenhos "davincianos" ao projetar o dispositivo de fadiga (que foram vários até chegarmos ao definitivo) e pelo suporte nos testes de fadiga. Ao amigo Nivaldo Manzini, um gênio da instrumentação, que me ensinou um pouco do muito que sabe, mesmo eu acabando com as colas do laboratório. Ao Marcelo Pinto, exímio soldador, que fez todas as soldas manualmente e a Antonio Carlos Ferreira, um mestre na análise metalúrgica, que analisou as amostras no laboratório de metalurgia.

A ArvinMeritor pelo suporte dado a autora enquanto esta realizava o presente trabalho; por ceder o laboratório de ensaios mecânicos e o laboratório de metalurgia e por fornecer as amostras deste trabalho.

A USP que acolheu esta Unespiana de braços abertos. 
Que o teu trabalho seja perfeito para que, mesmo depois da tua morte, ele permaneça. 


\section{RESUMO}

O presente trabalho teve como objetivo desenvolver uma metodologia prática e confiável para previsão de vida à fadiga de juntas soldadas a cordão pelo processo MIG/MAG, quando estas estão submetidas a carregamentos cíclicos combinados. A máxima tensão linear no pé da solda, região típica de início de trinca, conhecida como hot spot foi utilizada para prever a vida através do método de Fadiga de Alto Ciclo $S \times N$ (Tensão $x$ Vida), largamente empregado em códigos de projeto de estruturas soldadas. O Método dos Elementos Finitos foi utilizado para determinação das tensões estruturais resultantes do carregamento e das descontinuidades geométricas presentes nos cordões de solda. A análise de fadiga foi efetuada em ambiente virtual, através de um software (programa) de fadiga capaz de importar as tensões atuantes na região da solda para cada carregamento, combinando-as e obtendo assim a vida à fadiga decorrente da somatória dos diferentes tipos de carregamento ao qual a junta foi submetida. As propriedades monotônicas e cíclicas dos materiais da junta foram obtidas da literatura e de um extenso banco de dados disponível no software de fadiga. Estas propriedades foram ajustadas com base em ensaios de laboratório nas juntas investigadas. A medição ou modelagem das tensões residuais inerentes ao processo de soldagem não fazem parte do escopo deste trabalho. Contudo, os efeitos térmicos e metalúrgicos resultantes do processo de soldagem, como distorções, tensões residuais, variações microestruturais e propriedades mecânicas foram considerados de forma indireta, através da correção das curvas de fadiga nos corpos de prova investigados. Corpos de prova do tipo tubo-placa foram submetidos a carregamentos cíclicos combinados (flexão e torção) de amplitude constante. $O$ resultado da análise virtual de durabilidade foi, portanto, calibrado com base nestes experimentos e curvas disponíveis em códigos de projeto de fadiga como BS7608 e Eurocode 3. A aplicabilidade deste método numéricoexperimental e suas contribuições para a garantia da Integridade Estrutural do projeto de juntas soldadas são apresentadas. Seus desafios e melhorias são por fim discutidos.

Palavras-chaves: fadiga, carregamento cíclico combinado, integridade estrutural, hot spot, junta soldada, elementos finitos. 


\begin{abstract}
The main purpose of this work is to develop a practical and robust methodology to evaluate the fatigue life in seam weld joints fabricated with GMAW process when subjected to combine cyclic loading. The maximum linear stress at the typical crack initiation region, better known as hot spot stress, was used to calculate the fatigue life through high cycle fatigue method $\mathrm{S} \times \mathrm{N}$ (Stress $\mathrm{x}$ Life), widely used in design codes for the life assessment of welded structures. The Finite Element Method (FEM) was used to obtain the structural stresses distribution due the external loading and geometric discontinuities very common in seam weld joints. The fatigue analysis was conducted in virtual environment. The FEM stress results from each loading were imported to fatigue code FE-Fatigue and combined to perform the fatigue life prediction. The monotonic and cyclic properties of the joint materials were obtained in the literature and from the fatigue software database. These properties were adjusted based on laboratory fatigue tests in the investigated welded joints configurations. The measurement or modeling of the residual stresses resulted from the welded process is not part of this work. However, the thermal and metallurgical effects, like distortions and residual stresses, were considered indirectly through fatigue curves corrections in the samples investigated. A tube-plate specimen was submitted to combine cyclic loading (bending and torsion) with constant amplitude. The virtual durability analysis result was calibrated based on these laboratory tests and design codes such as BS7608 and Eurocode 3. The feasibility and application of the proposed numericalexperimental methodology and contributions for the welded joints structural integrity design are presented. The challenges and improvements are finally discussed.
\end{abstract}

Keywords: fatigue, combined cyclic loading, structural integrity, hot spot, welded joint, finite elements. 


\section{LISTA DE FIGURAS}

Figura 1 - Região de uma junta soldada (adaptado de FUCHS \& STEPHENS, 1980) 18

Figura 2 - Integridade Estrutural

Figura 3 - Geometria das amostras: (a) tubo-placa circular, (b) tubo-placa retangular

Figura 4 - Parâmetros do ensaio de fadiga biaxial realizado por Bäckström et al (1997). 25

Figura 5 - Processos de Soldagem - Adaptado de Messler (1999) 26

Figura 6 - Regiões da ZAC de uma soldagem monopasse (NASCIMENTO, 2004) .27

Figura 7 - $O$ defeito de entalhe numa junta $T$. .28

Figura 8 - O defeito de porosidade numa junta a topo .29

Figura 9 - Diagrama de corpo livre (BORESI; SCHMIDT e SIDEBOTTOM, 1993)...29

Figura 10 - Tensões agindo em um plano do sistema de coordenadas . .30

Figura 11 - Variação do limite de escoamento, do módulo de elasticidade e do coeficiente de expansão térmica de aços com a temperatura (OKUMURA e TANIGUCHI, 1982) 32

Figura 12 - Distribuição de tensões residuais devidas a vínculos internos em juntas soldadas a topo (OKUMURA e TANIGUCHI, 1982).

Figura 13 - Distribuição de tensões residuais devidas a vínculos externos em juntas soldadas a topo (OKUMURA e TANIGUCHI, 1982). .33

Figura 14 - Relação entre as tensões residuais trativas e as distorções de uma chapa soldada (Adaptado de NITSCHKE-PAGEL, 2006)

Figura 15 - Concentração de tensões numa junta do tipo $T$ (a) e numa junta a topo (b)

Figura 16 - Exemplo de tensão nominal numa viga (NIEMI, 1995)

Figura 17 - Tensão estrutural numa placa, composta pelas tensões de membrana e de flexão (NIEMI, 1995). .36

Figura 18 - Tensão de hot spot (NIEMI, 1995)

Figura 19 - Tensão de entalhe (notch) no pé da solda, composta pelas tensões de membrana, de flexão e pelo pico de tensão não linear (NIEMI, 1995). .37

Figura 20 - Elementos em 1D, 2D e 3D, com nós. 
Figura 21 - Uma visão geral da análise de tensão em fadiga (Adaptado de Niemi, 1995)

Figura 22 - Terminologia da tensão alternada.

Figura 23 - Diagrama mestre para o aço AISI4340 (BANNANTINE; COMER;

HANDROCK, 1990)

Figura 24 - Comparativo entre as equações da tensão média (a-Soderberg, b-

Goodman, c-Gerber, d-Morrow) 45

Figura 25 - Curva S-N generalizada .

Figura 26 - Medição da tensão de hot spot através da extrapolação da tensão (adaptado de NIEMI, 1995)

Figura 27 - Comparação da resistência à fadiga em juntas de canto de base metálica, R = 0 (BRANCO; FERNANDES; CASTRO, 1986).

Figura 28 - Tipos de juntas soldadas, conforme BS153 (1972).

Figura 29 - Curvas S x N, em função do tipo de junta, propostas pela BS7608 (1993)

- Legenda conforme figura 28.

Figura 30 - Classes de juntas cruciforme e T propostas pela norma Eurocode $3 \ldots 53$

Figura 31 - Classe de junta avaliada pelo método hot spot com carregamento através da solda.

Figura 32 - Curvas $S \times N$, em função do tipo de junta, propostas pela Eurocode 3 (2005)

Figura 33 - Comparação da vida à fadiga para as diferentes classificações de juntas soldadas (Adaptado de FUCHS; STEPHENS, 1980). .54

Figura 34 - Geometria das amostras utilizadas 56

Figura 35 - Nomenclatura utilizada no dimensional da junta . 57

Figura 36 - Microestrutura do material do tubo com ampliação de 500x . 59

Figura 37 - Microestrutura do material do flange com ampliação de 500x 59

Figura 38 - Microestrutura do material da solda com ampliação de 500x. 60

Figura 39 - Microestrutura da região entre a solda e o material da ZAC do tubo com ampliação de 100x 60

Figura 40 - Micrografia do ensaio de dureza Knoop (500g) e distribuição de dureza HRC ao longo da ZAC (b) - Material do tubo (metal base). 62

Figura 41 - Micrografia do ensaio de dureza Knoop (500g) e distribuição de dureza HRC ao longo da ZAC (b) - Material do flange. 63

Figura 42 - Eixo diferencial de um veículo comercial 
Figura 43 - Malha de Elementos Finitos. .66

Figura 44 - Carregamento no modelo $3 \mathrm{D}$

Figura 45 - Curva $\varepsilon \times N$ do metal base (FAP7) e a corrigida (obtida em laboratório) 68

Figura 46 - Diagrama dos 5 passos básicos para análise de durabilidade. .68

Figura 47 - Solda utilizada na junta tubo-placa................................................... 71

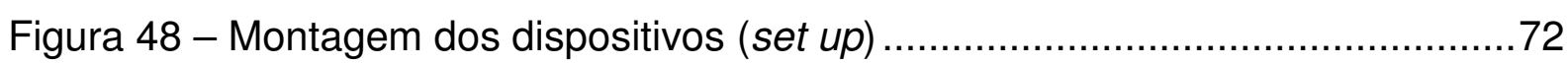

Figura 49 - Dispositivos utilizados no Ensaio de Fadiga .....................................73

Figura 50 - Ensaio de fadiga (a) e detalhe do dispositivo utilizado (b) ..................73

Figura 51 - Posicionamento da Roseta (a) juntamente com a fiação e a proteção (b)

Figura 52 - Curva de calibração da roseta localizada no LE (a) e no LD (b) da seção

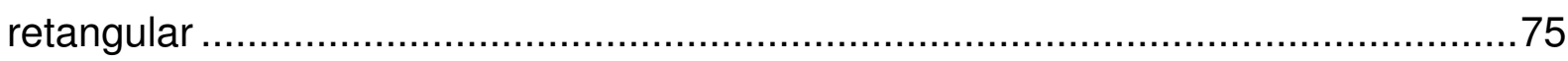

Figura 53 - Posicionamento das rosetas e força aplicada ..................................76

Figura 54 - Distribuição de tensões equivalentes no modelo de Elementos Finitos para o carregamento de $18 \mathrm{kN}$ (a) e detalhe na região crítica com indicação do ponto onde foi medida a tensão (b).

Figura 55 - Distribuição de tensões máximas principais no modelo de Elementos Finitos para o carregamento de $18 \mathrm{kN}$ (a) e detalhe na região crítica com indicação do ponto onde foi medida a tensão (b).

Figura 56 - Distribuição de vida para a tensão equivalente (a) e detalhe na região crítica (b)

Figura 57 - Distribuição de vida para a tensão máxima principal (a) e detalhe na região crítica (b)

Figura 58 - Trinca após o ensaio de resistência à fadiga sob carregamento de $18 \mathrm{kN}$ (a) e localização da trinca (2) - Amostra 01

Figura 59 - Trinca após o ensaio de resistência à fadiga sob carregamento de $18 \mathrm{kN}$

(a) e localização da trinca (2) - Amostra 02

Figura 60 - Foto da trinca e regiões da junta soldada na amostra 01

Figura 61 - Região de origem (a) e sentido de propagação (b) da trinca na amostra 01

Figura 62 - Micrografia da junta soldada na região da trinca - Amostra 01 .91

Figura 63 - Micrografia da junta soldada (a) apresentando a trinca principal (b) e secundária (c) - Amostra 02 


\section{LISTA DE TABELAS}

Tabela 1 - Visão geral dos diversos testes conduzidos por diferentes pesquisadores

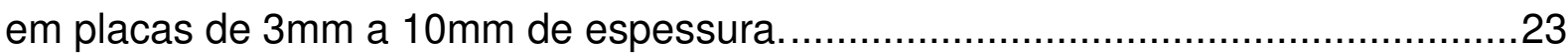

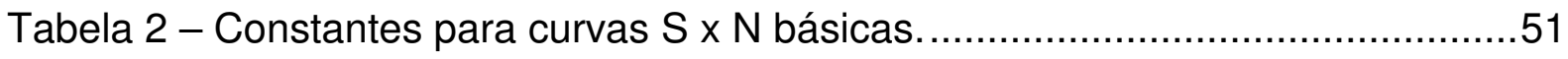

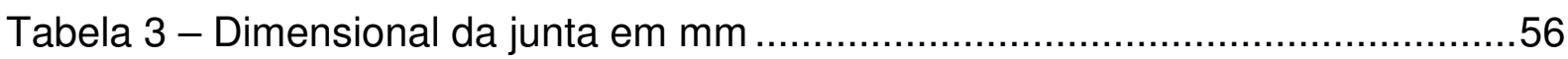

Tabela 4 - Composição química do material do tubo (em \%) .................................57

Tabela 5 - Composição química do material do flange.........................................58

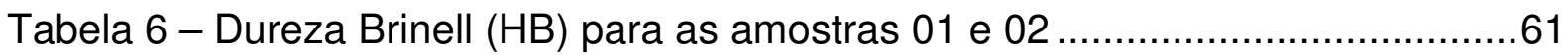

Tabela 7 - Propriedades do cordão de solda apresentado na Figura 47 ..................71

Tabela 8 - Resultado da tensão hot spot através do ANSYS para o carregamento de $18 \mathrm{kN}$

Tabela 9 - Resultado da tensão equivalente analítica para o carregamento de $18 \mathrm{kN}$

Tabela 10 - Resultado da tensão equivalente obtida experimentalmente

Tabela 11 - Comparativo entre os resultados de tensão equivalente no ponto analisado para o carregamento de $18 \mathrm{kN}$.

Tabela 12 - Resultado da vida à fadiga através do FE-Fatigue para o ponto analisado.

Tabela 13 - Resultados da vida à fadiga para as amostras ensaiadas em laboratório .88

Tabela 14 - Vida à fadiga utilizando as normas BS7608 e Eurocode 3, para a tensão de hot spot oriunda das diversas abordagens analisadas 


\section{LISTA DE SÍMBOLOS}

\begin{tabular}{|c|c|c|}
\hline Símbolo & Descrição & Unidade \\
\hline$S$ & Tensão Alternada & $\mathrm{MPa}$ \\
\hline$N$ & Número de Ciclos até ocorrer a falha & ciclos \\
\hline$t$ & Espessura & $\mathrm{m}$ \\
\hline$A_{m}$ & Razão de amplitude & - \\
\hline$F$ & Força axial & $\mathrm{N}$ \\
\hline$V$ & Força cisalhante & $\mathrm{N}$ \\
\hline$A$ & Área da seção transversal & $\mathrm{m}^{2}$ \\
\hline$A_{s}$ & Área de penetração de todas as soldas & $\mathrm{m}^{2}$ \\
\hline$M$ & Momento de flexão & N.m \\
\hline$I$ & Momento de Inércia da seção transversal & $\mathrm{m}^{4}$ \\
\hline$R$ & Razão de tensão & - \\
\hline$y$ & Distância do centróide ao ponto em estudo & $\mathrm{m}$ \\
\hline$[K]$ & Matriz de rigidez & $\mathrm{N} / \mathrm{m}$ \\
\hline$u$ & Deslocamento & $\mathrm{m}$ \\
\hline$K_{s}$ & Fator de concentração de tensão & - \\
\hline$C_{0}$ & Constante relacionada a tensão média da curva $S$ x $N$; & - \\
\hline$d$ & Números de desvio padrão abaixo da média & - \\
\hline$m$ & Inverso da inclinação da curva $\log S$ x $\log N$ & - \\
\hline$E$ & Módulo de Young & $\mathrm{GPa}$ \\
\hline$S_{y}$ & Tensão de Escoamento & $\mathrm{MPa}$ \\
\hline$S_{u}$ & Tensão de Ruptura & $\mathrm{MPa}$ \\
\hline$I$ & Corrente Elétrica & A \\
\hline$U$ & Tensão Elétrica & $\mathrm{V}$ \\
\hline$Q$ & Insumo de Calor & $\mathrm{J} / \mathrm{m}$ \\
\hline$r$ & $\begin{array}{l}\text { Distância do centro de gravidade do grupo de soldas ao ponto } \\
\text { de interesse da solda }\end{array}$ & $\mathrm{m}$ \\
\hline$J$ & $\begin{array}{l}\text { Momento de inércia polar do grupo de soldas em relação ao } \\
\text { centro de gravidade do grupo }\end{array}$ & $\mathrm{m}^{4}$ \\
\hline$J_{u}$ & Momento de inércia polar unitário & $\mathrm{m}^{4}$ \\
\hline
\end{tabular}




\begin{tabular}{|c|c|c|}
\hline$h$ & Tamanho da solda & $\mathrm{m}$ \\
\hline$I$ & Momento de inércia baseado na penetração da solda & $\mathrm{m}^{4}$ \\
\hline$I_{u}$ & Momento de inércia unitário & $\mathrm{m}^{4}$ \\
\hline$\varepsilon$ & Deformação & - \\
\hline$\sigma$ & Tensão trativa & $\mathrm{MPa}$ \\
\hline$\sigma_{n o m}$ & Tensão Nominal & $\mathrm{MPa}$ \\
\hline$\sigma_{s}$ & Tensão Estrutural & $\mathrm{MPa}$ \\
\hline$\sigma_{m}$ & Tensão de Membrana & $\mathrm{MPa}$ \\
\hline$\sigma_{b}$ & Tensão de Flexão & $\mathrm{MPa}$ \\
\hline$\sigma_{V M}$ & Tensão Equivalente ou de Von Mises & $\mathrm{MPa}$ \\
\hline$\sigma_{h s}$ & Tensão de Hot Spot & $\mathrm{MPa}$ \\
\hline$\sigma_{\text {ln }}$ & Tensão de Entalhe & $\mathrm{MPa}$ \\
\hline$\sigma_{n l p}$ & Tensão de Pico não Linear & $\mathrm{MPa}$ \\
\hline$\sigma_{\max }$ & Tensão Máxima & $\mathrm{MPa}$ \\
\hline$\sigma_{\min }$ & Tensão Mínima & $\mathrm{MPa}$ \\
\hline$\sigma_{a}$ & Amplitude de Tensão & $\mathrm{MPa}$ \\
\hline$\sigma_{m}$ & Tensão Média & $\mathrm{MPa}$ \\
\hline$\Delta \sigma$ & Variação de Tensão & $\mathrm{MPa}$ \\
\hline$\delta$ & Desvio padrão do $\log N$ & - \\
\hline$v$ & Número de Poisson & - \\
\hline$v$ & Velocidade de deposição & $\mathrm{m} / \mathrm{s}$ \\
\hline$\tau$ & Tensão cisalhante & $\mathrm{MPa}$ \\
\hline$\tau^{\prime}$ & Cisalhamento primário & $\mathrm{MPa}$ \\
\hline$\tau^{\prime \prime}$ & Cisalhamento secundário & $\mathrm{MPa}$ \\
\hline
\end{tabular}




\section{LISTA DE ABREVIATURAS}

ABCM Associação Brasileira de Engenharia e Ciências Mecânicas

ABNT Associação Brasileira de Normas Técnicas

ABS Associação Brasileira de Soldagem

AISI American Iron and Steel Institute

ASTM American Society for Testing and Materials

BS British Standard

EUR3 Norma Eurocode 3

HB Brinell Hardness (Dureza Brinell)

HRB Hardness Rockwell B (Dureza Rockwell B)

HRC Hardness Rockwell C (Dureza Rockwell C)

IIW International Institute of Welding

LD Lado Direito

LE Lado Esquerdo

MAG Metal Active Gas

MEF Método dos Elementos Finitos

MGAW Metal Gas Arc Welding

MIG Metal Inert Gas

SAE Society of Automotive Engineers

TIG Tungsten Inert Gas

ZAC Zona Afetada pelo Calor 


\section{SUMÁRIO}

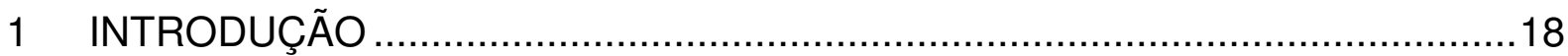

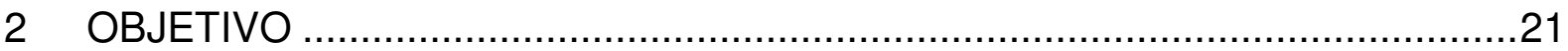

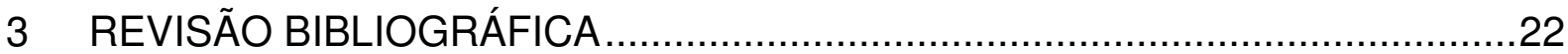

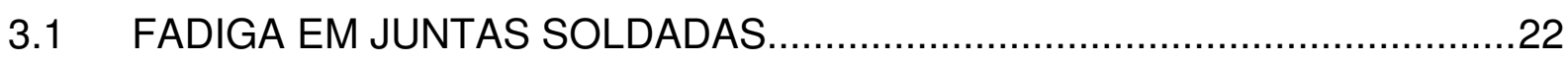

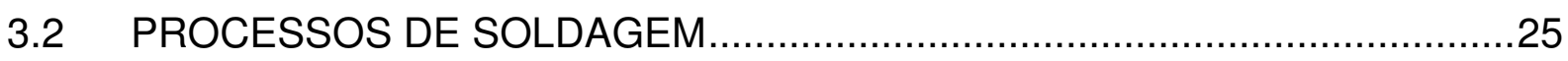

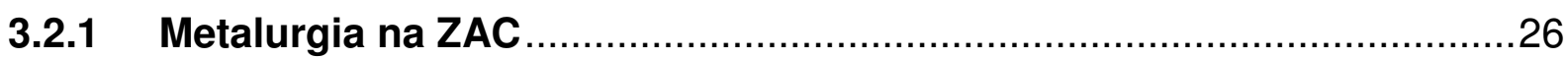

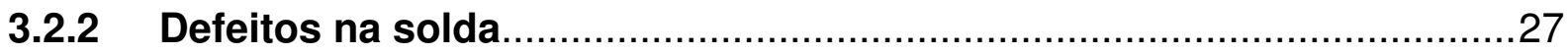

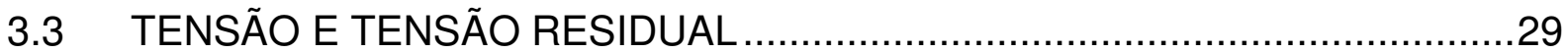

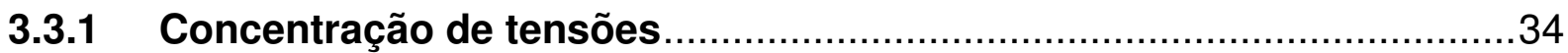

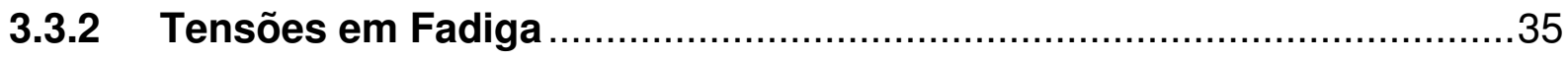

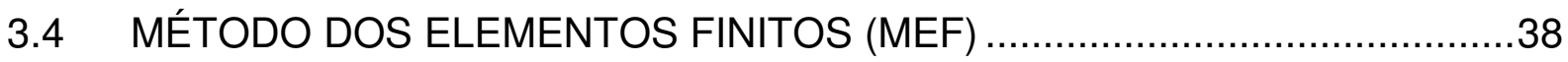

3.4.1 Passos na análise por Elementos Finitos .......................................... 40

3.4.2 Análise das tensões na junta soldada utilizando o MEF ......................40

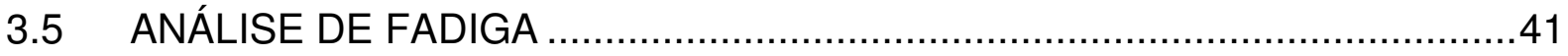

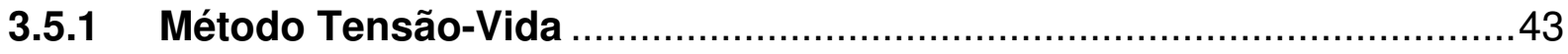

3.5.2 Análise de Fadiga pela abordagem de tensão hot spot.......................46

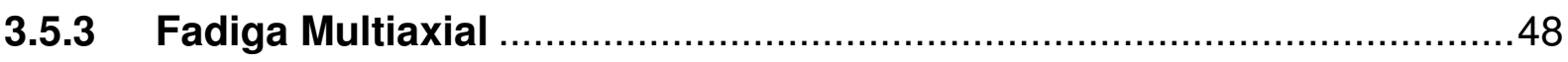

3.6 TÉCNICAS DE MELHORIA DA RESISTÊNCIA À FADIGA EM JUNTAS

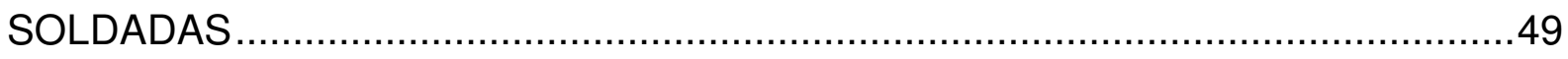

3.7 NORMAS DE FADIGA PARA JUNTAS SOLDADAS .................................

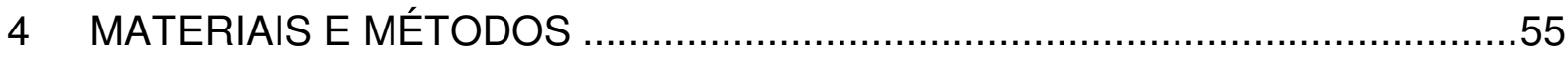

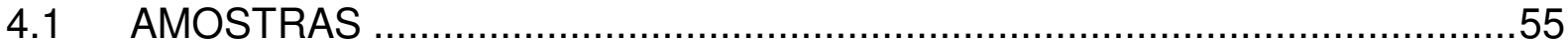

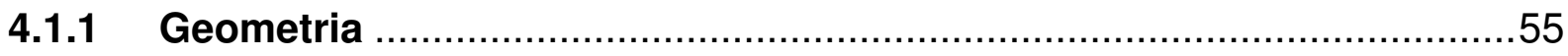

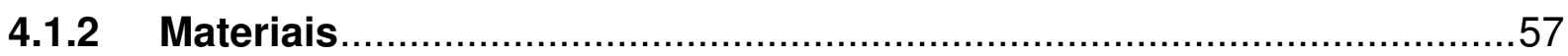

4.1.3 Parâmetros de soldagem das amostras ............................................64

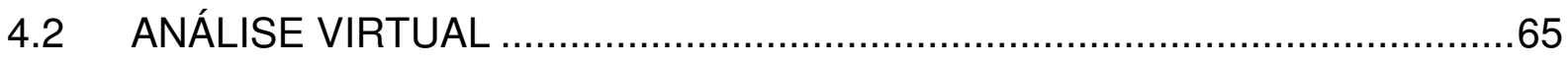

4.2.1 Análise das tensões por Elementos Finitos …………......................65

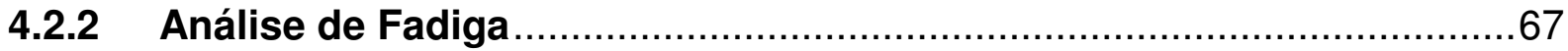

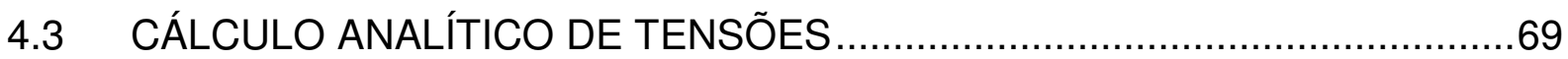

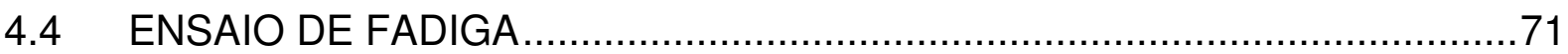


4.4.1 Dispositivos e parâmetros do ensaio de Fadiga ……….....................

4.4.2 Calibração do ensaio de Fadiga ..........................................................

4.4.3 Determinação da tensão hot spot ...................................................

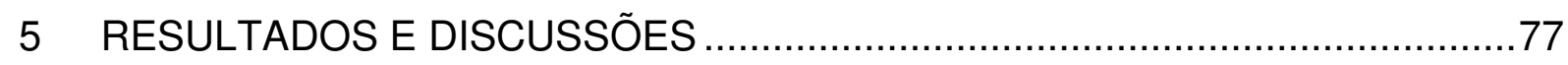

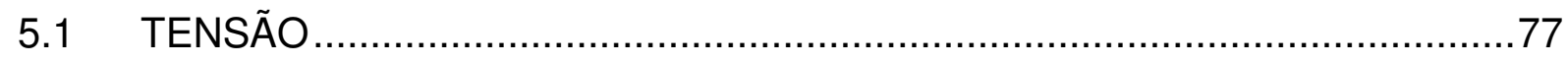

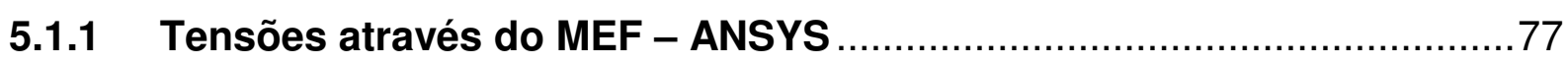

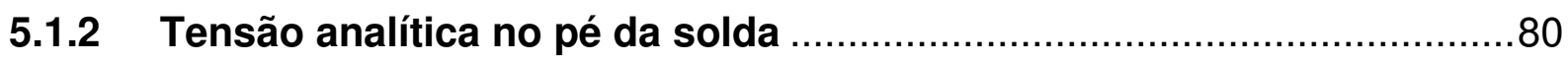

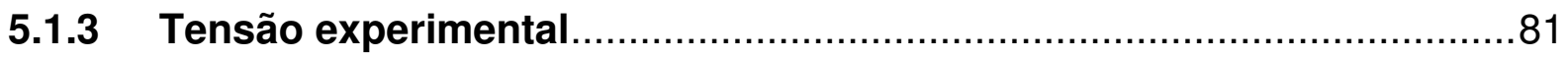

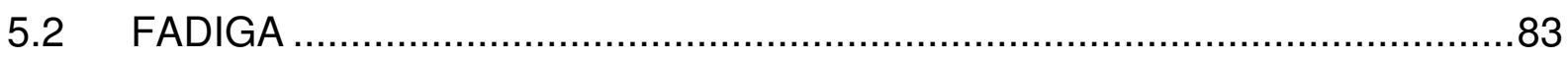

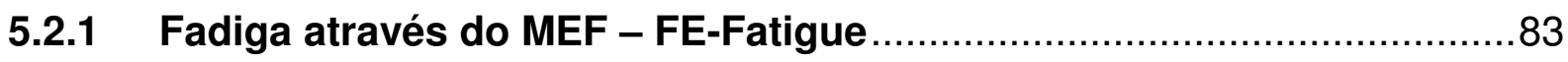

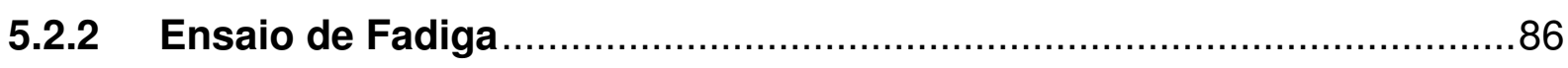

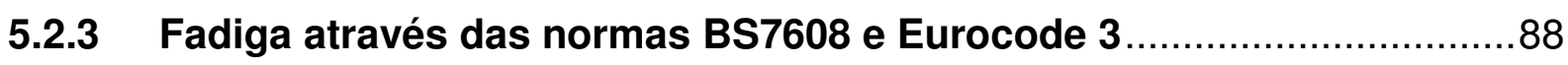

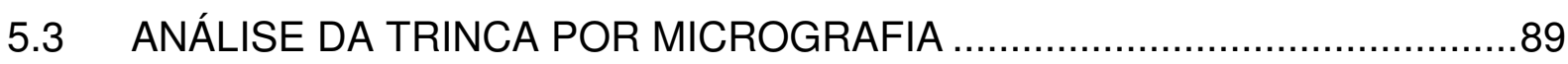

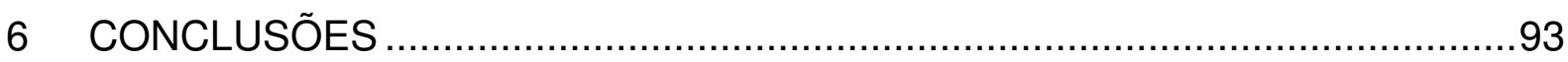

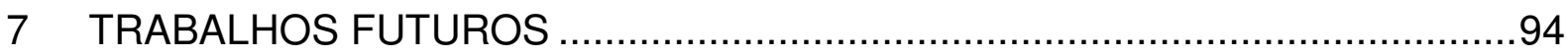

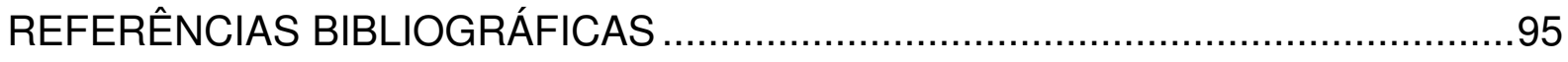




\section{INTRODUÇÃO}

A soldagem é um dos processos de união que alia flexibilidade e baixo custo, sua utilização está intrinsecamente ligada à indústria em geral, indo desde a manutenção de maquinário até a soldagem de componentes em um ônibus espacial.

Juntas metálicas, unidas por processos de soldagem, apresentam como conseqüência deste processo, regiões críticas, devido a variações de rigidez, concentradores de tensões geométricas e altos gradientes de temperatura, que resultam em distorções, variações microestruturais e de propriedades mecânicas e tensões residuais. Todos estes efeitos estão presentes na ZAC, apresentada na Figura 1, assim como as demais regiões de uma junta soldada.

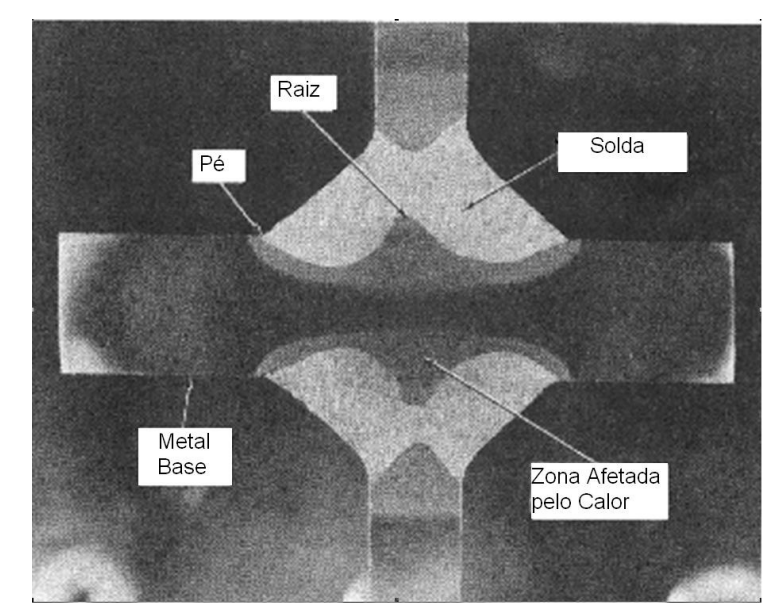

Figura 1 - Região de uma junta soldada (adaptado de FUCHS \& STEPHENS, 1980)

Normalmente em uma estrutura soldada submetida a carregamento cíclico o início da trinca se dá na "raiz" ou no "pé" da solda conforme apresentado na Figura 1. Nesta imagem três regiões estão bem definidas: o metal base, o material da solda e a ZAC. Estas três regiões possuem diferentes microestruturas, tensões residuais, defeitos e propriedades mecânicas. Os estudos de fadiga com este tipo de estrutura têm demonstrado que a integridade de um projeto depende entre outros fatores do nível de tensão que esta região estará sujeita em trabalho (GOES et al, 2008).

$O$ estudo da resistência da junta tem como objetivo a análise desses efeitos e sua otimização, visando evitar falhas prematuras por fadiga e garantir sua integridade e desempenho, quando submetida às condições de serviço. $O$ escopo deste trabalho 
está inserido, portanto, dentro do campo da Integridade Estrutural, que pode ser melhor entendida como a garantia da resistência e desempenho de um produto, através da combinação de três fatores principais, como Geometria, Material \& Processo e Esforços \& Condições de Serviço. Estes fatores são ilustrados com o auxílio do diagrama da Figura 2, onde os vértices do triângulo são os principais elementos da Integridade Estrutural.

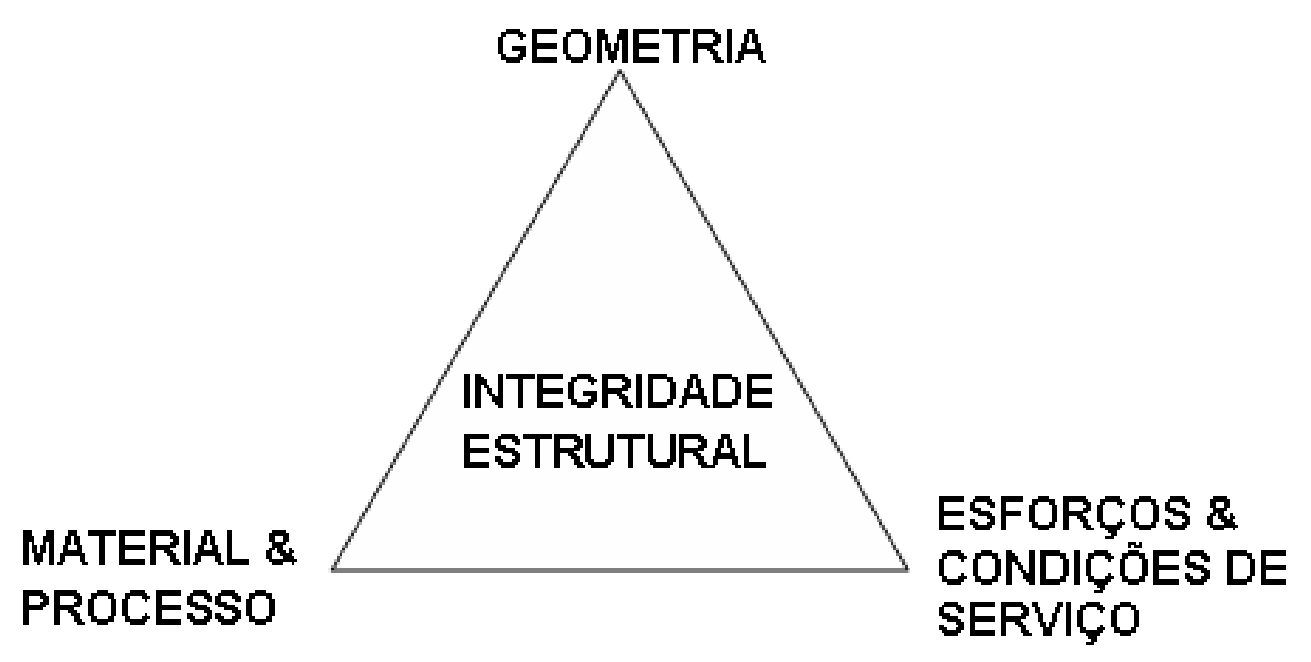

Figura 2 - Integridade Estrutural

A geometria envolve o projeto da junta, considerando a rigidez das peças unidas e a concentração de tensões. A avaliação do efeito da geometria somado ao carregamento externo na Integridade Estrutural da junta será efetuada através do Método de Elementos Finitos (MEF). O programa comercial ANSYS será utilizado para modelagem da junta e obtenção da distribuição de tensões no modelo, devido ao carregamento externo.

Os esforços cíclicos podem resultar na fadiga da junta que será analisada através do programa de Fadiga FE-Fatigue, integrado ao modelo de Elementos Finitos, validado em laboratório, através de ensaios de fadiga em corpos de prova.

$\mathrm{Na}$ região da ZAC, o material utilizado, tanto no cordão de solda quanto no metal base, e o processo fecham o triângulo da Integridade Estrutural. É nesta região onde se encontra as tensões residuais trativas que impactam negativamente na vida à fadiga do material. Estas tensões podem ser estimadas através de métodos numéricos, como o MEF, ou medidas por métodos experimentais. A medição da 
tensão residual está fora do escopo do presente trabalho, mas ao utilizar as curvas das diversas normas disponíveis, as tensões residuais já são contempladas, pois estas curvas são obtidas experimentalmente, considerando assim os efeitos que a tensão residual ocasiona na vida à fadiga do material. O presente trabalho validou a metodologia aqui apresentada através de testes experimentais de vida à fadiga, onde a tensão residual e todos os efeitos do processo de soldagem estão inseridos na curva de fadiga da junta.

É importante salientar que para garantir a Integridade Estrutural de uma junta soldada é necessário combinar adequadamente os três fatores aqui citados. A alteração em um destes deve ser seguida de uma verificação nos demais, garantindo assim a efetiva Integridade Estrutural da junta soldada.

Segundo Sonsino (2009), prever a vida à fadiga de componentes soldados requer uma adequada análise das tensões atuantes na junta, bem como do método de análise de fadiga, que diferem entre si pelo parâmetro utilizado para descrever a tensão (S) ou a deformação $(\varepsilon)$ atuante na junta e que ocasionam a vida à fadiga (N).

Sabendo que cada junta soldada tem um comportamento à fadiga que depende dos três itens mencionados na Figura 2 conclui-se que a cada novo projeto um teste laboratorial deve ser realizado para validação do mesmo. Entretanto, testes laboratoriais demandam tempo e seus custos são elevados, ocasionando dificuldades para realização dos mesmos, principalmente no ambiente industrial, onde a redução de custos é um fator importante no projeto. O tamanho das peças soldadas pode dificultar ou até impossibilitar a realização dos testes laboratoriais, como por exemplo, na indústria naval e na de veículos pesados (ônibus, caminhões e veículos fora de estrada como mineração). Visando minimizar estes problemas, o presente trabalho apresenta uma metodologia numérico-experimental que possibilita a avaliação virtual das diversas configurações de junta soldada, ainda na fase de projeto, garantido a integridade do produto, com um número mínimo de protótipos, atingindo assim o grande objetivo da indústria: redução de custos e de tempo de desenvolvimento. 


\section{OBJETIVO}

Geral: Compreender os fundamentos de fadiga em juntas soldadas.

Específico: Desenvolver um procedimento numérico-experimental prático e confiável para previsão de vida à fadiga de juntas do tipo tubo-placa, unidas através do processo de soldagem MIG/MAG, quando estas estão submetidas a carregamentos cíclicos combinados. 


\section{REVISÃo BIBLIOGRÁFICA}

\subsection{FADIGA EM JUNTAS SOLDADAS}

A fadiga dos materiais é um processo muito complexo, que ainda nos dias de hoje não é totalmente conhecido. $O$ dano no material se inicia na estrutura cristalina e torna-se visível através da seqüência: deformação plástica, formação de microtrincas nas bandas de escorregamento, coalescência das micro-trincas e finalmente a propagação da trinca principal.

A fadiga de juntas soldadas é ainda mais complexa. A soldagem afeta o material através do processo de aquecimento e subseqüente resfriamento, ocasionado pelo processo de fusão que adiciona o material da solda (para soldas com adição de material), resultando em materiais não homogêneos e diferentes (FRICKE, 2003). Somado a isto, a solda usualmente não é perfeita, contendo inclusões, poros, cavidades, etc. $O$ perfil entre a solda e o metal base provoca descontinuidades geradoras de alta concentração de tensões. Por último, as tensões residuais e as distorções devido ao processo de soldagem afetam o comportamento à fadiga.

Diversos autores têm abordado o assunto de fadiga em juntas soldadas, mas quando o material é submetido a carregamento combinado, pode-se citar, segundo Bäckström (2003): Kouba \& Stallmayer (1959), Gurney \& Woodley (1962) e Braithwaite (1964) como os precursores neste assunto.

Uma visão geral dos testes conduzidos por pesquisadores que utilizaram amostras semelhantes as do presente trabalho (tubo-placa) é apresentado na Tabela 1.

Yung e Lawrence (1986), Siljander; Kurath e Lawrence (1992), Sonsino (1995, 1997) e Razmjoo (1996) realizaram testes de fadiga biaxial em amostras soldadas do tipo tubo-placa circular (Figura 3a), as amostras foram fabricadas em aço ASTM A519 com o tubo sem costura. Todas as amostras apresentaram falha no pé da solda, quando submetidas a carregamento combinado proporcional das tensões de flexão e de torção. 
Tabela 1 - Visão geral dos diversos testes conduzidos por diferentes pesquisadores em placas de $3 \mathrm{~mm}$ a $10 \mathrm{~mm}$ de espessura.

\begin{tabular}{|l|c|c|}
\hline \multirow{2}{*}{ Pesquisador } & \multicolumn{2}{|c|}{ Quantidade de amostras em cada teste } \\
\cline { 2 - 3 } & $\begin{array}{c}\text { Flexão e Torção } \\
\text { Proporcional }\end{array}$ & $\begin{array}{c}\text { Flexão e Torção } \\
\text { Não Proporcional }\end{array}$ \\
\hline Yung e Lawrence (1986) & 11 & 0 \\
\hline Siljander; Kurath e Lawrence (1992) & 10 & 10 \\
\hline Sonsino (1995, 1997) & 20 & 20 \\
\hline Razmjoo (1996) & 7 & 7 \\
\hline Bäckström et al (1997) & 9 & 4 \\
\hline Total & 57 & 41 \\
\hline
\end{tabular}

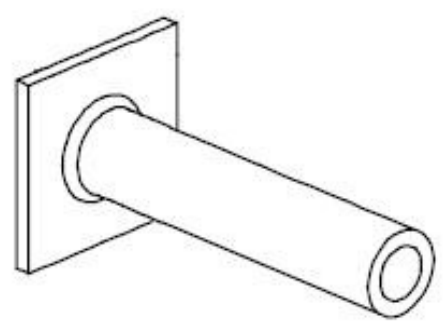

(a)

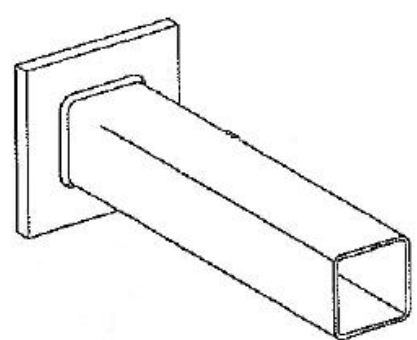

(b)

Figura 3 - Geometria das amostras: (a) tubo-placa circular, (b) tubo-placa retangular

Os testes realizados por Yung e Lawrence (1986) apresentaram vida à fadiga entre $1 \mathrm{E} 10^{4}$ e $2 \mathrm{E} 10^{6}$ ciclos. Os dados experimentais foram correlacionados utilizando as amplitudes de tensão de flexão local, tensão equivalente local e tensão máxima principal local. A melhor correlação dos dados de testes foi obtida quando a tensão cisalhante foi incluída na análise.

Siljander; Kurath e Lawrence (1992) incluíram no trabalho o carregamento não proporcional. Os resultados dos testes foram correlacionados utilizando vários parâmetros de fadiga multiaxial baseados na tensão local. As tensões locais foram obtidas através do MEF. Siljander concluiu que os resultados dos testes, tanto para carregamento proporcional quanto para não proporcional, era melhor correlacionado utilizando o modelo de tensão cisalhante equivalente de Findley. 
Sonsino $(1995,1997)$ trabalhou com carregamento proporcional e não proporcional. Todas as amostras passaram por processo de alívio de tensões (térmico) e falharam no pé da solda, apresentando vida entre $1 \mathrm{E} 10^{4}$ e $4 \mathrm{E} 10^{6}$ ciclos. Para o carregamento não proporcional a tensão máxima principal ou a tensão de Von Mises não foram relevantes, sendo apresentada uma nova proposta chamada de tensão equivalente efetiva (EESH - effective equivalent stress). Neste novo método a trinca se inicia pela tensão cisalhante e envolve o cálculo da interação de todas as componentes da tensão cisalhante da superfície no pé da solda, tal metodologia é válida somente para carregamento não proporcional, que não faz parte do escopo do presente trabalho.

As amostras investigadas por Razmjoo (1996) apresentaram vida à fadiga entre $1 \mathrm{E} 10^{5}$ e $1 \mathrm{E} 10^{7}$ ciclos. Quando as amostras foram submetidas a carregamento de flexão apenas ou combinado de flexão e torção a trinca iniciou-se no pé da solda e quando foram submetidas a torção apenas, a falha iniciou-se na garganta da solda. A tensão máxima principal foi o melhor critério para carregamento proporcional que o critério de Von Mises. Para o carregamento não proporcional nenhum dos métodos analisados foram satisfatórios. Razmjoo sugeriu que a tensão máxima principal pode ser usada para o carregamento não proporcional desde que um fator extra de segurança de 1.7 seja utilizado nas curvas $S \times N$ oriundas da norma BS5400 ou BS7608 (1993).

Bäckström et al (1997) realizaram testes de fadiga biaxial em amostras soldadas do tipo tubo-placa retangular (Figura 3b) na condição de como soldadas. O tubo foi fabricado através de conformação mecânica e unido em apenas um dos lados, conforme apresentado na Figura 4, que também ilustra os parâmetros do ensaio realizado por Bäckström et al (1997). Quando as amostras foram submetidas a carregamento de flexão apenas ou de flexão e torção combinados a trinca iniciou no pé da solda. Nos testes de torção apenas, a falha ocorreu no tubo, no raio externo da seção retangular. A vida à fadiga apresentou resultados entre $1 \mathrm{E} 10^{4}$ e $2 \mathrm{E} 10^{6}$ ciclos. A tensão de hot spot foi comparada com uma abordagem que emprega conceitos do plano crítico como um parâmetro de falha. Concluiu-se que o plano crítico apresentou uma melhor correlação dos dados que a tensão principal. Para uma melhor abordagem sobre este tema, vide Bäckström et al (1997). 


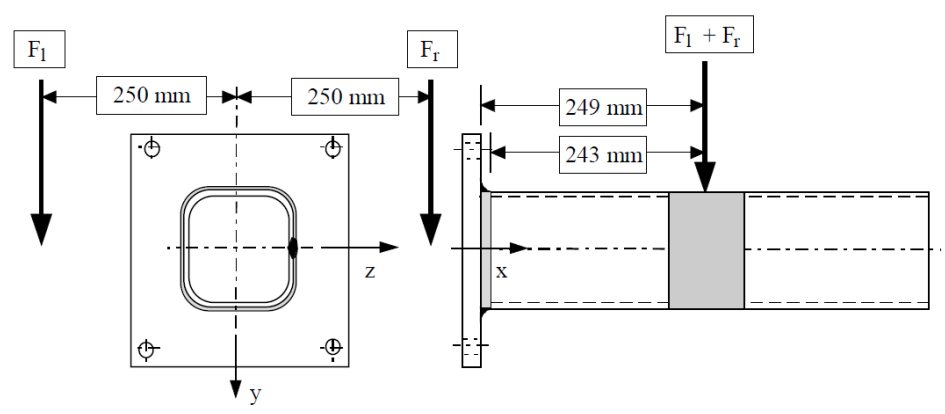

Figura 4 - Parâmetros do ensaio de fadiga biaxial realizado por Bäckström et al (1997)

\subsection{PROCESSOS DE SOLDAGEM}

Segundo Okumura e Taniguchi (1982), a união de dois ou mais materiais metálicos é conhecida desde as eras pré-históricas, mas foi o advento da eletricidade que deu o impulso necessário para que o processo de soldagem tornar-se tão importante quanto o é atualmente.

Os processos de soldagem podem ser classificados, segundo Chiaverini (1986), em: processos por fusão e processos de pressão, Okumura e Taniguchi (1982) acrescentam o processo de brasagem e Messler (1999) propõe uma classificação baseada na divisão entre processos com pressão e os sem pressão, incluindo neste último a soldagem a laser. A Figura 5 apresenta os principais processos de soldagem, sendo identificado o utilizado no presente trabalho: processo MIG/MAG.

A região da solda obtida pelo processo MIG/MAG possui três regiões distintas, apresentadas na Figura 1, sendo que a trinca se inicia geralmente no pé ou na raiz da solda, região esta pertencente à ZAC. 


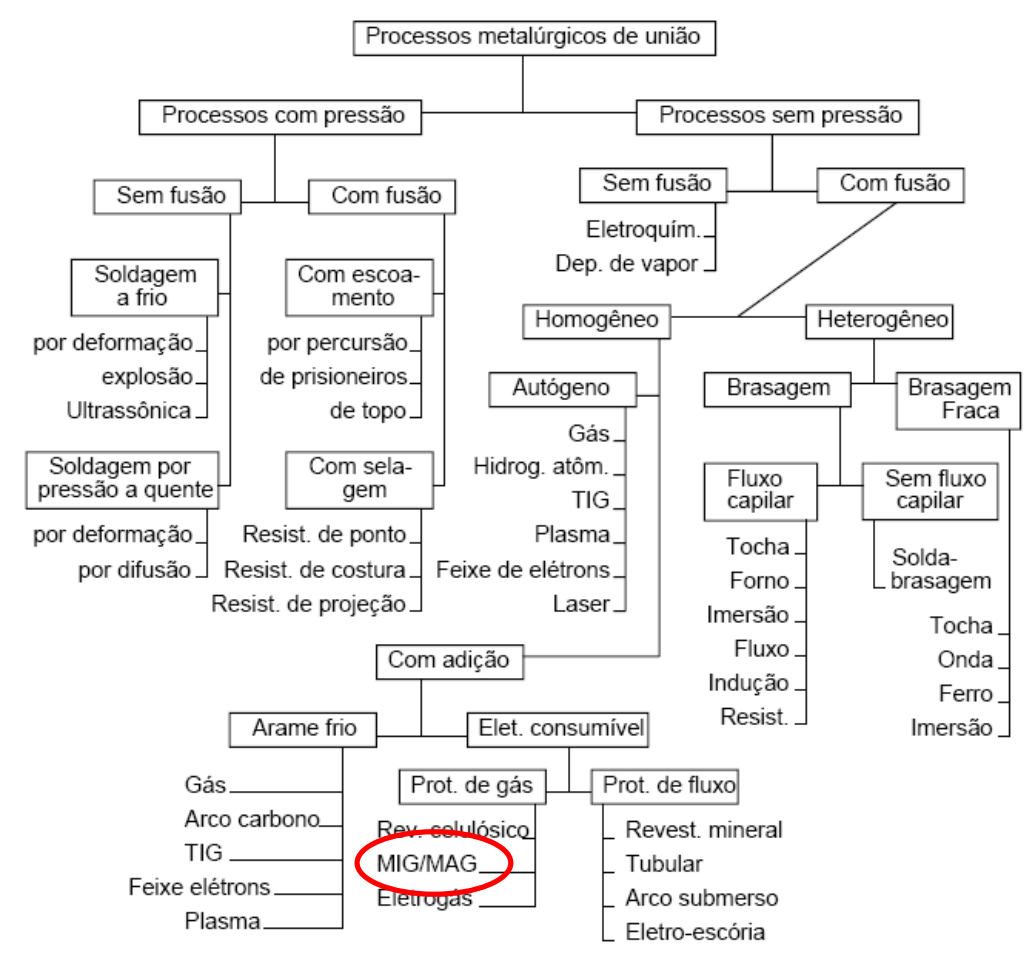

Figura 5 - Processos de Soldagem - Adaptado de Messler (1999)

\subsubsection{Metalurgia na ZAC}

As propriedades da ZAC são afetadas pelo tipo de estrutura formada e pelos ciclos térmicos que ocorrem durante a soldagem. Os fatores de maior importância que provocam mudanças na microestrutura, afetando as propriedades da zona da solda, são: a máxima temperatura atingida no aquecimento e a velocidade de resfriamento no intervalo compreendido entre $800^{\circ} \mathrm{C}$ e $500^{\circ} \mathrm{C}$. Segundo Okumura e Taniguchi (1982), conforme a velocidade de resfriamento é possível ocorrer as seguintes mudanças na seqüência apresentada:

Martensita $\Longrightarrow$ Bainita acicular $\Longrightarrow$ Bainita em forma de placas $\Longrightarrow$ ferrita+perlita

Durante um ciclo térmico, o tempo de resfriamento, em uma determinada faixa de temperatura, influi muito no desempenho da junta soldada, principalmente no que se refere às fraturas. A partir das curvas de ciclo térmico para todos os pontos ao longo 
da junta é possível obter as temperaturas máximas, atingidas em função das distâncias ao centro da solda, esta função chama-se repartição térmica e é através dela que percebe-se a relação entre a microestrutura da ZAC e a distância ao centro da solda. A Figura 6 apresenta as subdivisões da ZAC formadas em função do gradiente de temperatura gerado pelo processo de soldagem monopasse.

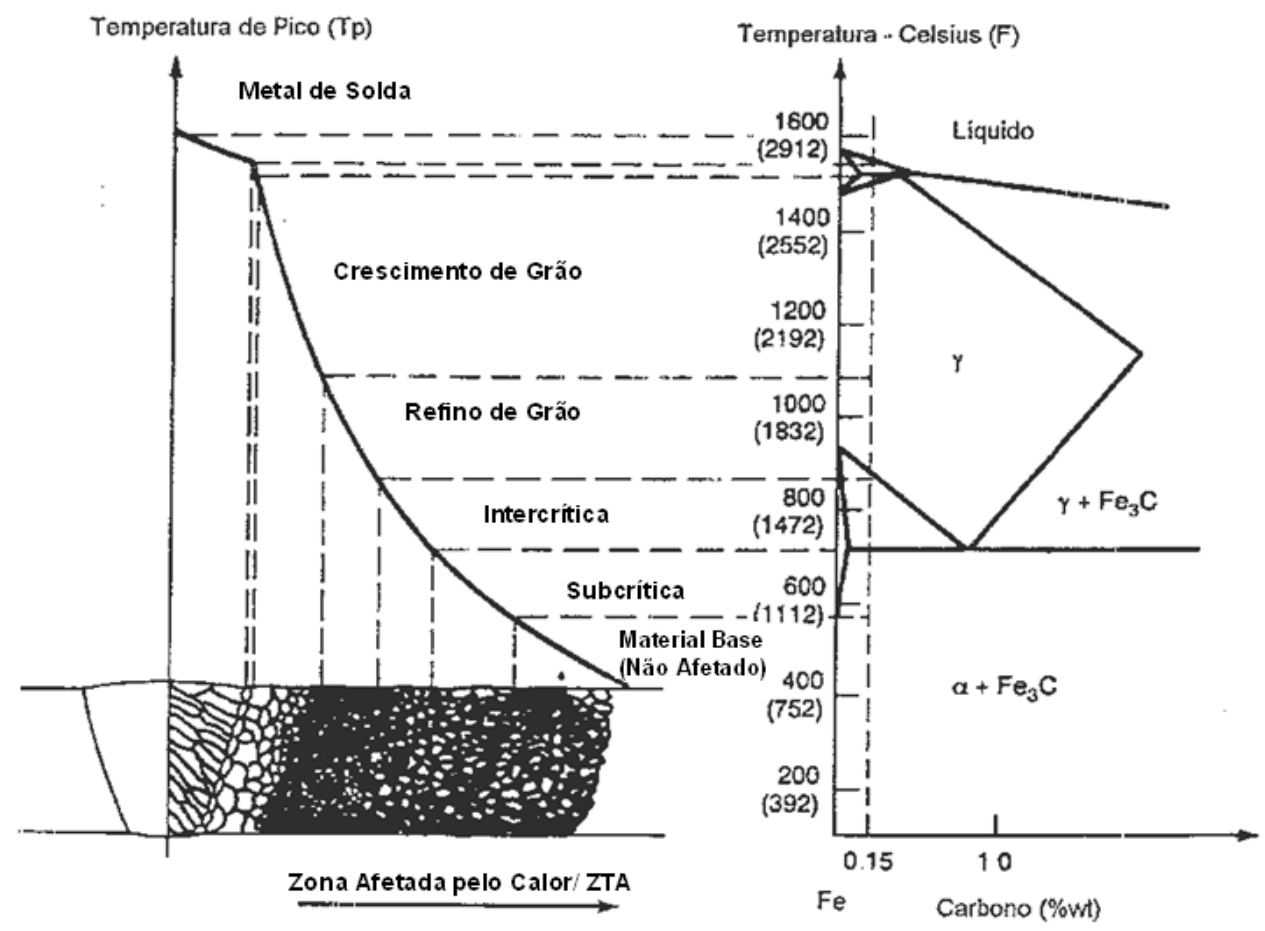

Figura 6 - Regiões da ZAC de uma soldagem monopasse (NASCIMENTO, 2004)

Segundo Nascimento (2004), a ZAC pode ser subdividida nas seguintes regiões: Região de Crescimento de Grão; Região de Refino de Grão; Região Intercrítica (também conhecida como parcialmente transformada) e Região Subcrítica (também conhecida como região de esferoidização de carbonetos).

\subsubsection{Defeitos na solda}

A soldagem é um método que requer um bom conhecimento e exige boa habilidade do soldador, quando realizada manualmente. Em função do método e do próprio 
processo de soldagem, a solda apresenta diversos defeitos, alguns visíveis e outros mais difíceis de serem detectados. Dentre os defeitos principais da solda, pode-se citar, segundo Gustafsson e Saarinen (2007):

- Entalhes - são criados durante o processo de soldagem quando o metal base é fundido, formando um pequeno desnível no pé da solda, como apresentado na Figura 7;

- Penetração incompleta - ocorre quando a espessura da solda é inferior à espessura calculada em projeto, diminuindo a resistência da junta. Também ocorre quando a profundidade da solda no metal base é insuficiente para garantir a resistência da junta;

- Falha na fusão - é uma área onde o material da solda e o metal base não são suficientemente unidos. Esta falha depende do equipamento de soldagem ou do próprio soldador, quando realizada a mão.

- Porosidade - A porosidade numa solda ocorre quando gases ficam presos na solda durante o processo de soldagem (Figura 8). Os gases presentes no metal são alterados com a temperatura e podem criar as porosidades quando a solda é resfriada. Alguns métodos de soldagem possuem gases de proteção e a alteração no fluxo dos mesmos também pode ocasionar o defeito de porosidade.

- Início e fim da solda - Este tipo de defeito ocorre quando o início da solda é sobreposto pelo final da solda. Os pontos de início e término da solda possuem alta concentração de tensões e quando são sobrepostos essa concentração aumenta, podendo ocasionar numa diminuição da vida à fadiga devido ao início da trinca se iniciar neste ponto.

Entalhe

Figura 7 - O defeito de entalhe numa junta $\mathrm{T}$ 
Porosidade

Figura 8 - O defeito de porosidade numa junta a topo

Os defeitos de soldagem contribuem negativamente para a vida à fadiga da junta, que para ser analisada depende da tensão atuante na junta e das tensões residuais oriundas do processo de soldagem.

\subsection{TENSÃO E TENSÃO RESIDUAL}

Para entender o fenômeno da fadiga é essencial entender as componentes de um estado de tensão. Segundo Zahavi (1992), tensão é a força interna por unidade de área de um corpo reagindo contra um carregamento aplicado. O diagrama de corpo livre apresentado na Figura 9 mostra as diversas forças que atuam em cada face do cubo.

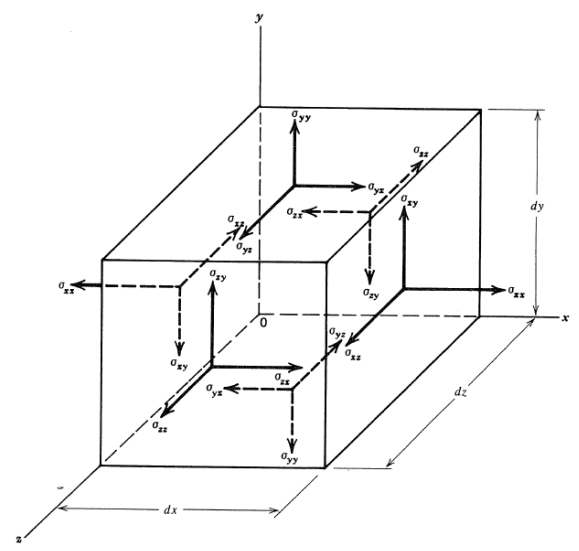

Figura 9 - Diagrama de corpo livre (BORESI; SCHMIDT e SIDEBOTTOM, 1993)

Para o corpo em equilíbrio, tem-se o seguinte tensor de tensões (equação 1). 


$$
\mathrm{T}=\left[\begin{array}{lll}
\sigma_{x x} & \sigma_{x y} & \sigma_{x z} \\
\sigma_{x y} & \sigma_{y y} & \sigma_{y z} \\
\sigma_{x z} & \sigma_{y z} & \sigma_{z z}
\end{array}\right]
$$

Onde é possível observar que são necessárias seis componentes de tensão para descrever o estado de tensões de um ponto num determinado corpo.

As tensões num plano oblíquo do sistema cartesiano, apresentadas na Figura 10, são obtidas através das equações de 2 a 5 e a resultante das tensões cisalhantes neste mesmo ponto, através da equação 6 (TIMOSHENKO e GOODIER, 1982).

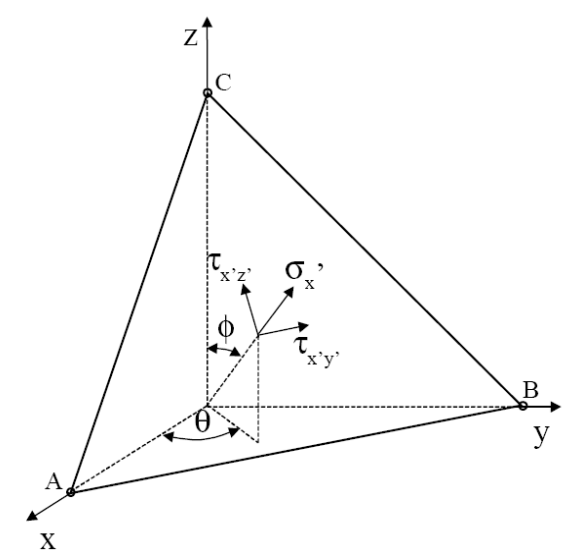

Figura 10 - Tensões agindo em um plano do sistema de coordenadas

$$
\begin{gathered}
{\left[\begin{array}{lll}
a_{11} & a_{12} & a_{13} \\
a_{21} & a_{22} & a_{23} \\
a_{31} & a_{32} & a_{33}
\end{array}\right]=\left[\begin{array}{ccc}
\cos \theta \cdot \sin \phi & -\sin \phi & -\cos \theta \cdot \cos \phi \\
\sin \theta \cdot \sin \phi & \cos \theta & -\sin \theta \cdot \cos \phi \\
\cos \phi & 0 & \sin \phi
\end{array}\right]} \\
\quad \sigma_{x^{\prime}}=\sigma_{x} \cdot a_{11}^{2}+\sigma_{y} \cdot a_{21}^{2}+\sigma_{z} \cdot a_{31}^{2} \\
+2 \cdot\left(\tau_{x y} \cdot a_{11} \cdot a_{21}+\tau_{x z} \cdot a_{11} \cdot a_{31}+\tau_{y z} \cdot a_{31} \cdot a_{21}\right) \\
\tau_{x^{\prime} y^{\prime}}=\sigma_{x} \cdot a_{11} \cdot a_{12}+\sigma_{y} \cdot a_{21} \cdot a_{22}+\sigma_{z} \cdot a_{31} \cdot a_{32} \\
+\tau_{x y} \cdot\left(a_{11} \cdot a_{22}+a_{21} \cdot a_{12}\right)+\tau_{y z} \cdot\left(a_{21} \cdot a_{32}+a_{31} \cdot a_{22}\right) \\
+\tau_{z x} \cdot\left(a_{31} \cdot a_{12}+a_{11} \cdot a_{32}\right)
\end{gathered}
$$




$$
\begin{aligned}
& \tau_{x^{\prime} z^{\prime}}=\sigma_{x} \cdot a_{11} \cdot a_{13}+\sigma_{y} \cdot a_{21} \cdot a_{23}+\sigma_{z} \cdot a_{31} \cdot a_{33} \\
& +\tau_{x y} \cdot\left(a_{11} \cdot a_{23}+a_{21} \cdot a_{13}\right)+\tau_{y z} \cdot\left(a_{21} \cdot a_{33}+a_{31} \cdot a_{23}\right) \\
& +\tau_{z x} \cdot\left(a_{31} \cdot a_{13}+a_{11} \cdot a_{33}\right)
\end{aligned}
$$

$$
\tau^{\prime}=\sqrt{\tau_{x^{\prime} y^{\prime}}^{2}+\tau_{x^{\prime} z^{\prime}}^{2}}
$$

Conhecendo as tensões $\sigma_{x}, \sigma_{y}$ e $\tau_{x y}$ é possível determinar as tensões principais em um determinado ponto de um plano. A tensão máxima principal é obtida através da equação 7 , assim como a mínima através da equação 8 e o ângulo entre a tensão máxima principal e o eixo x pela equação 9.

$$
\begin{gathered}
\sigma_{1}=\frac{\sigma_{x}+\sigma_{y}}{2}+\sqrt{\left(\frac{\sigma_{x}-\sigma_{y}}{2}\right)^{2}+\tau_{x y}^{2}} \quad \alpha=\varphi \\
\sigma_{2}=\frac{\sigma_{x}+\sigma_{y}}{2}-\sqrt{\left(\frac{\sigma_{x}-\sigma_{y}}{2}\right)^{2}+\tau_{x y}^{2}} \quad \alpha=\varphi+\frac{\pi}{2} \\
\tan 2 \varphi=\frac{2 \tau_{x y}}{\sigma_{x}-\sigma_{y}} \\
\tau_{x y} \sin 2 \varphi \geq 0
\end{gathered}
$$

Após uma breve introdução sobre tensões é possível definir tensão residual, que segundo Masubushi (1980), são as tensões que podem existir num corpo se todas as cargas externas forem removidas. Podem ocorrer quando um corpo é sujeito a mudanças bruscas e não uniformes de temperatura, conhecidas como tensões térmicas, devido a transformações de fase ou efeitos mecânicos que resultem em deformações plásticas.

As tensões residuais na soldagem podem ser divididas em três modelos:

- Tensões de restrição - são caracterizadas pelo processo ao qual o metal base é submetido, ou seja, o metal é aquecido e resfriado em seguida, causando expansões térmicas e contrações do material. Como estes efeitos são restringidos pelas regiões frias adjacentes, há a produção de tensões de 
soldagem. Por outro lado, o limite de escoamento do metal baixa com o aumento de temperatura (conforme Figura 11), como resultado, o metal é deformado plasticamente na zona de soldagem. Segundo Okumura e Taniguchi (1982), esta deformação permanecerá parcialmente, após se completar a soldagem, e entrará em equilíbrio elástico com a zona adjacente, produzindo-se então as tensões residuais.

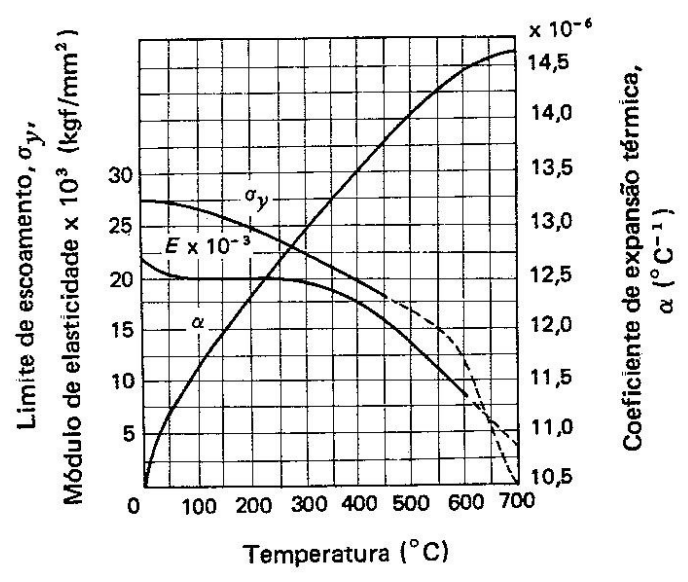

Figura 11 - Variação do limite de escoamento, do módulo de elasticidade e do coeficiente de expansão térmica de aços com a temperatura (OKUMURA e TANIGUCHI, 1982)

- Tensões microestruturais - o tipo de transformação microestrutural e o tempo em que ocorre a mesma são de fundamental importância para este tipo de tensão residual.

- Tensões de espessura - o gradiente de resfriamento ao longo da espessura da chapa influencia diretamente a produção de tensões residuais.

Ainda segundo Okumura e Taniguchi (1982), as tensões residuais podem ser divididas, geralmente, em dois grupos: as de vínculos internos e as de externos. A primeira são tensões auto-equilibradas, geradas pelo aquecimento e resfriamento local de um membro estrutural não vinculado externamente e a segunda são tensões residuais geradas pela ação restritiva de vínculos externos. A Figura 12 e a Figura 13 apresentam exemplos típicos desta divisão. 


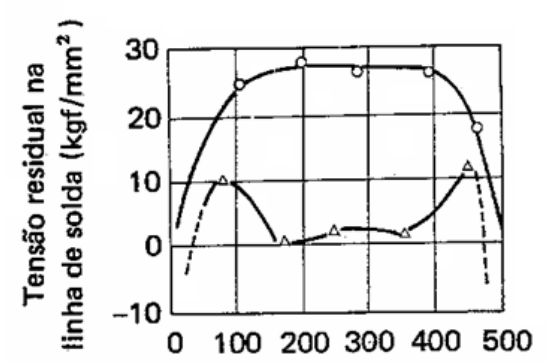

Distância do ponto de partida da soldagem $(\mathrm{mm})$

- Tensões logitudinais

$\Delta$ Tensões transversais

(a)

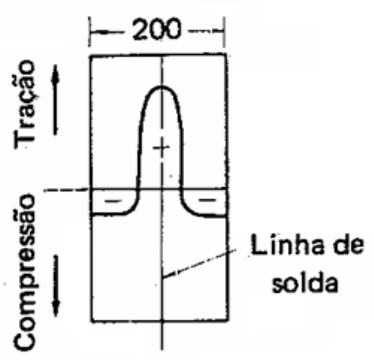

Distribuição de tensões residuais em uma seção transversal à linha de solda

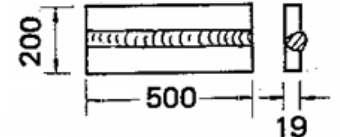

Condição de soldagem para 0 corpo de prova:

Processo por arco submerso, com 2 camadas:

$V=36 \mathrm{~V}$

$I=700 \mathrm{~A}$

$v=30 \mathrm{~cm} / \mathrm{min}$.

(b)

(c)

Figura 12 - Distribuição de tensões residuais devidas a vínculos internos em juntas soldadas a topo (OKUMURA e TANIGUCHI, 1982)
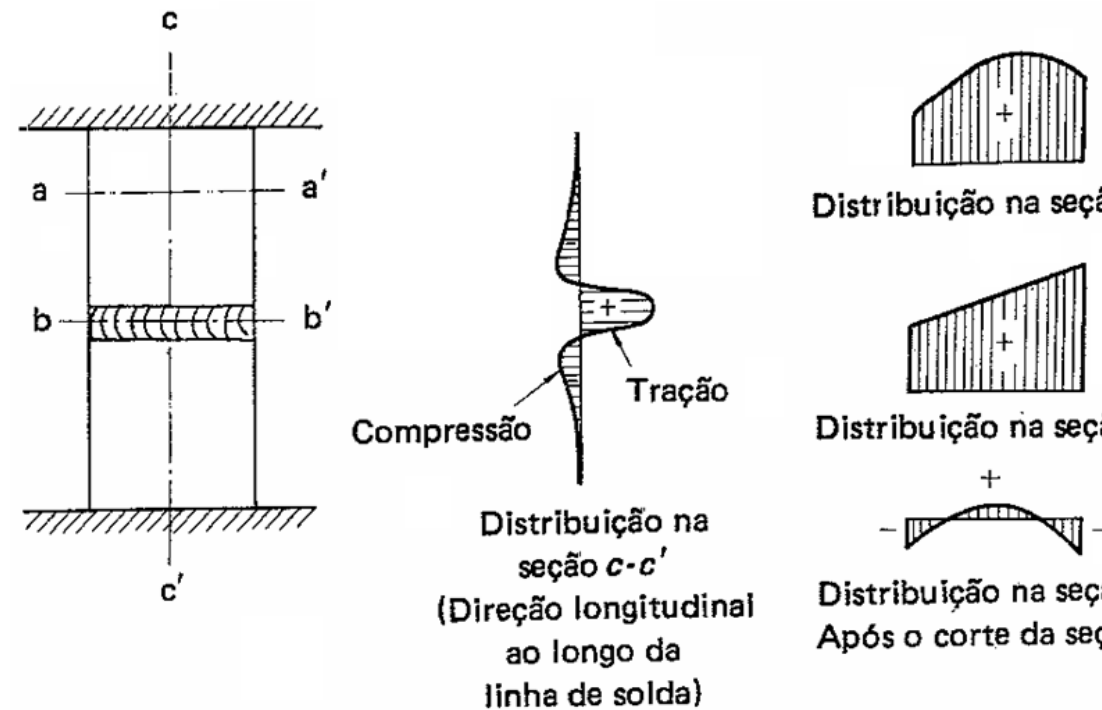

Distr íbuição na seção $b-b^{\prime}$

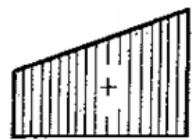

Distribu ição na seção $a \cdot a^{\prime}$

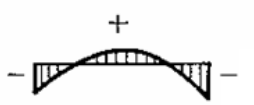

Distribuição na seção $b-b^{\prime}$ Após o corte da seçấo $a-a^{\prime}$

Figura 13 - Distribuição de tensões residuais devidas a vínculos externos em juntas soldadas a topo (OKUMURA e TANIGUCHI, 1982)

A Figura 14 sintetiza a relação entre as distorções (empenamentos) e a tensão residual trativa na ZAC de uma chapa de aço soldada, onde pode-se prever os tipos de problemas incorrentes, ainda na fase de projeto.

Percebe-se que as tensões residuais trativas sofrem aumento com uma maior rigidez, espessura, módulo de elasticidade e tensão de escoamento da chapa, em contrapartida, o aumento de distorções é provocado quando as mesmas propriedades anteriores são reduzidas. Com o cordão de solda ocorre o inverso, ao aumentá-lo tem-se o aumento das distorções e ao diminuí-lo aumenta-se as tensões residuais trativas. 


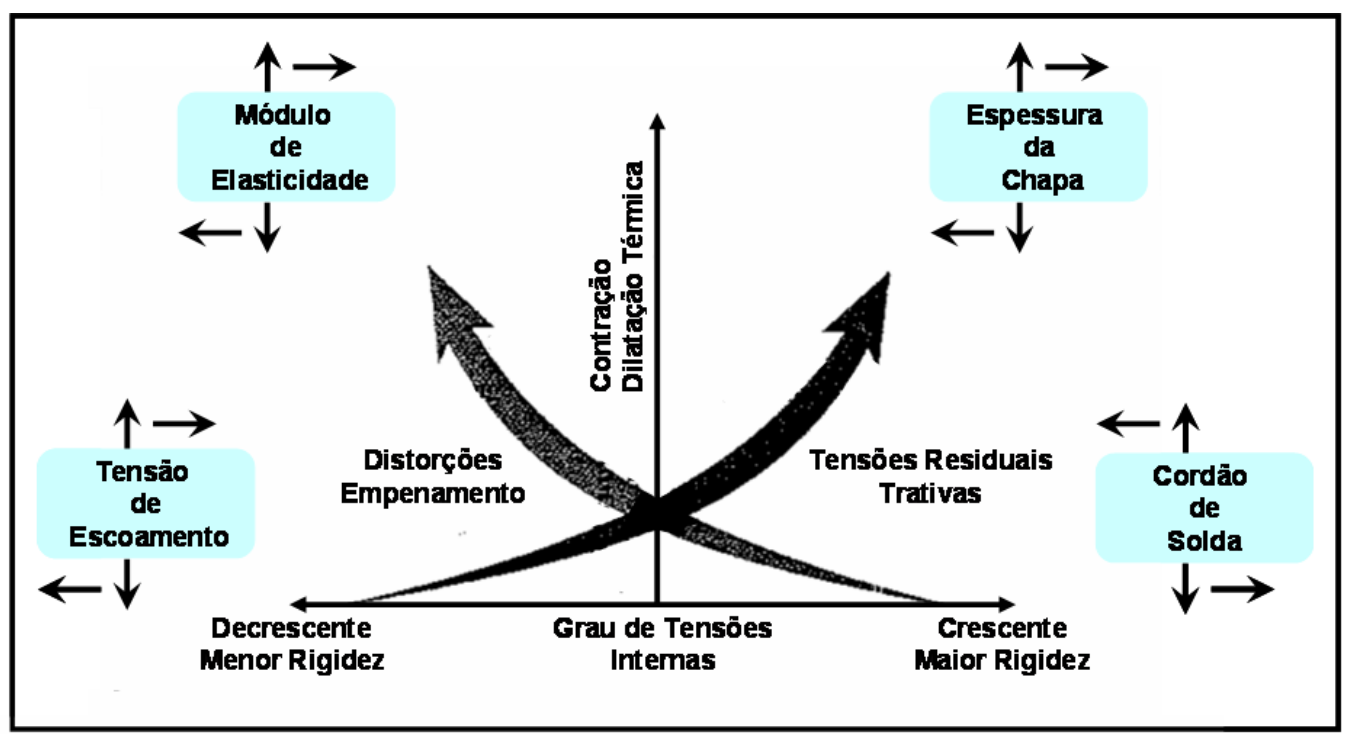

Figura 14 - Relação entre as tensões residuais trativas e as distorções de uma chapa soldada (Adaptado de NITSCHKE-PAGEL, 2006)

As tensões residuais podem ser obtidas através do MEF ou medidas experimentalmente, onde pode ser citado difração de raios- $X$, ultra-som e os mecânicos, como por exemplo, o de extensometria elétrica, conhecido como furo cego.

Para uma abordagem mais detalhada do método de difração de raios- $X$, vide norma SAEJ784a (1971) e os trabalhos de Silva (2005), Noyan e Cohen (1987) e SAE720242 (1972), já o método de ultra-som é descrito por Tanala et al (1995) e o de furocego pela norma ASTM 837-95 (1995) e pelos trabalhos de Gomes (1990) e Grant et al (2002).

\subsubsection{Concentração de tensões}

Solda e detalhes soldados contêm áreas de alta concentração de tensões. Juntas soldadas transferem forças de um elemento para outro através da própria solda, conforme apresentado na Figura 15. Esta mudança de direção e conseqüentemente da área resulta em concentração de tensão. A geometria da junta também contribui no fluxo de tensão, como pode ser observado na Figura 15a para uma junta do tipo T e na Figura 15b para uma junta a topo. 


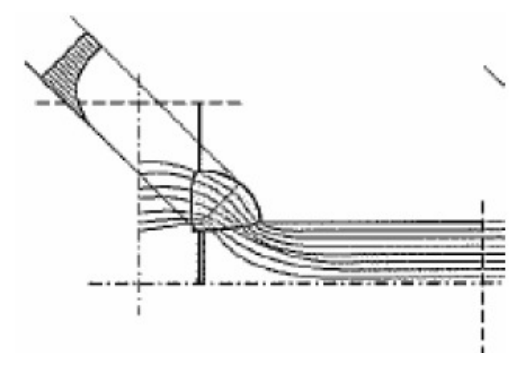

(a)

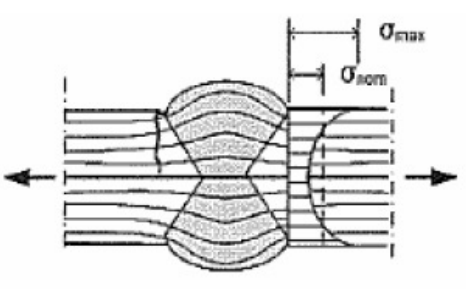

(b)

Figura 15 - Concentração de tensões numa junta do tipo T (a) e numa junta a topo (b)

A trinca de fadiga inicia-se na região com alta concentração de tensões. Na junta soldada, devido a seu perfil, há a ocorrência de concentração de tensões geométrica, onde o fluxo no elemento ou no detalhe é perturbado pela mudança na geometria e, em alguns casos, na rigidez da junta.

O projeto da junta tem papel fundamental para minimizar a concentração de tensões, podendo assim melhorar a vida à fadiga da junta soldada.

\subsubsection{Tensões em Fadiga}

As tensões utilizadas na análise de fadiga são oriundas de carregamentos, peso morto, vento, neve, onda, aceleração, vibrações, etc.

Segundo Niemi (1995), na análise de fadiga em juntas soldadas são utilizadas as seguintes categorias de tensões:

- Tensão nominal

- Tensão estrutural (hot spot)

- Tensão de entalhe (notch)

A escolha da categoria de tensão depende do método utilizado para expressar os dados de vida à fadiga.

A tensão nominal $\left(\sigma_{\text {nom }}\right)$ geralmente é calculada utilizando fórmulas simples, como a abaixo:

$$
\sigma_{\text {nom }}=\frac{F}{A}+\frac{M}{I} \cdot y
$$


Um exemplo de tensão nominal numa viga de acordo com a equação 10 é apresentado na Figura 16.

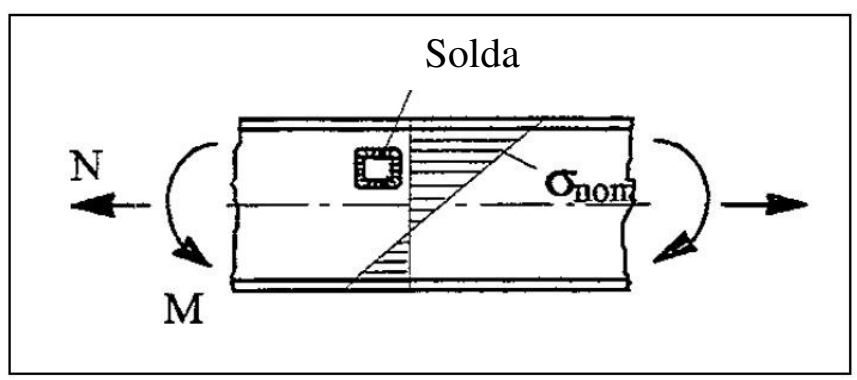

Figura 16 - Exemplo de tensão nominal numa viga (NIEMI, 1995)

A tensão estrutural $\left(\sigma_{s}\right)$ difere-se da nominal por considerar as descontinuidades da estrutura. Este tipo de tensão é linearmente distribuída através da espessura da placa e é composta de duas partes: tensão de membrana $\left(\sigma_{m}\right)$ e tensão de flexão $\left(\sigma_{b}\right)$, conforme ilustrado na Figura 17. A tensão de membrana é a tensão média através da espessura da placa enquanto que a tensão de flexão é a metade da diferença entre a tensão na superfície superior e a da superfície inferior.

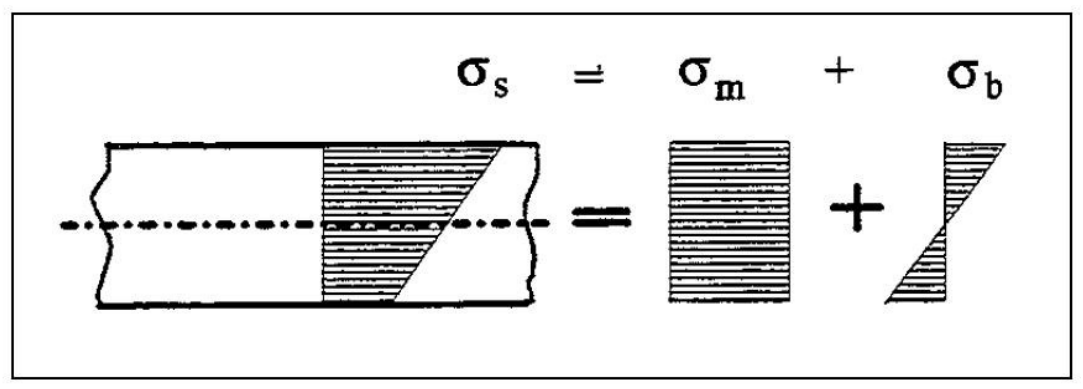

Figura 17 - Tensão estrutural numa placa, composta pelas tensões de membrana e de flexão (NIEMI, 1995)

A tensão de hot spot $\left(\sigma_{h s}\right)$ refere-se a tensão estrutural no ponto crítico da estrutura, onde espera-se que a falha por fadiga ocorra devido à descontinuidade gerada pelo próprio processo de soldagem. Geralmente o hot spot é localizado no pé da solda, não incluindo o pico de tensão não linear causado pelo entalhe, conforme apresentado na Figura 18. 


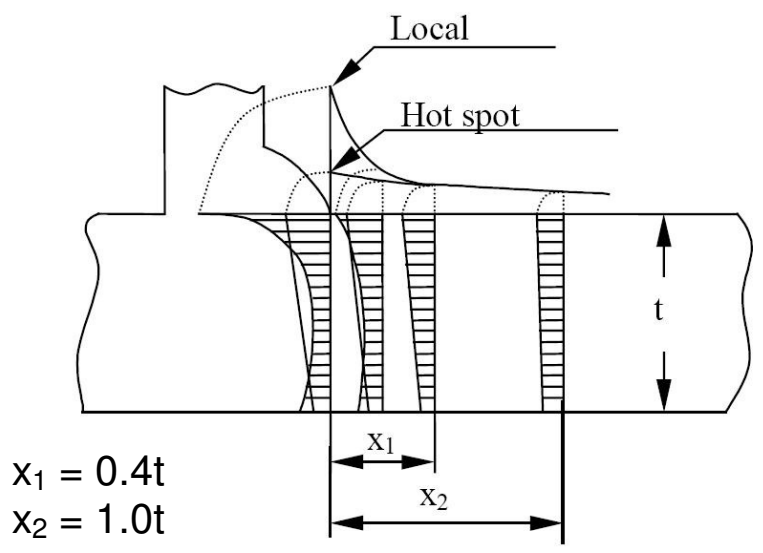

Figura 18 - Tensão de hot spot (NIEMI, 1995)

As distâncias $x_{1}$ e $x_{2}$ são utilizadas para obter as tensões de referência, que serão extrapoladas para obtenção da tensão de hot spot.

A tensão de entalhe $\left(\sigma_{\ln }\right)$ é a tensão total localizada na região de maior concentração de tensões, como por exemplo, no pé da solda, como ilustrado na Figura 19. Esta tensão é composta por três tensões: membrana, flexão e pico não linear $\left(\sigma_{n l p}\right)$. A primeira é calculada através da espessura da placa, a segunda pela metade da diferença entre as tensões estruturais da superfície superior e da inferior e a última é calculada através da tensão máxima na parte não linear de uma distribuição de tensões, geralmente através da espessura da placa, causada pelo entalhe.

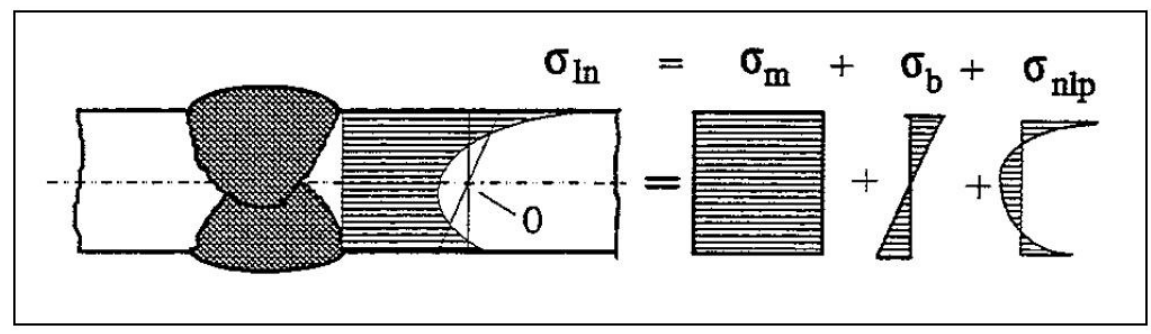

Figura 19 - Tensão de entalhe (notch) no pé da solda, composta pelas tensões de membrana, de flexão e pelo pico de tensão não linear (NIEMI, 1995)

Obter a tensão atuante numa junta soldada é imprescindivel para o cálculo da vida à fadiga da junta. A tensão pode ser obtida experimentalmente ou analiticamente, neste último caso o método dos elementos finitos (MEF) é uma excelente ferramenta para auxílio, principalmente quando a geometria analisada é complexa. 


\subsection{MÉTODO DOS ELEMENTOS FINITOS (MEF)}

Segundo Camarão (1994), o MEF pode ser definido como um procedimento numérico capaz de aproximar e resolver as equações que governam o comportamento de qualquer sistema físico contínuo, através de sua discretização em sub-regiões chamadas elementos. O princípio do MEF se baseia em métodos matemáticos, como o de Rayleigh-Ritz do cálculo variacional (ZIENKIEWICZ, 1973), teoremas de energia e teoria da elasticidade, dentre outras. É aplicado na solução aproximada de diversos problemas de engenharia, tais como:

- Transferência de calor;

- Mecânica dos sólidos ou estrutural;

- Mecânica dos fluidos.

Em Análise Estrutural de regime permanente, a relação entre força e deslocamento no sólido discretizado é dada pela equação 11 :

$$
[K]\{u\}=\{F\}
$$

O modelo de Elementos Finitos é uma representação geométrica da estrutura física real ou do corpo que está sendo analisado. Este modelo é construído pela divisão do corpo em um número discreto de células, chamadas elementos e constituídos por nós. A ordem da matriz de rigidez ([K]) apresentada na equação 11 depende da quantidade destes elementos (ZAHAVI, 1992).

Existem vários tipos de elementos que são aplicados de acordo com a geometria do modelo e o tipo de análise, ou seja:

- Linha, em estrutura de barras;

- Área (triangular ou quadrangular), em chapas, placas e estruturas sólidas planas ou axissimétricas;

- Tridimensionais sólidos (hexaedro ou tetraedro), em peças forjadas - barras, blocos e flanges - e em fundidos, como carcaças, vasos de pressão e corpos de válvulas, por exemplo.

A Figura 20 apresenta diversos tipos de elementos em 1D, 2D e em 3D. 
$2 \mathrm{D}$
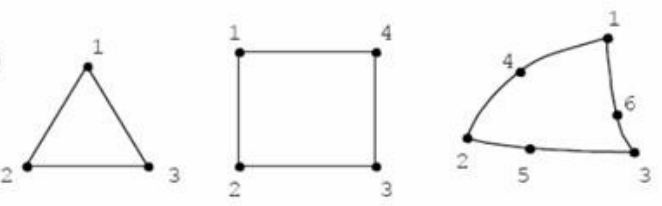

1D

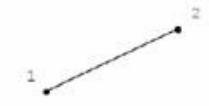

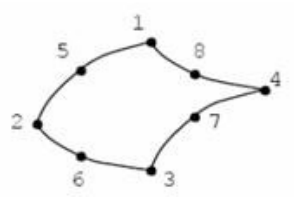

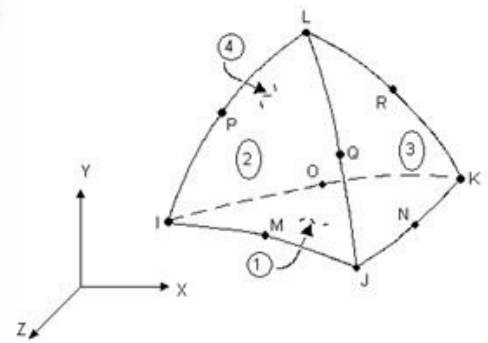

Figura 20 - Elementos em 1D, 2D e 3D, com nós.

Os nós e elementos podem ser brevemente descritos como abaixo:

- NÓs

- variáveis nodais $\Rightarrow$ solução calculada nos nós de cada elemento

- o número de variáveis nodais em cada nó é característica do tipo de elemento

- ELEMENTO

- estabelece o comportamento das variáveis nodais

- a ligação entre os elementos se dá através dos nós comuns

Estes elementos são governados por uma equação linear ou não-linear, dependendo do seu comportamento na estrutura ou no sistema físico.

A integração do comportamento de cada elemento resulta na determinação da resposta da estrutura à solicitação externa.

Obter esses resultados manualmente, através de cálculo diferencial, torna-se uma tarefa árdua e que demanda um considerável tempo, neste ínterim pode ser mencionado um importante aliado: os programas de Elementos Finitos.

Existem no mercado diversos programas de MEF, como por exemplo: Abaqus, ANSYS, Adina, Cosmos, Algor e Nastran, que a cada ano são aperfeiçoados com o intuito de diminuir o tempo de processamento dos cálculos.

No próximo item são apresentados os principais passos necessários para uma análise por Elementos Finitos. 


\subsubsection{Passos na análise por Elementos Finitos}

Segundo Camarão (1994), a análise por elementos finitos normalmente compreende três passos, que seguem:

I - Pré-processamento - consiste na criação do modelo pelo usuário, que envolve:

a) Definição da geometria, nós e elementos.

b) Especificação das propriedades dos materiais, carregamentos e condições de contorno.

II - Solução da análise pelo programa de MEF:

a) Formulação das equações que descrevem o fenômeno.

b) Solução destas equações.

c) Cálculo dos resultados (temperatura, deslocamento, tensões e reações de apoio, por exemplo), nos nós e elementos.

III - Pós-processamento.

Análise de resultados pela criação de gráficos ou visualização da deformação e distribuição de tensões, deslocamentos ou temperaturas no modelo. Ou seja, o comportamento do modelo poderá ser investigado de acordo com a necessidade do usuário.

Uma descrição mais detalhada dos procedimentos e técnicas aplicados ao MEF pode ser obtida através dos trabalhos de Zienkiewicz (1973), Bathe (1982) e Segerlind (1984).

\subsubsection{Análise das tensões na junta soldada utilizando o MEF}

O cálculo da distribuição de tensões em juntas soldadas depende basicamente da geometria do cordão, fator de concentração de tensões, esforços externos e comportamento elástico ou plástico do material. O método clássico para se calcular 
as tensões nominais num filete de solda requer a determinação do carregamento por unidade de comprimento, transmitido através da solda. Este carregamento é usualmente composto por três componentes, ou seja, normal, cisalhante e de flexão. Este cálculo pode ser feito por diversos métodos, o mais simples e comum é se obter as propriedades da seção, tratando-se o cordão de solda como uma linha.

Considerando a solda como uma viga fletida é possível obter o momento, o carregamento axial e cisalhante e a tensão na junta soldada. Este método clássico não é prático para tratar geometrias complexas, tais como cordões espaciais (3D) e não considera os efeitos de concentração de tensões devido a transições geométricas e a própria geometria do cordão. Visando reduzir tempo e aumentar a confiabilidade na determinação das tensões em juntas soldadas, a aplicação do MEF tem sido crescente, combinando-se com curvas experimentais de fadiga de juntas soldadas. A precisão dos resultados numéricos depende de diversos aspectos, como a escolha do tipo de elemento, as condições de contorno e o modelamento da junta soldada (IIW, 1995).

Após obter a tensão atuante é possível realizar a análise de fadiga na estrutura.

\subsection{ANÁLISE DE FADIGA}

Obter a tensão cíclica atuante é de suma importância para calcular a vida à fadiga do material. Esta tensão pode ser obtida experimentalmente ou analiticamente, sendo esta última possível através de fórmulas simples ou do MEF, como discorrido no capítulo anterior.

Para entender melhor o fenômeno de fadiga, é preciso conhecer primeiro seu significado que, segundo Bannantine; Comer e Handrock (1990) é um processo que causa falha prematura ou dano de um componente sujeito a um carregamento cíclico. O processo ocorre pela iniciação e propagação de trincas, e em geral, a superfície da fratura é perpendicular à direção da tensão principal de tração aplicada.

Desde 1850 diversos pesquisadores têm estudado a fadiga dos metais, dentre os quais pode-se citar: August Wöhler, Bauschinger, Ewing, Humphrey, Jenkin, Griffith, 
Moore, Kommers, Coffin, Manson e Irwin (BANNANTINE; COMER; HANDROCK, 1990).

A Figura 21 resume os diversos efeitos de aumento da tensão, as categorias de tensão e as abordagens de fadiga utilizadas (a abordagem por fratura mecânica foi excluída).

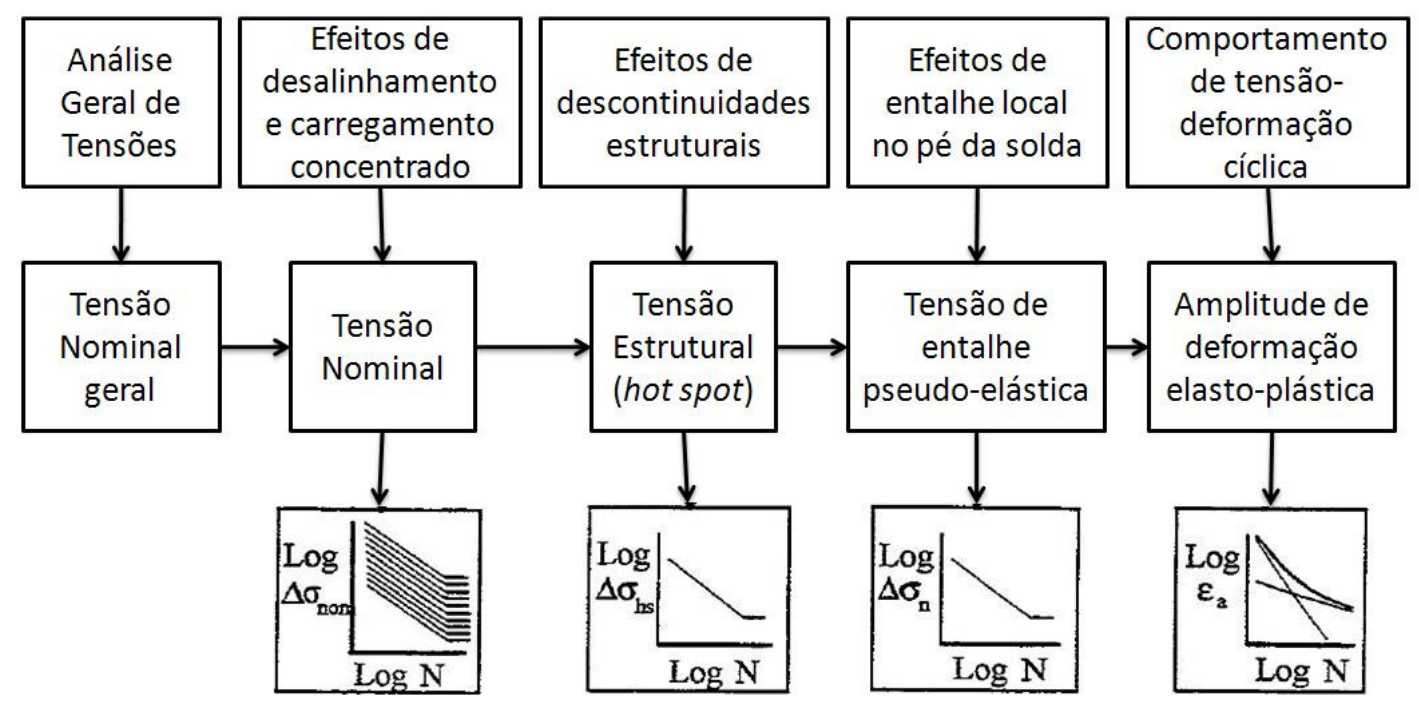

Figura 21 - Uma visão geral da análise de tensão em fadiga (Adaptado de Niemi, 1995)

Para a análise de vida à fadiga é necessário submeter o componente ou amostra a uma tensão cíclica, sendo que para isto é utilizado algum dispositivo. A máquina de teste de flexão rotativa, de R. R. Moore, que se baseia na metodologia de Wöhler é o dispositivo para teste de fadiga mais empregado. Esta máquina submete o corpo de prova à flexão pura (sem cisalhamento) por meio de pesos.

O mecanismo da fadiga compreende as seguintes fases sucessivas: nucleação ou iniciação da fissura de fadiga, propagação dessa fissura e ruptura final (BRANCO; FERNANDES; CASTRO, 1986).

Os seguintes métodos são utilizados para prever a vida em fadiga:

- Tensão-Vida

- Deformação-Vida

- Mecânica da Fratura

No presente trabalho, será abordado apenas o primeiro método, ou seja, tensãovida, pois a falha de juntas soldadas ocorre em grandes ciclos, não sendo, portanto, fadiga de baixo ciclo. 


\subsubsection{Método Tensão-Vida}

O método de Tensão-Vida, também conhecido como S-N, foi a primeira aproximação utilizada para entender e quantificar a fadiga nos metais. O método baseia-se nas premissas de Wöhler ou no diagrama S-N, que é elaborado pela tensão alternada (S) versus a quantidade de ciclos até ocorrer a falha (N) (BANNANTINE; COMER; HANDROCK, 1990).

Ao trabalhar com a tensão alternada, utiliza-se as relações que seguem:

$$
\begin{gathered}
\Delta \sigma=\sigma_{\max }-\sigma_{\min } \\
\sigma_{a}=\frac{\sigma_{\max }-\sigma_{\min }}{2} \\
\sigma_{m}=\frac{\sigma_{\text {max }}+\sigma_{\min }}{2} \\
R=\frac{\sigma_{\min }}{\sigma_{\max }} \\
A_{m}=\frac{\sigma_{a}}{\sigma_{m}}
\end{gathered}
$$

A Figura 22 apresenta as relações acima descritas. Os valores de $R$ e $A_{m}$, para os carregamentos mais comuns, são apresentados abaixo:

- Completamente reverso: $R=-1 \quad A_{m}=\infty$

- Zero ao máximo: $\quad R=0 \quad A_{m}=1$

- Zero ao mínimo: $\quad R=\infty \quad A_{m}=-1$ 


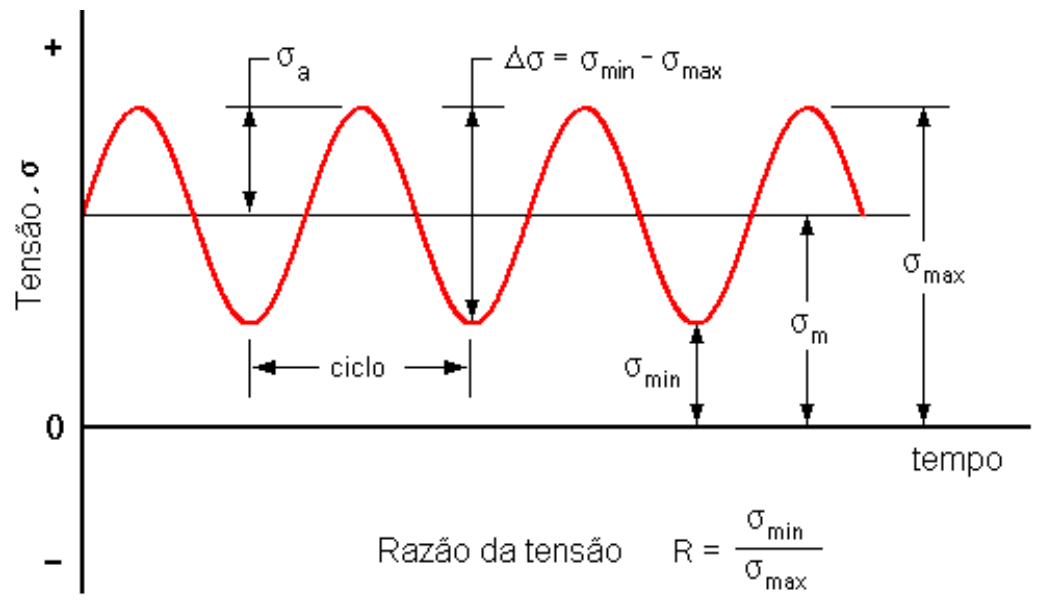

Figura 22 - Terminologia da tensão alternada.

Os resultados do ensaio de fadiga podem ser lançados num diagrama mestre, conforme exemplifica a Figura 23.

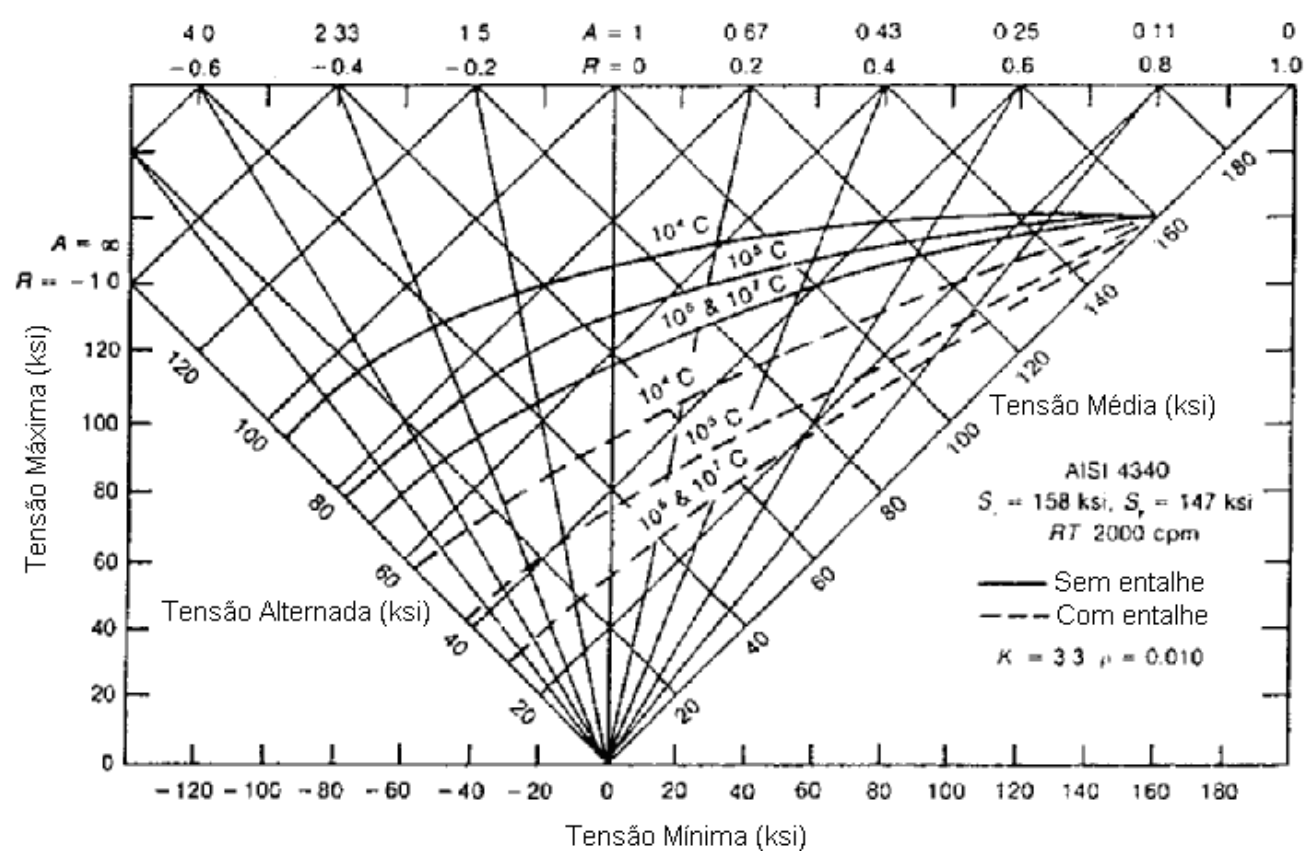

Figura 23 - Diagrama mestre para o aço AISI4340 (BANNANTINE; COMER; HANDROCK, 1990)

Os testes requeridos para gerar o diagrama mestre são relativamente caros, por isso algumas relações empíricas foram desenvolvidas para gerar a região da vida infinita. As relações de Soderberg (EUA, 1930), Goodman (Inglaterra, 1899), Gerber (Alemanha, 1874) e Morrow (EUA) são apresentadas nas equações 17, 18, 19 e 20, respectivamente. A Figura 24 apresenta um comparativo entre estas relações. 


$$
\begin{array}{cc}
\frac{\sigma_{a}}{S_{e}}+\frac{\sigma_{m}}{S_{y}}=1 & \text { Soderberg } \\
\frac{\sigma_{a}}{S_{e}}+\frac{\sigma_{m}}{S_{u}}=1 & \text { Goodmann } \\
\frac{\sigma_{a}}{S_{e}}+\left(\frac{\sigma_{m}}{S_{u}}\right)^{2}=1 & \text { Gerber } \\
\frac{\sigma_{a}}{S_{e}}+\frac{\sigma_{m}}{\sigma_{f}}=1 & \text { Morrow }
\end{array}
$$

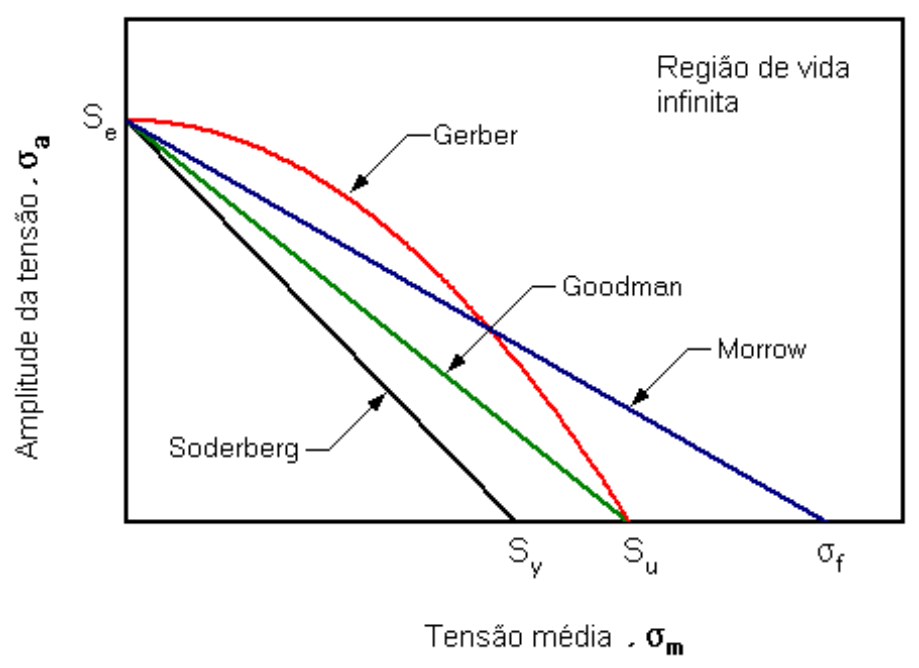

Figura 24 - Comparativo entre as equações da tensão média (a-Soderberg, b-Goodman, c-Gerber, dMorrow)

As seguintes afirmações podem ser consideradas para a tensão média:

- O método de Soderberg é muito conservador e raramente utilizado;

- Os atuais testes de fadiga tendem a falhar entre as curvas de Goodman e Gerber;

- Para aços de alta dureza as curvas de Morrow e Goodman são essencialmente as mesmas. Para aços dúcteis $\left(\sigma_{\uparrow}>S_{u}\right)$ a curva de Morrow é menos sensível para a tensão média; 
A Figura 25 apresenta uma curva S-N generalizada.

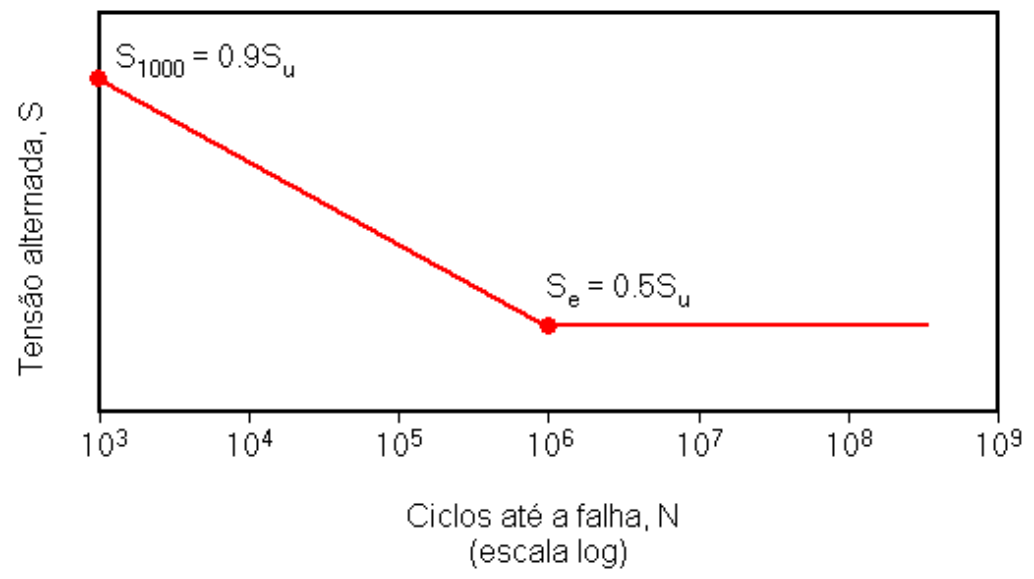

Figura 25 - Curva S-N generalizada

\subsubsection{Análise de Fadiga pela abordagem de tensão hot spot}

Nesta abordagem a resistência à fadiga é expressa como uma curva $S \times N$, geralmente baseada na medida da tensão próxima ao ponto de início da trinca na amostra, o que contrasta com a abordagem pela tensão nominal, que é baseada na resistência à fadiga em condições de tensão nominal, calculada, por exemplo, através da equação 10.

Geralmente é utilizada em juntas cujo pé da solda está orientado transversalmente à componente de tensão cíclica. Esta abordagem não é adequada para juntas cuja trinca seja oriunda de defeitos ou da raiz da solda, tendo, portanto sua aplicação voltada para trincas no pé da solda.

Uma vantagem da abordagem por tensão hot spot é a possibilidade de prever a vida à fadiga de diversos tipos de configuração de juntas utilizando apenas uma curva $S$ $x \mathrm{~N}$. Adicionalmente curvas $\mathrm{S}$ x $\mathrm{N}$ podem ser necessárias com a variação do tipo de solda, a espessura efetiva da solda ou os efeitos do meio ao qual a junta esta submetida.

A tensão hot spot é determinada experimentalmente através de testes laboratoriais, utilizando extensômetros (strain gauges) e extrapolando o valor da tensão para o ponto crítico, desconsiderando a tensão não linear, conforme ilustrado na Figura 26. 


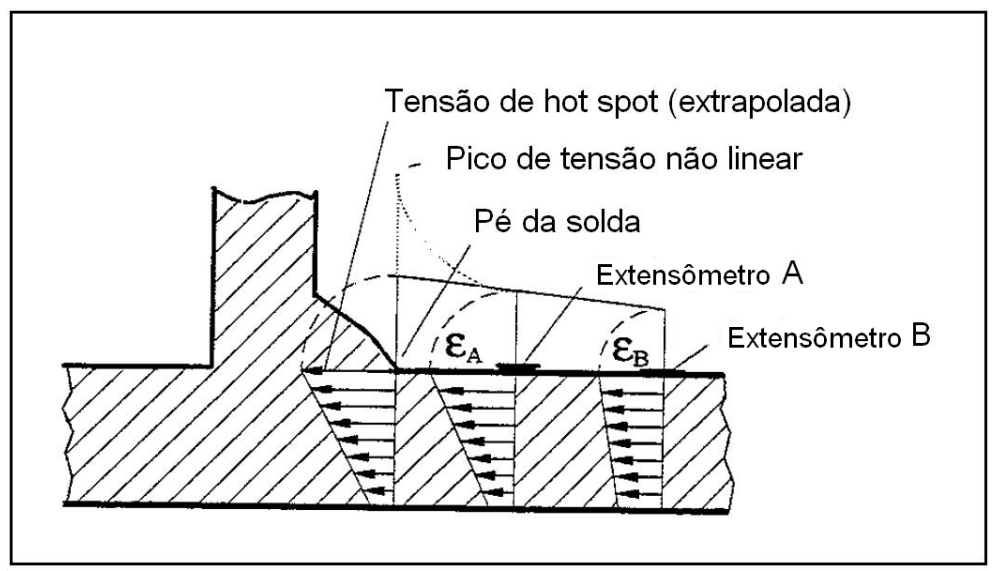

Figura 26 - Medição da tensão de hot spot através da extrapolação da tensão (adaptado de NIEMI, 1995)

Importante salientar que o extensômetro deve ser colocado numa distância suficiente do pé da solda para que os efeitos da tensão não linear não afetem a medição.

É possível obter a tensão de hot spot através das análises descritas abaixo:

- calcular a tensão nominal e multiplicá-la pelo fator de concentração de tensão $\left(K_{s}\right)$, para uma apropriada descontinuidade estrutural;

- faixas de deformação são medidas através de testes, conforme apresentado na Figura 26;

- tensões e deformações são analisadas através do MEF utilizando elementos de casca ou sólidos.

Quando a tensão é obtida através do MEF, os resultados já incluem os efeitos biaxiais.

De acordo com a definição de tensão estrutural, a tensão de hot spot é linearmente distribuída na direção da espessura, consistindo de uma componente de membrana e de uma componente de flexão, sendo que uma desvantagem deste método é considerar a tensão de superfície, não havendo uma distinção entre os efeitos da tensão de membrana e a de flexão na propagação da trinca. 


\subsubsection{Fadiga Multiaxial}

Em diversas aplicações, componentes são sujeitos a um complexo estado de tensão e deformação, que combina carregamento de flexão e de torção, ocorrendo freqüentemente em descontinuidades geométricas. Este complexo estado de tensões é caracterizado pela não proporcionalidade entre as três tensões principais ou pela alteração na direção das tensões principais durante o ciclo de carregamento. Segundo Bannantine; Comer e Handrock (1990), a fadiga sob essas condições é chamada de Fadiga Multiaxial, sendo esta uma importante consideração de projeto para uma operação segura e para a otimização de diversos componentes em engenharia.

$\mathrm{Na}$ análise da Fadiga Multiaxial, além de ser considerada a tensão e a deformação, é necessário obter o estado de tensão/deformação como uma função da periodicidade de aplicação.

São diversas as abordagens que envolvem a teoria da fadiga multiaxial, que podem ser divididas, segundo Gustafsson e Saarinen (2007) em cinco grupos:

- Modelos baseados em tensão;

- Modelos baseados em deformação;

- Modelos baseados em energia;

- Modelos de fratura mecânica;

- Métodos para componentes soldados.

Cada grupo engloba ainda diversas metodologias de análise.

Segundo Gustafsson e Saarinen (2007), para os modelos baseados em tensão pode-se citar a tensão equivalente empírica (fórmulas de Gough e Lee), a tensão constante (Sines), a tensão média (Papadopoulos, F Morel) e o plano crítico (Findley, McDiarmid, Dang Van e Susmel \& Lazzarin).

Os modelos baseados em deformação são relacionados com o plano crítico e foram estudados por: Brown, Miller, Lohr, Ellison, Socie, Fatemi e Smith, dentre outros (Gustafsson; Saarinen, 2007).

Os modelos baseados em energia são subdivididos em energia elástica, energia plástica e na somatória entre plástica e elástica. O método de Garud pode ser citado 
para energia plástica e o de Ellyin para a somatória entre plástica e elástica (Gustafsson; Saarinen, 2007).

A fratura mecânica tem seu modelo baseado na análise do crescimento de micro trincas freqüentemente ligada umas as outras formando uma trinca maior que ocasiona a falha. Este modelo é baseado na lei Paris.

O presente trabalho analisa a fadiga sob um aspecto de carregamento combinado e não como uma análise multiaxial, abordando este tema apenas com uma breve revisão descrita acima. Para um maior aprofundamento em fadiga multiaxial, consultar o trabalho de Gustafsson e Saarinen (2007) que revisaram os modelos de fadiga multiaxial em juntas soldadas.

\subsection{TÉCNICAS DE MELHORIA DA RESISTÊNCIA À FADIGA EM JUNTAS SOLDADAS}

Diversos métodos podem ser utilizados para melhorar a resistência à fadiga de uma junta soldada, dentre os quais, pode-se citar:

- Preparação TIG ou Plasma - onde é feita uma passagem superficial destes processos de soldagem com o intuito de reduzir ou remover concentrações de tensão e defeitos;

- Redução da concentração de tensões - através da modificação do projeto da junta ou pela melhoria do acabamento da mesma;

- Introdução de tensões residuais compressivas - podendo ser obtida através de martelamento superficial, onde o cordão de solda é martelado através de um equipamento pneumático (BRANCO; FERNANDES; CASTRO, 1986); sobrecarga, onde a região soldada é submetida a cargas superiores à de escoamento, plastificando assim o material; compressão localizada, onde pode-se citar o processo de jateamento por granalhas;

- Revestimentos - como a pintura epoxy e a metálica, onde o princípio é excluir a interação com o meio ambiente;

A Figura 27 apresenta um comparativo entre os diversos meios para aumentar a vida em fadiga de juntas soldadas. 


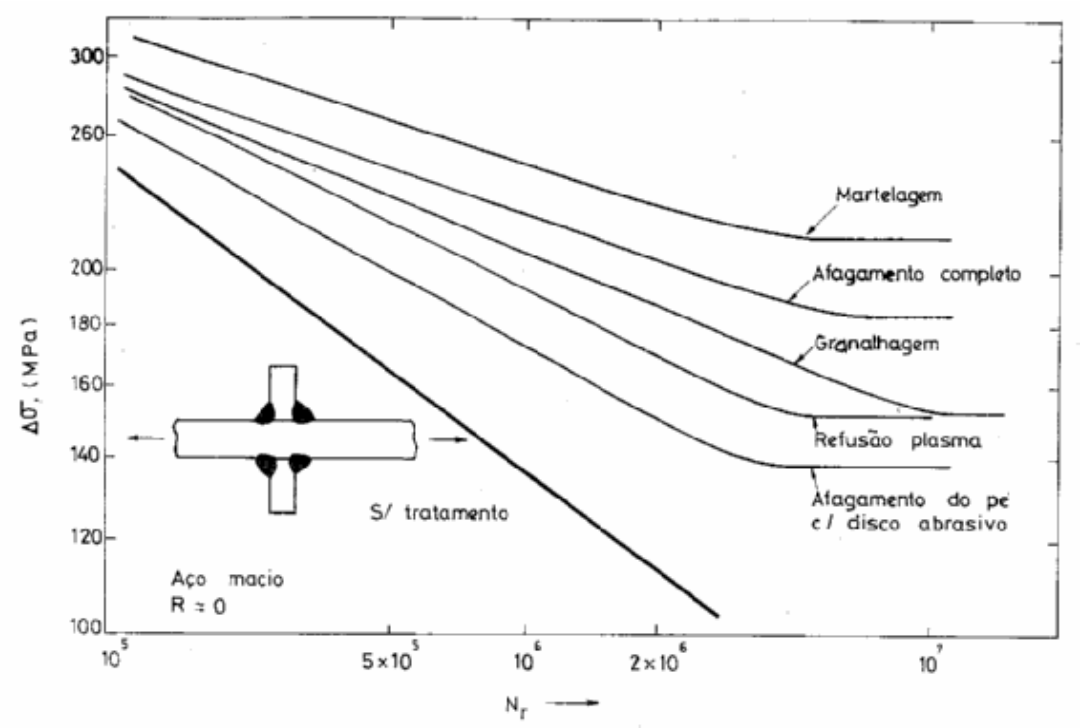

Figura 27 - Comparação da resistência à fadiga em juntas de canto de base metálica, $R=0$ (BRANCO; FERNANDES; CASTRO, 1986)

\subsection{NORMAS DE FADIGA PARA JUNTAS SOLDADAS}

A vida em fadiga é calculada através de curvas $S \times N$ padronizadas por diversas normas, como, por exemplo, a BS7608 (1993). Essa norma é baseada em ensaios de fadiga realizados em diversos tipos de juntas soldadas, sendo a tensão nominal calculada através da teoria de elasticidade e considerando os efeitos da tensão axial, fletora e cisalhante. Tensões residuais nos detalhes da solda não são consideradas nesta norma, mas estão implícitas nos ensaios realizados. Esta norma recomenda que seja utilizada a tensão hot spot para juntas de seção tubular, mencionando que o valor da mesma é inferior ao pico de tensão, mas suficientemente consistente para definir a faixa de tensão a ser utilizada.

A norma BS7608 (1993) segue as classes de juntas propostas na BS153 (1972), conforme resumido na Figura 28. 


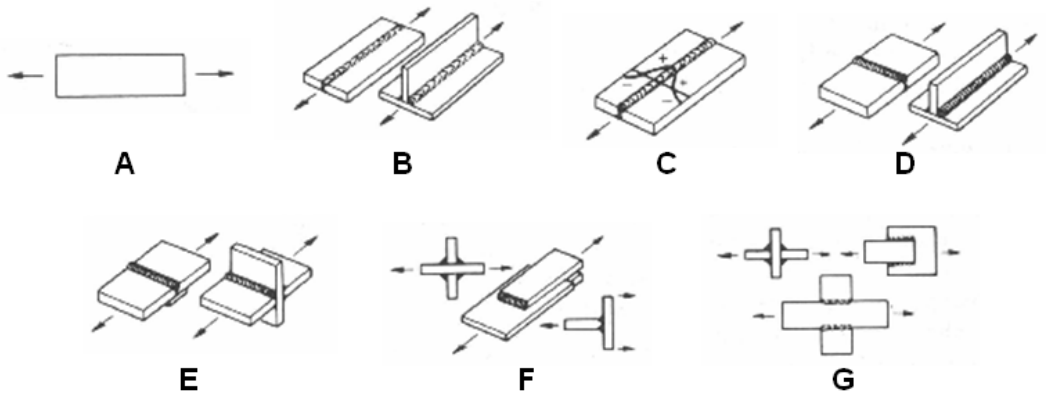

Figura 28 - Tipos de juntas soldadas, conforme BS153 (1972)

Para cada classe de junta, a relação entre a tensão, $S$, e o número de ciclos até a falha, $N$, sob condições de carregamento com amplitude constante é descrito na equação abaixo:

$$
\log N=\log C_{0}-d / \delta-m \log S
$$

Os valores relevantes para os termos descritos, são apresentados na Tabela 2.

Tabela 2 - Constantes para curvas $\mathrm{S} \times \mathrm{N}$ básicas.

\begin{tabular}{|c|c|c|c|c|c|c|c|c|}
\hline \multirow{2}{*}{ Classe } & \multirow{2}{*}{$C_{0}$} & \multicolumn{2}{|c|}{$C_{0}$} & \multirow{2}{*}{$m$} & \multicolumn{2}{|c|}{ Desvio Padrão, $\delta$} & \multirow{2}{*}{$C_{d}$} & \multirow{2}{*}{$\begin{array}{l}S_{0}\left(N=10^{7}\right. \\
\text { ciclos }) M P a\end{array}$} \\
\hline & & $\log _{10}$ & $\log _{e}$ & & $\log _{10}$ & $\log _{e}$ & & \\
\hline B & $2.343 \times 10^{15}$ & 15.3697 & 35.3900 & 4.0 & 0.1821 & 0.4194 & $1.01 \times 10^{15}$ & 100 \\
\hline $\mathrm{C}$ & $1.082 \times 10^{14}$ & 14.0342 & 32.3153 & 3.5 & 0.2141 & 0.4700 & $4.23 \times 10^{15}$ & 78 \\
\hline $\mathrm{D}$ & $3.988 \times 10^{12}$ & 12.6007 & 29.0144 & 3.0 & 0.2095 & 0.4824 & $1.52 \times 10^{15}$ & 53 \\
\hline E & $3.289 \times 10^{12}$ & 12.5169 & 28.8216 & 3.0 & 0.2509 & 0.5777 & $1.04 \times 10^{15}$ & 47 \\
\hline $\mathrm{F}$ & $1.726 \times 10^{12}$ & 12.2370 & 28.1770 & 3.0 & 0.2183 & 0.5027 & $0.63 \times 10^{15}$ & 40 \\
\hline $\mathrm{F} 2$ & $1.231 \times 10^{12}$ & 12.0900 & 27.8387 & 3.0 & 0.2279 & 0.5248 & $0.43 \times 10^{15}$ & 35 \\
\hline $\mathrm{G}$ & $0.566 \times 10^{12}$ & 11.7525 & 27.0614 & 3.0 & 0.1793 & 0.4129 & $0.25 \times 10^{15}$ & 29 \\
\hline W & $0.368 \times 10^{12}$ & 11.5662 & 26.6324 & 3.0 & 0.1846 & 0.4251 & $0.16 \times 10^{15}$ & 25 \\
\hline S & $2.13 \times 10^{23}$ & 23.3284 & 53.7156 & 8.0 & 0.5045 & 1.1617 & $2.08 \times 10^{15}$ & 82 \\
\hline $\mathrm{T}$ & $4.577 \times 10^{12}$ & 12.6606 & 29.1520 & 3.0 & 0.2484 & 0.5720 & $1.46 \times 10^{15}$ & 53 \\
\hline
\end{tabular}


Estes valores são aplicáveis aos aços cobertos pela norma BS7608 (1993), utilizando a equação 22.

$$
\log C_{d}=\log C_{0}-d \delta
$$

Onde a equação 21 pode ser reescrita como:

$$
S^{m} N=\log C_{d}
$$

A Figura 29 apresenta as curvas de fadiga para as diversas classes de juntas, onde para o presente trabalho foi utilizada a junta classe $F$.

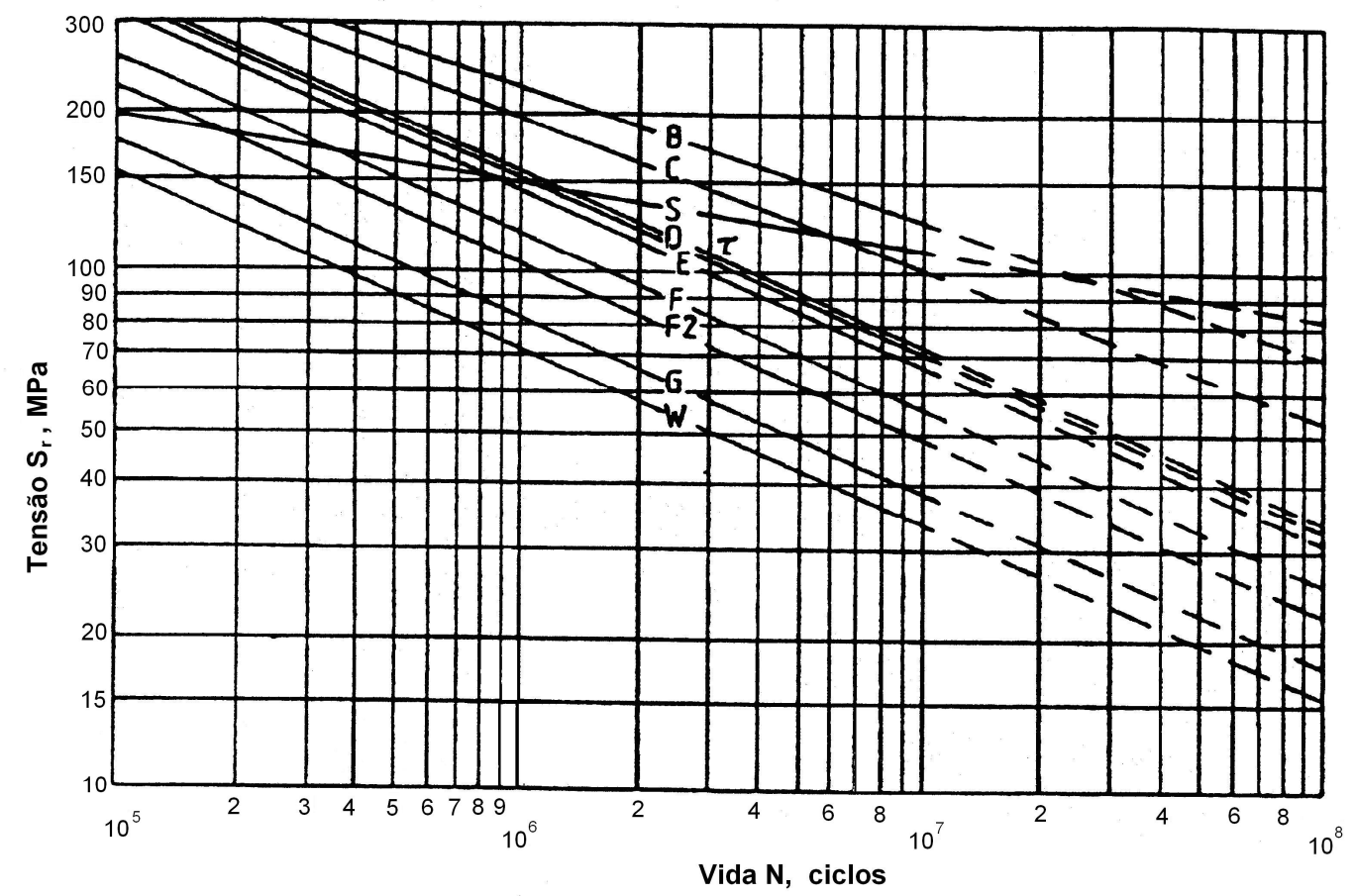

Figura 29 - Curvas S x N, em função do tipo de junta, propostas pela BS7608 (1993) - Legenda conforme figura 28.

A norma Eurocode 3 (2005) também trata da resistência à fadiga de juntas soldadas quando estas estão sujeitas a carregamentos cíclicos.

A tensão utilizada é a nominal e dentre os tipos de juntas propostos pela norma, a classe 90 é a que mais se aproxima da amostra testada no presente trabalho. A 
Figura 30 apresenta algumas das classes propostas para juntas cruciformes e $T$, segundo a norma Eurocode 3 (2005), para estas classes a tensão proposta é a nominal.

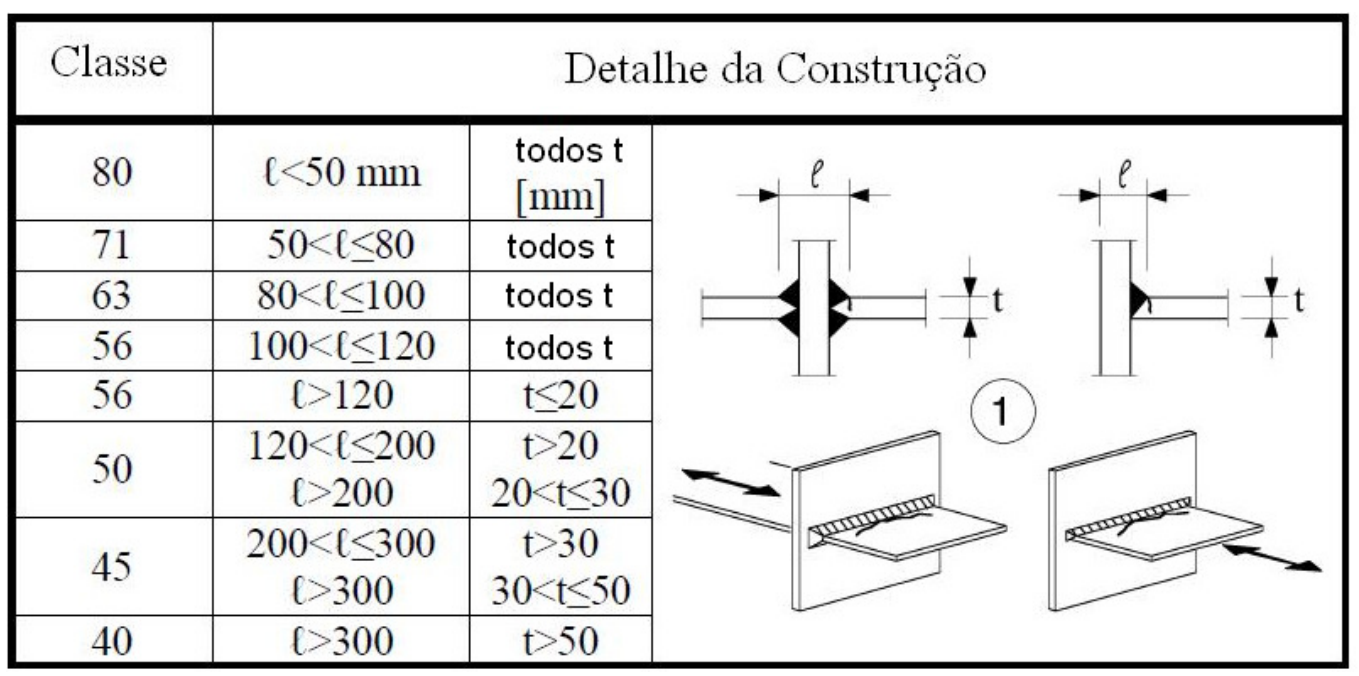

Figura 30 - Classes de juntas cruciforme e T propostas pela norma Eurocode 3

A norma Eurocode 3 (2005) também propõe a utilização da tensão hot spot para a análise da resistência à fadiga para alguns tipos de juntas, condicionado ao início da trinca no pé da solda. A Figura 31 apresenta a classe 90, tipo de junta esta que mais se aproxima à estudada no presente trabalho.

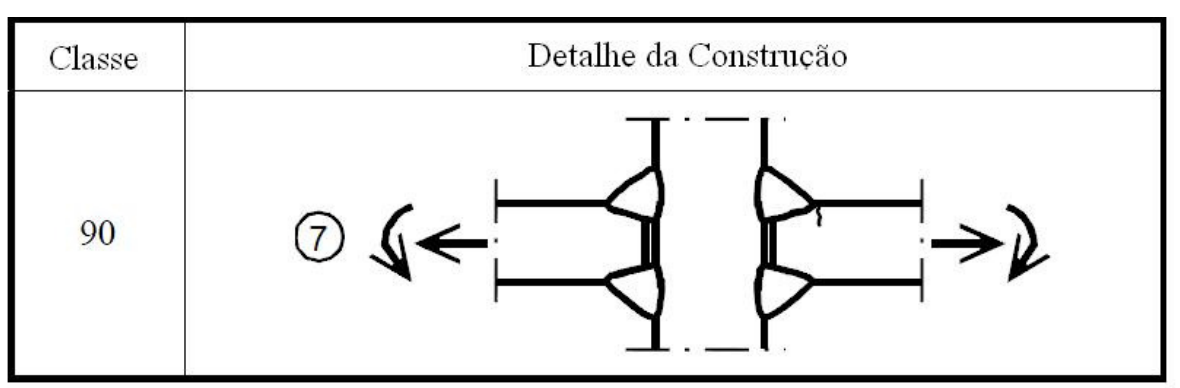

Figura 31 - Classe de junta avaliada pelo método hot spot com carregamento através da solda

A Figura 32 apresenta as curvas $\mathrm{S} \times \mathrm{N}$ para os diversos tipos de juntas propostas pela norma Eurocode 3 (2005). 


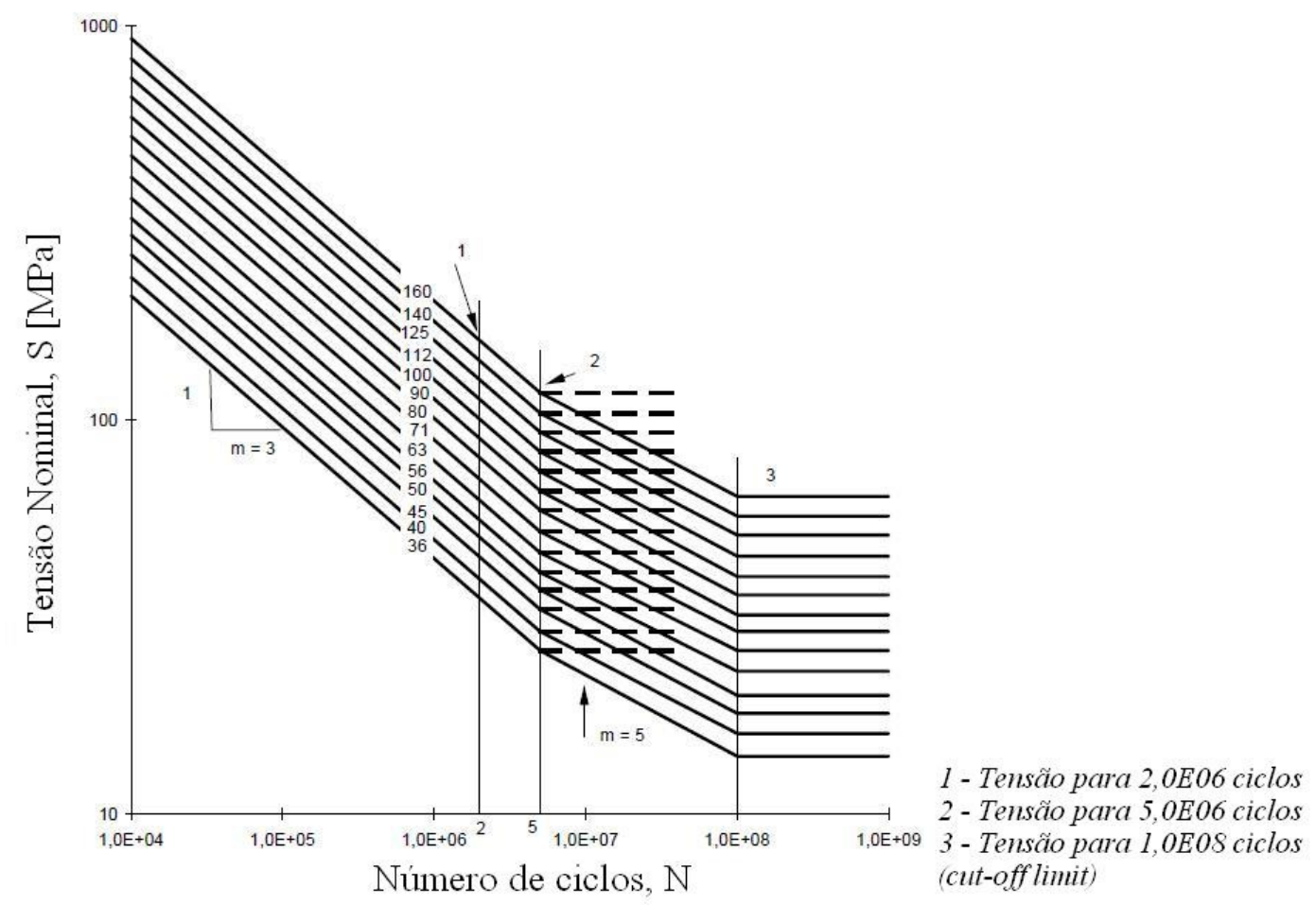

Figura 32 - Curvas S x N, em função do tipo de junta, propostas pela Eurocode 3 (2005)

Fuchs e Stephens (1980) compararam a tensão necessária para que se atinja o número de ciclos $\mathrm{N}=2.10^{6}$, dada as diferentes classificações de juntas propostas pela BS153 (1972), o resultado é apresentado em forma de pareto na Figura 33.

Através de tal figura é possível concluir que o tipo de junta influencia diretamente na resistência à fadiga.

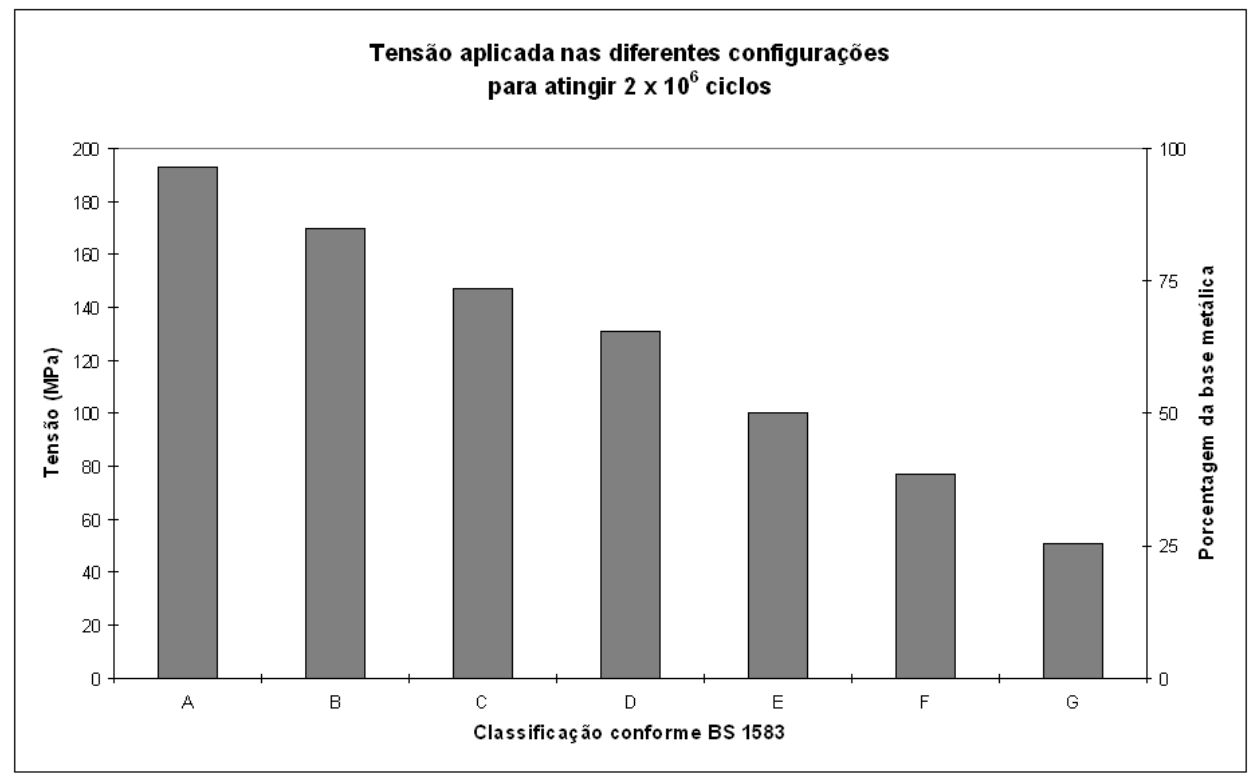

Figura 33 - Comparação da vida à fadiga para as diferentes classificações de juntas soldadas (Adaptado de FUCHS; STEPHENS, 1980) 


\section{MATERIAIS E MÉTODOS}

O desenvolvimento de um procedimento numérico-experimental para prever a vida à fadiga de uma junta soldada irá envolver: o projeto da junta, a análise de tensões e a resistência à fadiga, considerando o efeito das tensões residuais e fatores geométricos de concentração de tensões, presentes nos testes realizados e nas curvas de fadiga utilizadas.

Primeiramente foi feita a análise virtual de tensões para melhor escolha da geometria da amostra, sendo seguida da análise de vida à fadiga, que utilizou os resultados do EF. Os testes experimentais foram então realizados, calibrando assim a curva utilizada.

A seguir serão apresentadas as principais metodologias adotadas neste trabalho.

\subsection{AMOSTRAS}

As amostras utilizadas no presente trabalho foram baseadas nos trabalhos de Sonsino (1995, 1997, 2009), Gustafsson e Saarinen (2007) e Bäckström (2003). As amostras do tipo tublo-placa de seção retangular foram fabricadas utilizando parte de um componente da indústria automobilística (eixo diferencial) soldado a uma placa de aço. As amostras foram gentilmente cedidas pela ArvinMeritor do Brasil Sistemas Automotivos.

\subsubsection{Geometria}

Diversas foram as geometrias do tipo tubo-placa construídas virtualmente até chegar ao projeto ótimo que é apresentado na Figura 34. 

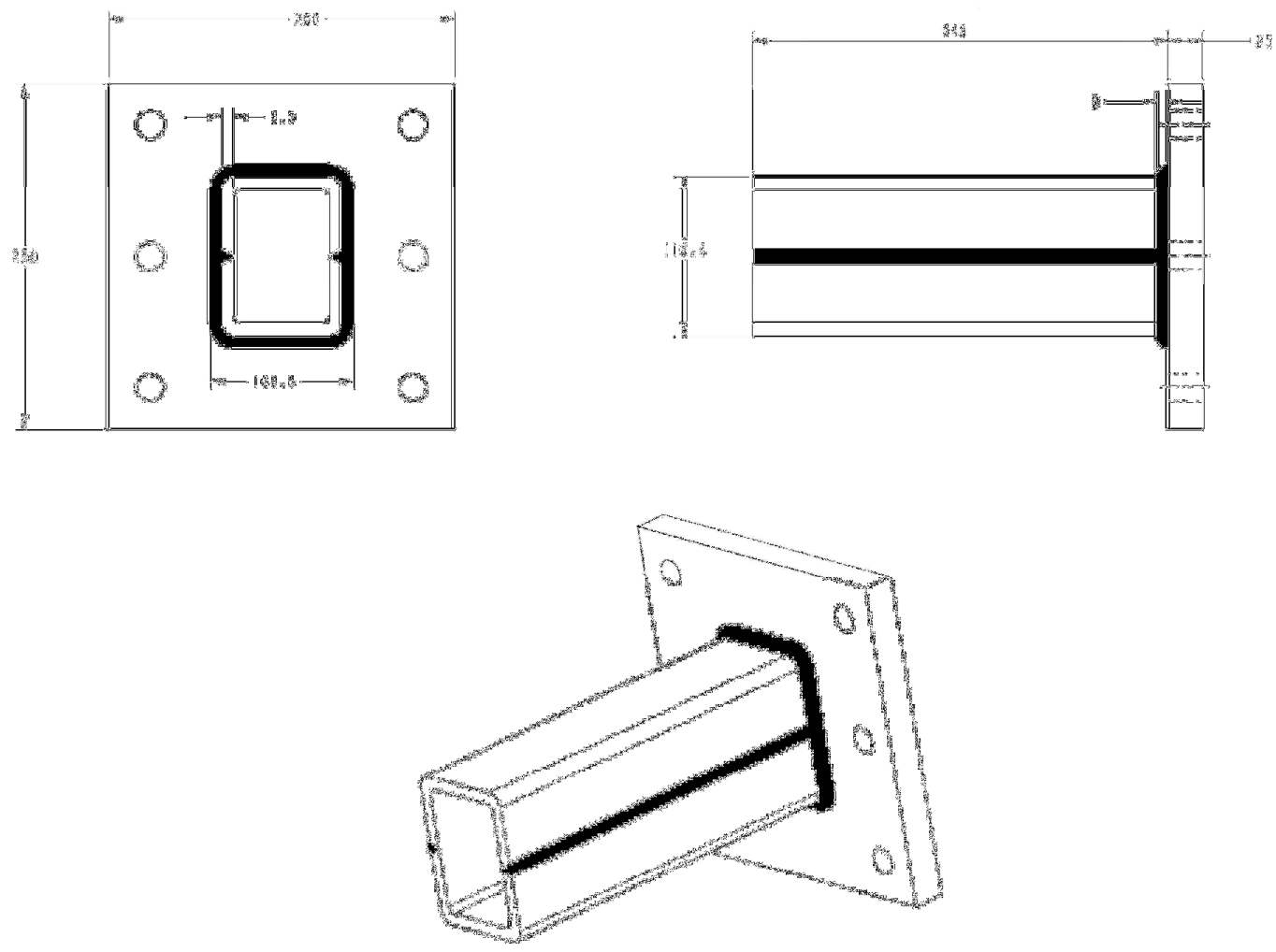

Figura 34 - Geometria das amostras utilizadas

- Dimensional da Junta Soldada

Após a fabricação das amostras (duas ao total) foi realizado o dimensional da junta soldada que é apresentado na Tabela 3, cuja nomenclatura utilizada é apresentada na Figura 35.

Tabela 3 - Dimensional da junta em mm

\begin{tabular}{|c|c|c|}
\hline Dimensão & Amostra 01 & Amostra 02 \\
\hline A & 12,10 & 10,80 \\
\hline B & 11,30 & 10,10 \\
\hline C & 7,70 & 8,60 \\
\hline D & 3,30 & 2,00 \\
\hline E & 1,20 & 1,00 \\
\hline
\end{tabular}




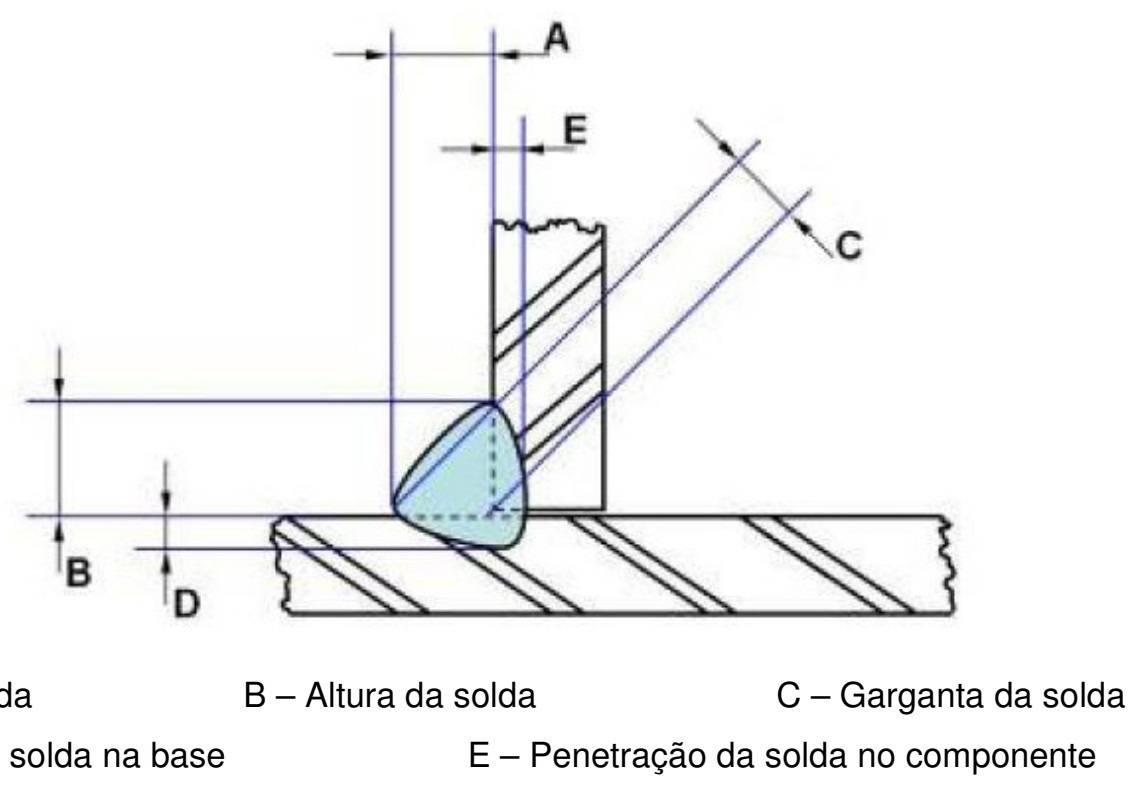

Figura 35 - Nomenclatura utilizada no dimensional da junta

\subsubsection{Materiais}

O material utilizado na confecção do tubo das amostras é similar ao aço SAE1022 micro ligado ao nióbio, titânio e vanádio, desenvolvido para conferir carbono equivalente (CE) máximo de 0,50. Este aço é comumente usado em carcaças estampadas de eixos automotivos, com espessuras típicas de 9.5, 12 e 16mm. Optou-se por este material pela sua utilização na indústria automotiva já ser consagrada, por este material utilizar um processo de soldagem idêntico ao analisado neste trabalho e pela disponibilidade de material.

\section{- Análise Química}

A especificação química do material do tubo é apresentada na Tabela 4, juntamente com os valores encontrados na análise química das amostras.

Tabela 4 - Composição química do material do tubo (em \%)

\begin{tabular}{|c|c|c|c|c|c|c|c|c|c|c|c||}
\hline ELEMENTO & $\mathbf{C}$ & $\mathbf{M n}$ & $\mathbf{S i}$ & $\mathbf{P}$ & $\mathbf{S}$ & $\mathbf{A l}$ & $\mathbf{N b}$ & $\mathbf{T i}$ & $\mathbf{N}$ & $\mathbf{C a}$ & $\mathbf{\Sigma} \mathbf{N b} / \mathbf{V}$ \\
\hline Especificado & 0,23 & 1,60 & 0,50 & 0,035 & 0,010 & 0,055 & 0,060 & 0,040 & 0,010 & 0,005 & 0,12 \\
\hline Amostra 01 & 0,17 & 1,39 & 0,21 & 0,023 & 0,002 & 0,042 & 0,031 & 0,017 & 0,007 & 0,003 & 0,034 \\
\hline
\end{tabular}


O material SAE1518 foi utilizado na confecção do flange que, após soldagem do tubo, formou a junta tubo-placa utilizada no presente trabalho, tendo sua especificação apresentada na Tabela 5 juntamente com os valores encontrados na análise química das amostras.

A análise química dos materiais do tubo e do flange foi realizada pela empresa PROAQT.

Tabela 5 - Composição química do material do flange

\begin{tabular}{|c|c|c|c|c|c|c|c|c|c|c|}
\hline ELEMENTO & $\mathbf{C}$ & $\mathbf{M n}$ & $\mathbf{S i}$ & $\mathbf{P}$ & $\mathbf{S}$ & $\mathbf{A l}$ & $\mathbf{C r}$ & $\mathbf{N i}$ & $\mathbf{C u}$ & Mo \\
\hline Especificado & 0,17 & 0,30 & N/A & $\begin{array}{c}0,040 \\
\text { MAX }\end{array}$ & $\begin{array}{c}0,050 \\
\text { MAX }\end{array}$ & N/A & N/A & N/A & N/A & N/A \\
\hline Amostra 01 & 0,176 & 1,173 & 0,234 & 0,013 & 0,005 & 0,031 & 0,016 & 0,011 & 0,007 & 0,001 \\
\hline
\end{tabular}

\section{- Carbono Equivalente}

Além da composição química dos materiais a serem soldados, o teor de carbono equivalente (CE) também influencia na soldabilidade do material, tal valor é calculado através da equação 24 , onde o teor de cada elemento é obtido através de análise química do material utilizado.

$$
C E=C+\frac{M n}{6}+\frac{C r+M o+V}{5}+\frac{N i+C u}{15}
$$

A amostra analisada apresentou teor de CE de 0,41.

\section{- Microestrutura}

A caracterização microestrutural dos materiais da junta soldada foi realizada utilizando Nital $2 \%$. Os corpos de prova para análise foram retirados do tubo (metal base), do flange, da solda e da ZAC na região do tubo.

A Figura 36 apresenta a microestrutura do material do tubo onde é possível observar a microestrutura composta de ferrita granular com perlita. 


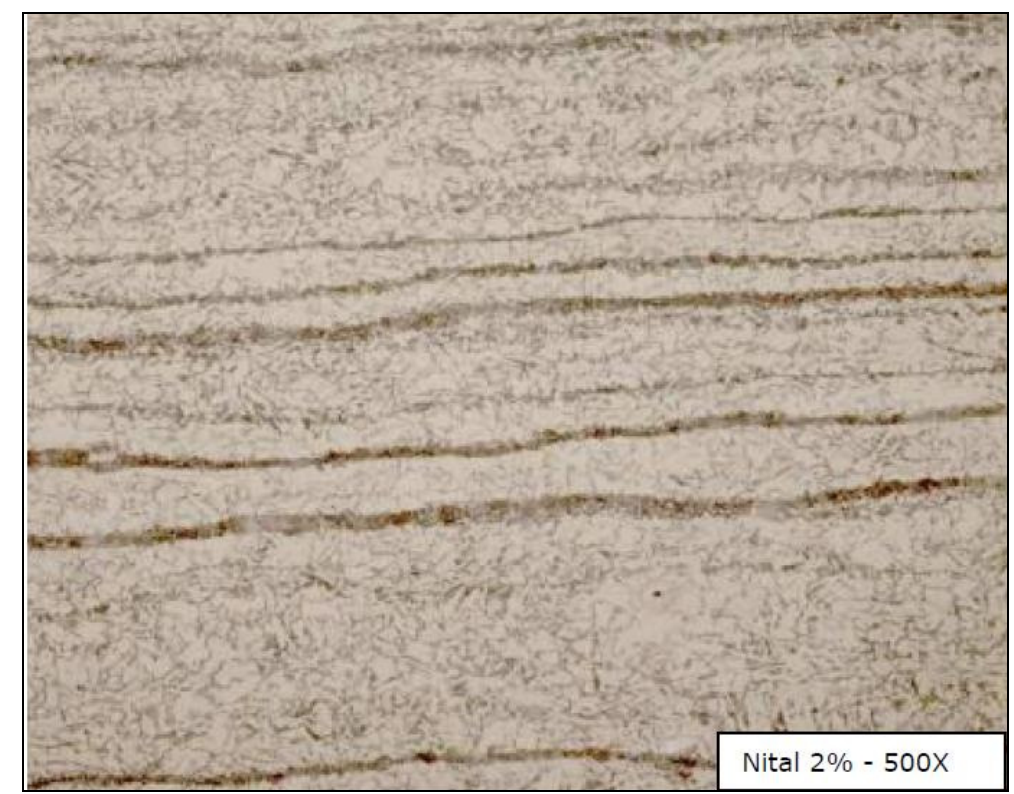

Figura 36 - Microestrutura do material do tubo com ampliação de 500x

A Figura 37 apresenta a microestrutura do flange composta por ferrita e perlita e a Figura 38 a da solda, com estrutura predominantemente ferrítica. A microestrutura da ZAC na região do tubo é apresentada na Figura 39, onde é possível observar a presença de ferrita e perlita.

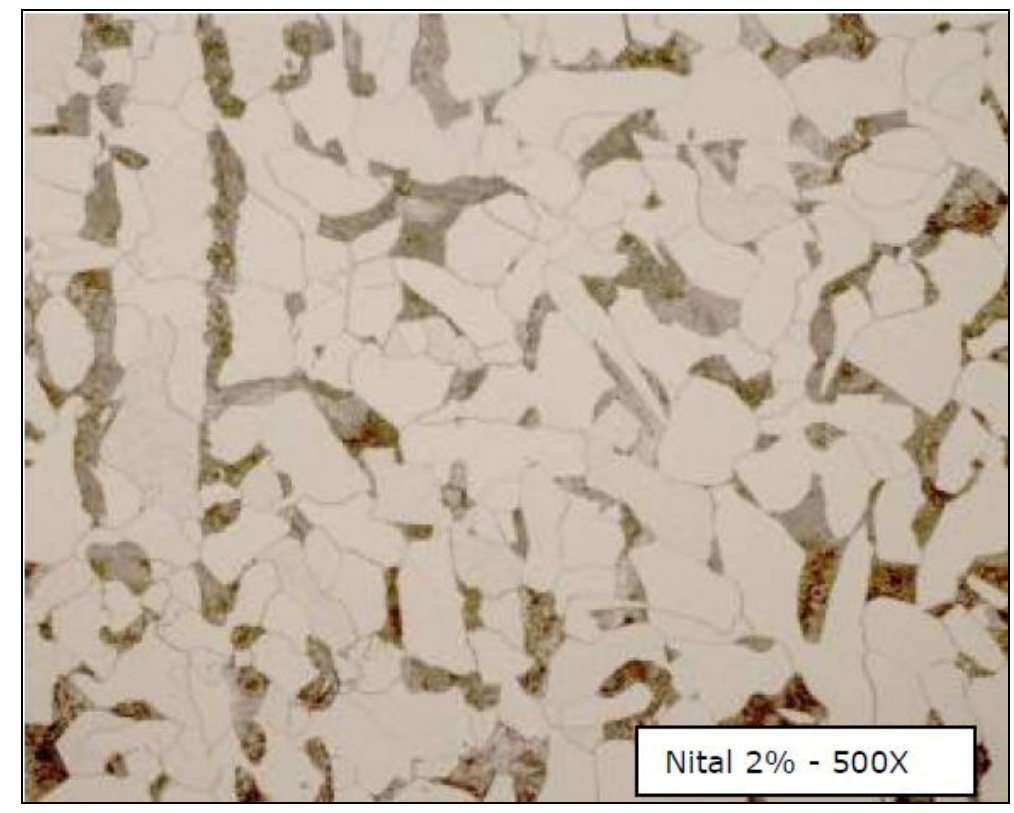

Figura 37 - Microestrutura do material do flange com ampliação de 500x 


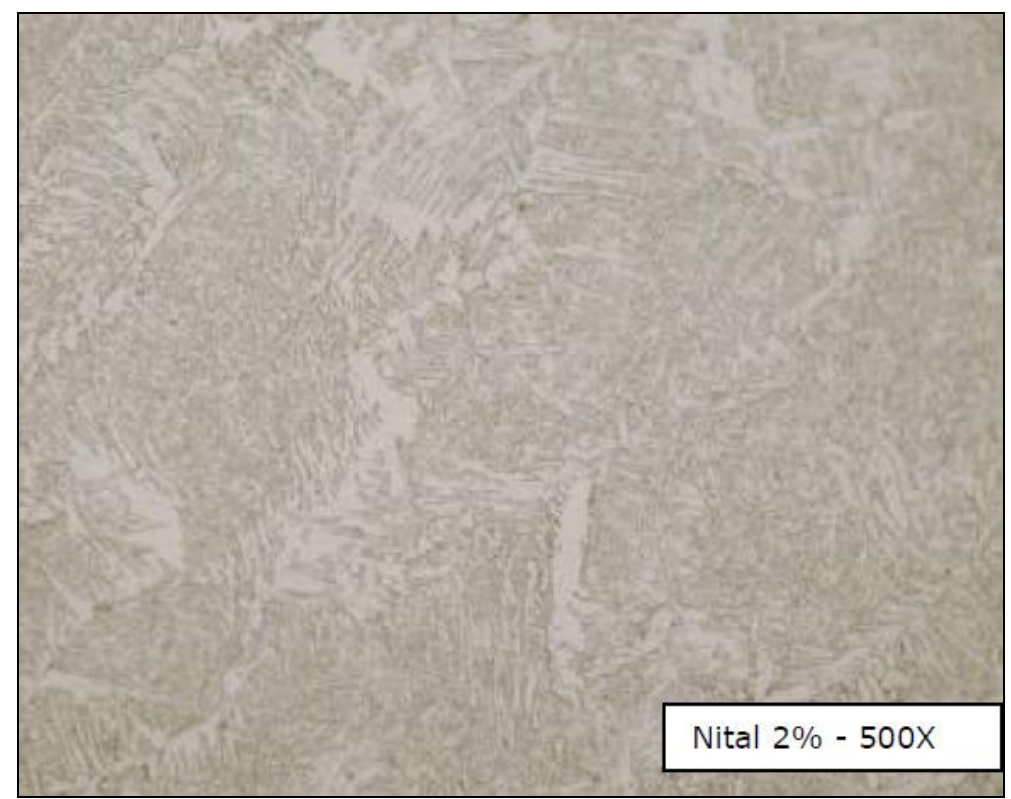

Figura 38 - Microestrutura do material da solda com ampliação de 500x

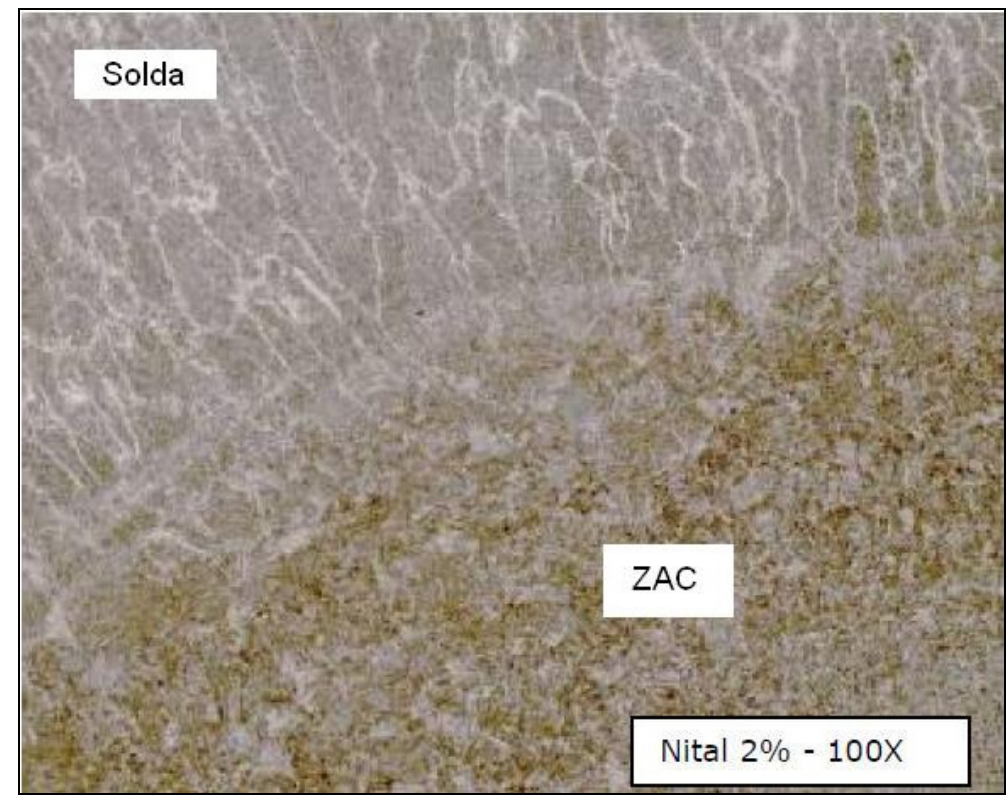

Figura 39 - Microestrutura da região entre a solda e o material da ZAC do tubo com ampliação de $100 x$ 
- Propriedades Mecânicas do Material

As propriedades monotônicas típicas do metal base do tubo são apresentadas abaixo:

- $\mathrm{E}=210 \mathrm{GPa}$

- $v=0,3$

- $\mathrm{S}_{\mathrm{y}}=350 \mathrm{MPa}$

- $\mathrm{S}_{\mathrm{u}}=530 \mathrm{MPa}$

Os valores de temperabilidade Jominy típicos deste material, com base nesta composição química são: J1/16 polegada $=42 ; \mathrm{J} 2 / 16=37 ; \mathrm{J} 3 / 16=29 ; \mathrm{J} 4 / 16=21$.

As amostras foram submetidas ao ensaio de dureza Brinell, cujo resultado é apresentado na Tabela 6.

Tabela 6 - Dureza Brinell (HB) para as amostras 01 e 02

\begin{tabular}{|c|c|c|c|}
\hline Amostra & Tubo & Flange & Solda \\
\hline 01 & 191 & 161 & 217 \\
\hline 02 & 187 & 143 & 217 \\
\hline
\end{tabular}

O ensaio de dureza Knoop (500g) foi realizado para verificar a variação de dureza na ZAC tanto do metal base do tubo quanto do flange. Em todas as amostras ensaiadas foi utilizado Nital 2\% para revelação da micrografia e ampliação de 50x. A dureza Knoop foi transformada em dureza HRC e o resultado apresentado em forma gráfica.

A Figura 40a apresenta a micrografia com os pontos do ensaio de dureza Knoop (500g) na ZAC do material do tubo (metal base) e a Figura 40b o gráfico da distribuição de dureza HRC ao longo da ZAC. 


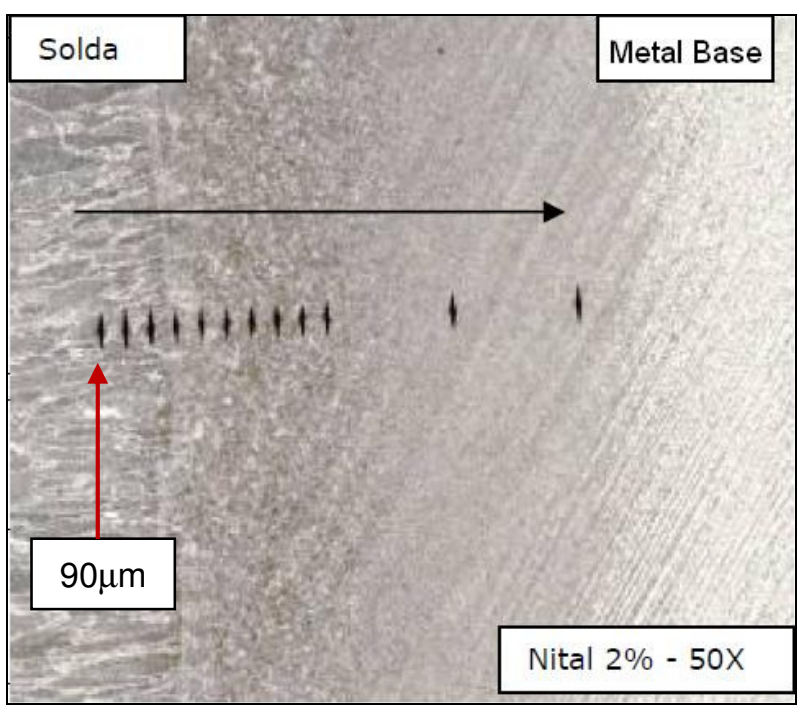

(a)

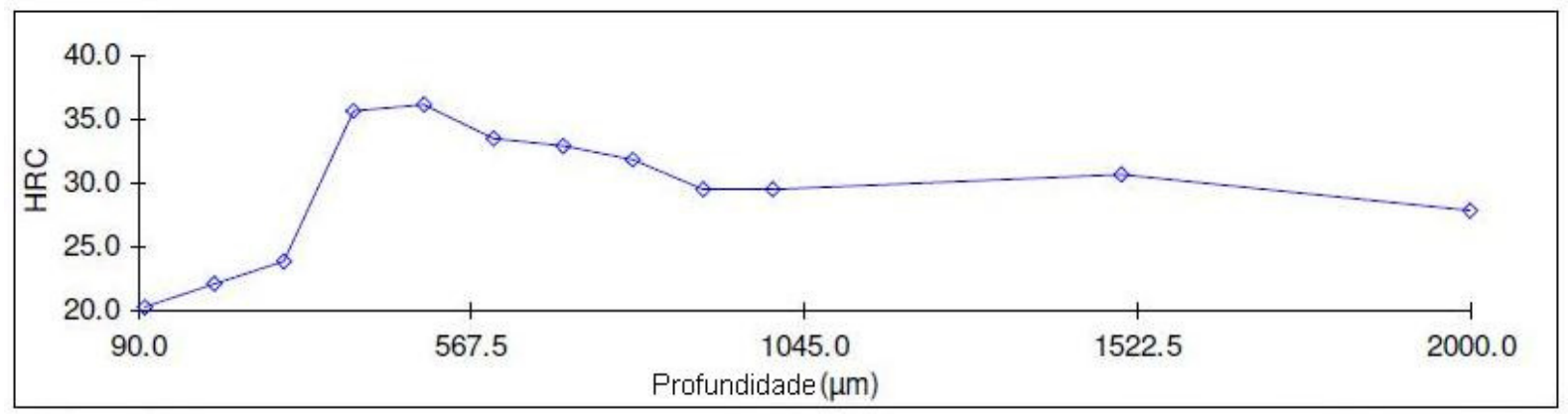

(b)

Figura 40 - Micrografia do ensaio de dureza Knoop (500g) e distribuição de dureza HRC ao longo da ZAC (b) - Material do tubo (metal base)

A Figura 41a apresenta a micrografia com os pontos do ensaio de dureza Knoop (500g) para a ZAC na região do flange da amostra 01 e a Figura 41b o gráfico da distribuição de dureza HRC ao longo da ZAC. 


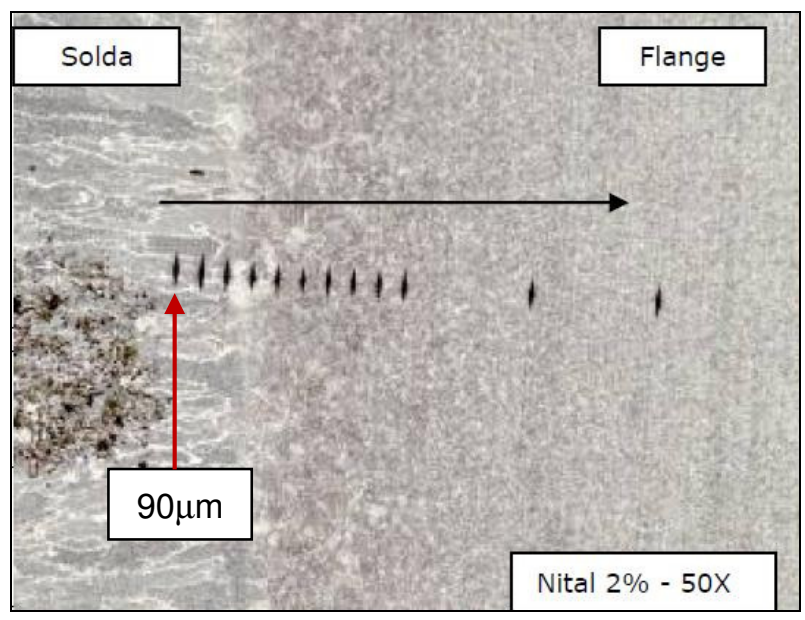

(a)

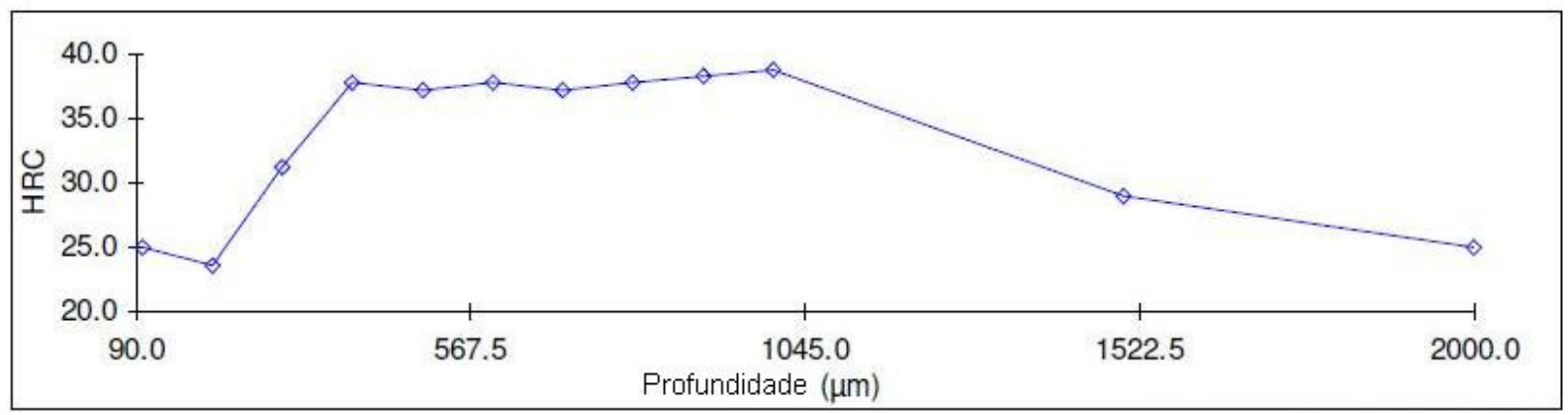

(b)

Figura 41 - Micrografia do ensaio de dureza Knoop (500g) e distribuição de dureza HRC ao longo da ZAC (b) - Material do flange

- Preparação dos corpos de prova

Os equipamentos utilizados tanto no preparo dos corpos de prova quanto na análise dos mesmos são apresentados abaixo:

\section{- Preparo:}

- Cortadeira metalográfica STONE, capacidade de corte de $250 \mathrm{~mm}$, corte refrigerado com óleo solúvel.

- Cortadeira metalográfica BUEHLER 10-100, capacidade de corte de 100mm, corte refrigerado com óleo solúvel.

- Embutidora pneumática BUEHLER SIMPLIMET 1000.

- Lixadeira de cinta de lixa grana 120.

- Lixadeira de bancada com prato rotativo granas 240, 500 e 600. 
- Politriz automática STRUERS TEGRAPOL 21 com suspensão de diamante policristalina de 3 microns.

- Análise:

- Câmera fotográfica NIKON D40 com objetiva 105mm AF micro.

- Estéreo microscópio OLYMPUS SZ61 6.7x-45x.

- Microscópio invertido OLYMPUS GX51 50x - 1000x.

- Capturador de imagens MEDIA CYBERNETICS PL-A662.

- Microdurômetro digital automático CLEMEX JS-2000.

- Durômetro Brinell REICHERTER BRIVISKOP 3000D.

\subsubsection{Parâmetros de soldagem das amostras}

A junta do tipo tubo-placa foi construída utilizando como tubo uma seção da perna de uma carcaça previamente fabricada (Figura 42) e soldando esta seção numa placa fabricada em aço SAE1518, originando assim a amostra apresentada na Figura 34.

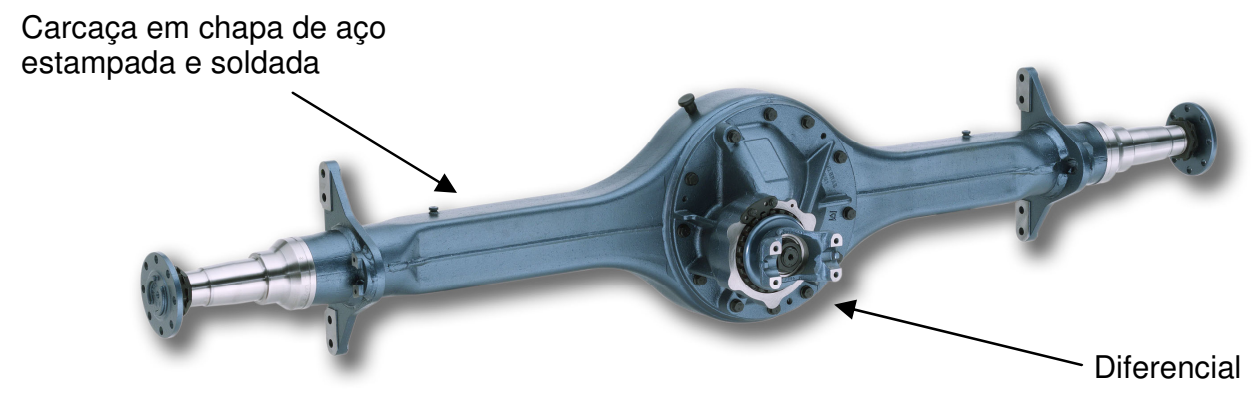

Figura 42 - Eixo diferencial de um veículo comercial

O processo de soldagem MIG/MAG manual foi utilizado para fabricação da junta. Foram efetuados dois cordões de solda simétricos com início sobre a solda longitudinal de união das duas metades que formam o tubo, local este com menor concentração de tensão, segundo os estudos de Elementos Finitos. 
Ao total seis amostras foram fabricadas utilizando a fonte de solda Deltaweld 602 MILLER com arame ER-70S6 BELGO e porcentagem de gases de 80\% Argônio e $20 \% \mathrm{CO}_{2}$ (80/20). Os parâmetros do processo de soldagem são descritos abaixo:

- $I: 310 \mathrm{~A}$

- $U: 28 \mathrm{~V}$

- $\quad v: 0,212 \mathrm{~m} / \mathrm{s}$

Com os dados acima é possível calcular o insumo de calor $Q$ (heat input), conforme equação abaixo:

$$
Q=\frac{U . I}{v}
$$

No presente trabalho foi utilizado um insumo de calor $Q$ de $40,9 \mathrm{~kJ} / \mathrm{m}$.

\subsection{ANÁLISE VIRTUAL}

O projeto 3D da geometria a ser analisada foi realizado através do programa ProEngineer. Foram idealizados vários modelos até estabelecer a geometria ótima apresentada na Figura 34.

A análise virtual engloba a etapa de análise por Elementos Finitos, cujo resultado de tensão (arquivo .rst) é utilizado na previsão de vida à fadiga, juntamente com a escolha da curva $\mathrm{S} \times \mathrm{N}$ do material.

\subsubsection{Análise das tensões por Elementos Finitos}

Para uma correta utilização do MEF é necessário estabelecer o tipo de modelo a ser utilizado como, por exemplo, casca ou sólido, o tipo de carregamento a ser empregado e o refinamento da malha. Esta análise simula a estrutura e a geometria do cordão de solda (sem efeitos metalúrgicos), além da rigidez dos elementos da junta.

Alexandre et al (2001) apresenta alguns casos de análise de juntas soldadas, utilizando o MEF e comparando seus resultados com os cálculos analíticos também 
realizados por ele. Através de suas conclusões foi utilizado o modelo sólido para análise da junta proposta no presente trabalho.

Os estudos do refinamento de malha em juntas soldadas realizados por Goes; Batalha e Camarão (2008) e por Goes et al (2009) foram utilizados no desenvolvimento do EF aqui proposto.

O modelo sólido foi construído através do programa Pro/Engineer Wild Fire 2 e importado através do programa ANSYS Workbench gerando assim a malha de Elementos Finitos, onde a região de interesse (maior tensão no pé da solda) foi refinada. A Figura 43 apresenta o modelo de Elementos Finitos, onde foi utilizado o elemento tetraédrico quadrático de 10 nós (ANSYS Solid187).

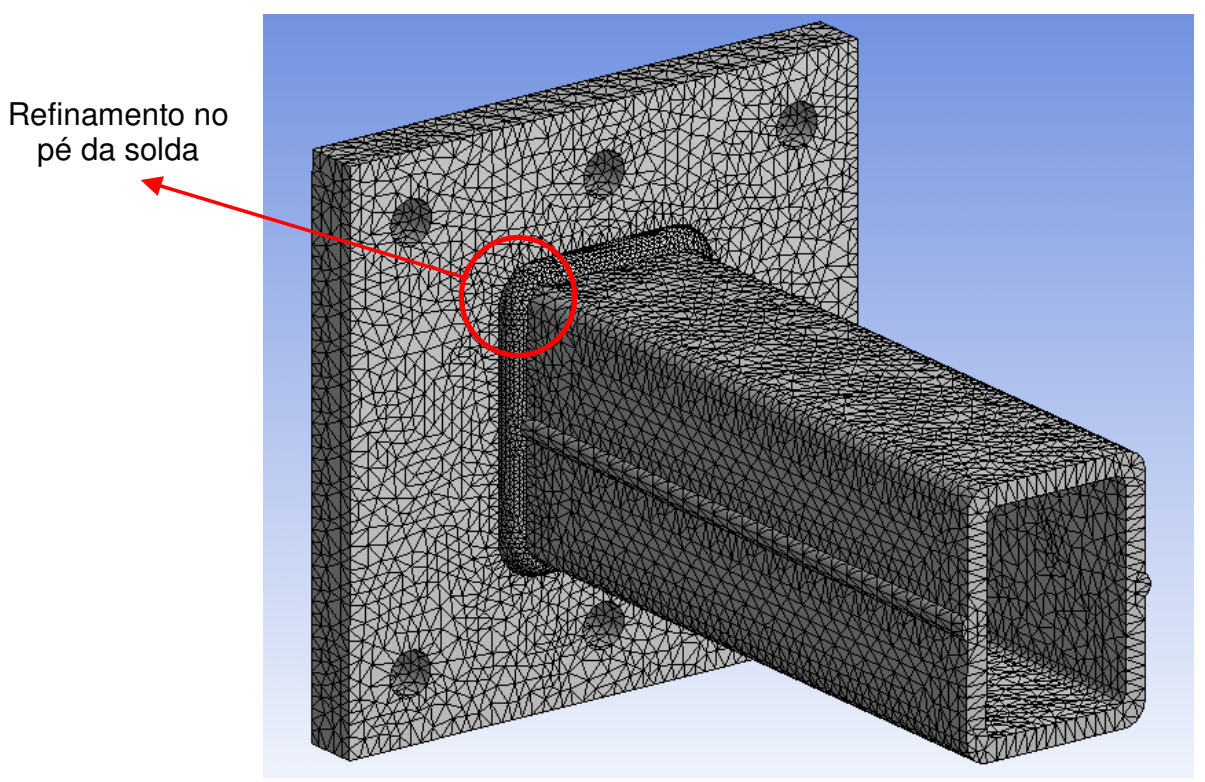

Figura 43 - Malha de Elementos Finitos

As condições de contorno foram estabelecidas de modo a representar o teste a ser realizado em laboratório. Os furos na placa foram fixados eliminando todos os graus de liberdade e a carga aplicada através de carregamento remoto do ANSYS Workbench. A Figura 44 apresenta o posicionamento da carga aplicada na face da seção retangular. $O$ modelo foi construído com $545 \mathrm{~mm}$ de tubo, simulando assim o local da aplicação da carga, pois a amostra possui $590 \mathrm{~mm}$ e o dispositivo $90 \mathrm{~mm}$ de largura, gerando uma carga concentrada a $45 \mathrm{~mm}$ da boca do tubo.

Após o refinamento da malha foi realizada a análise linear-elástica, com carga de 18 $\mathrm{kN}$. 


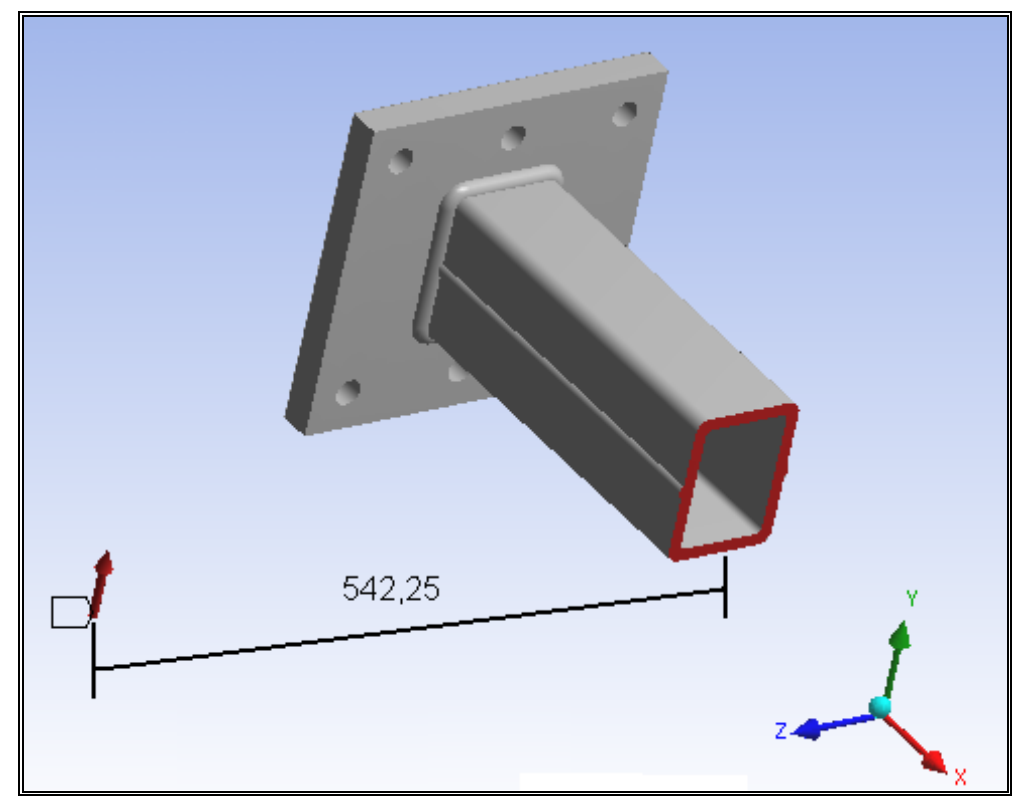

Figura 44 - Carregamento no modelo 3D

\subsubsection{Análise de Fadiga}

No presente trabalho foi adotado o método Tensão $\times$ Vida $(S \times N)$, integrando-se o programa de Elementos Finitos ANSYS com o de análise de fadiga FE-Fatigue.

Os resultados das tensões nodais obtidas através do ANSYS são importados pelo FE-Fatigue e a curva pode ser escolhida no próprio programa, que possui um extenso banco de dados, ou inserida manualmente. $O$ resultado da distribuição de vida à fadiga é apresentado no modelo 3D.

No presente trabalho foi utilizada a curva obtida por Goes et al (2008), cujo artigo utilizava o mesmo material, similar ao SAE1022. A curva foi obtida através do banco de dados FAP7 (Fatigue Analysis Program - programa desenvolvido pela ArvinMeritor), calibrada através de teste do componente carcaça em laboratório, com o objetivo de tornar a curva representativa para a junta soldada em estudo. No artigo citado, optou-se pela curva Deformação $\times$ Vida $(\varepsilon \times N)$ por cobrir os trechos de alto $e$ baixo ciclo.

A Figura 45 apresenta as duas curvas: do metal base do tubo (sem solda) e da chapa com estrutura soldada. 


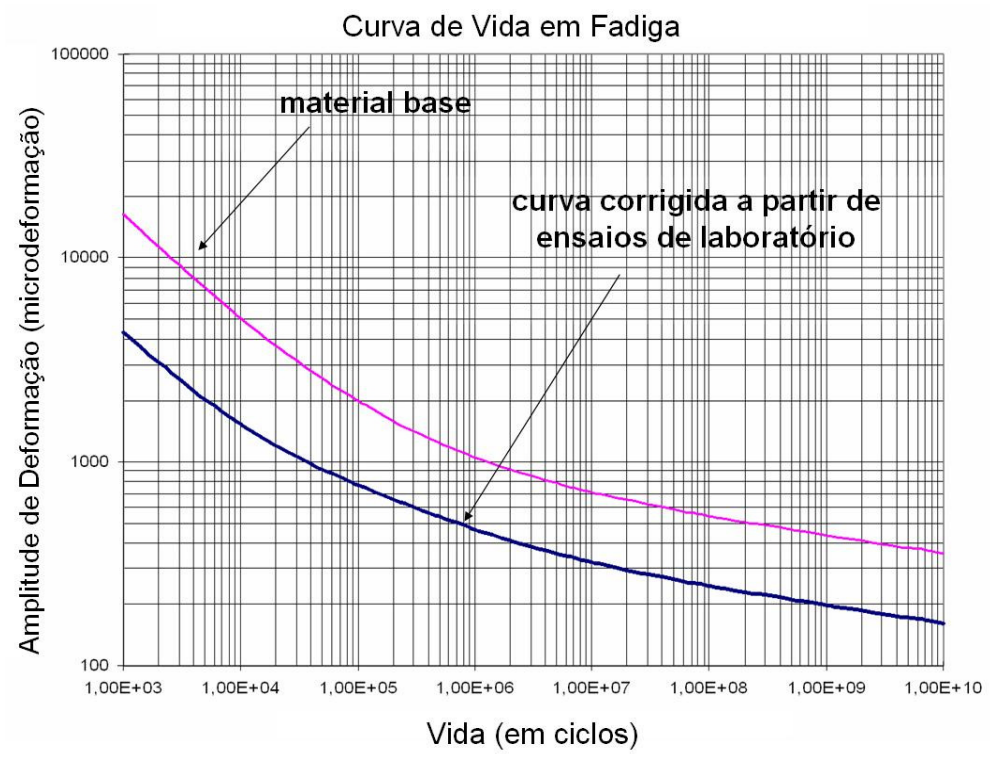

Figura 45 - Curva $\varepsilon \times N$ do metal base (FAP7) e a corrigida (obtida em laboratório)

A análise de fadiga aqui proposta é baseada no diagrama da Figura 46 que ilustra os cinco passos básicos para análise de durabilidade da junta

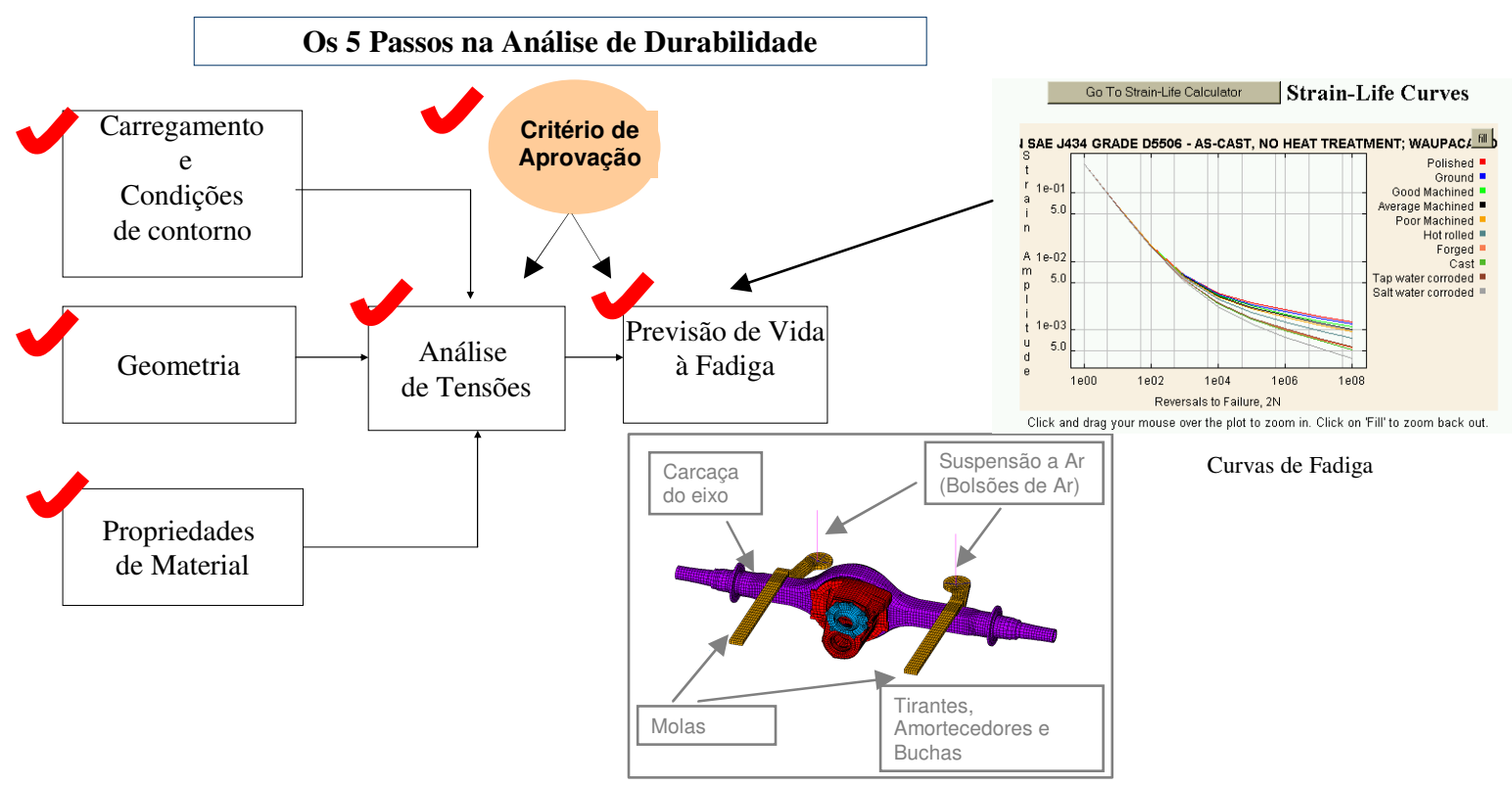

Figura 46 - Diagrama dos 5 passos básicos para análise de durabilidade

Dentre as diversas abordagens para previsão da vida à fadiga em componentes soldados, adotou-se a de tensão estrutural de hot spot (IIDA, 1984), combinada com curvas experimentais de Tensão x Vida (S x N), obtidas das normas BS7608 (1993) e Eurocode 3 (2005), além da curva calibrada em laboratório. 
De acordo com a norma Britânica BS7608 (1993), a previsão de vida na junta soldada apresenta os seguintes passos:

I. Seleção da classe ou classes de solda para junta investigada.

- geometria da junta

- direção de carregamento

- local provável de falha

- tipo de solda (penetração total, parcial).

II. Determinação do histórico de tensão para o carregamento adotado.

- usualmente a maior variação de tensão principal

- alguns casos a tensão nominal em placas

- alguns casos a máxima tensão próxima da raiz do cordão

\subsection{CÁLCULO ANALÍTICO DE TENSÕES}

Para comparar os resultados de tensões obtidos pelo MEF foi efetuado o cálculo analítico.

Considerando a amostra do presente trabalho como uma viga em balanço soldada a uma placa, tem-se agindo na solda uma força cisalhante e um momento (SHIGLEY, 1984).

A força cisalhante produz um cisalhamento primário $\tau^{\prime}$ na solda com intensidade descrita na equação abaixo:

$$
\tau^{\prime}=V / A_{s}
$$

O momento no apoio produz um momento secundário $\tau^{\prime \prime}$ ou cisalhante das soldas, e o valor da tensão será:

$$
\tau^{\prime \prime}=\frac{M r}{J}
$$


Uma solução mais usual para este tipo de problema é considerar o cordão de solda como uma linha. $O$ momento de inércia polar resultante será então equivalente ao momento de inércia polar unitário. A vantagem desta abordagem é que o momento de inércia polar unitário é o mesmo, independente das dimensões da solda. Como a largura da penetração do cordão, segundo Shigley (1984), corresponde a 0,707.h, a relação entre o momento de inércia polar unitário e o momento de inércia polar de um cordão é:

$$
J=0,707 h J_{u}
$$

Para a geometria utilizada, baseada no sistema de coordenadas apresentado na Figura 44, a tensão máxima cisalhante pode ser calculada pela equação abaixo:

$$
\tau_{\text {res }}=\sqrt{\left(\tau_{z}^{\prime \prime}\right)^{2}+\left(\tau_{y}^{\prime}+\tau_{y}^{\prime \prime}\right)^{2}}
$$

Além do esforço de torção, a viga pode estar sujeita a um esforço de flexão na junta soldada, que também ocasionará um cisalhamento primário (equação 26) e o momento uma tensão normal de flexão $\sigma$ na solda. Considerando que esta tensão age perpendicularmente à área de penetração, a tensão atuante é calculada pela equação abaixo:

$$
\sigma=\frac{M r}{I}
$$

O momento de Inércia pode ser calculado pela relação que segue:

$$
I=0,707 h I_{u}
$$

A tensão equivalente ou de Von Mises é calculada considerando os esforços devido à torção e à flexão, conforme equação abaixo:

$$
\sigma_{V M}=\sqrt{\left(\sigma_{x}\right)^{2}+3 \cdot \tau_{r e s}^{2}}
$$


A Figura 47 apresenta a solda utilizada no presente trabalho e a Tabela 7 as propriedades do cordão de solda.

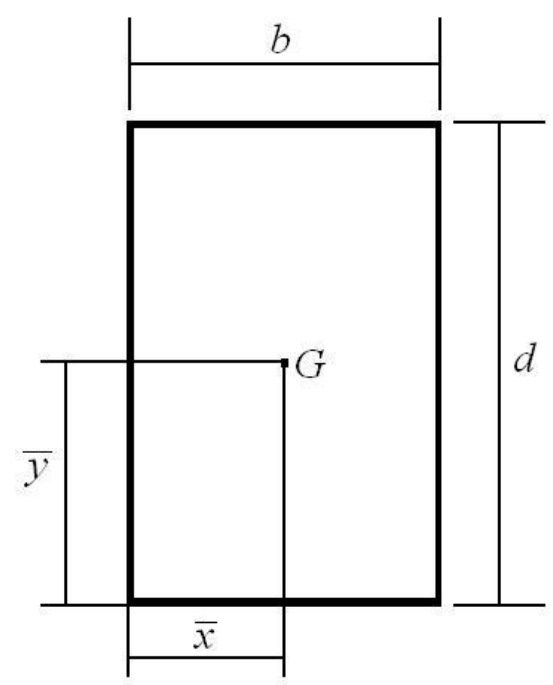

Figura 47 - Solda utilizada na junta tubo-placa

Tabela 7 - Propriedades do cordão de solda apresentado na Figura 47

\begin{tabular}{|l|c|c|c|}
\hline Área de penetração & Localização de $\mathbf{G}$ & $\begin{array}{c}\text { Momento de Inércia } \\
\text { Polar Unitário }\left(\boldsymbol{J}_{u}\right)\end{array}$ & $\begin{array}{c}\text { Momento de Inércia } \\
\text { Unitário }\left(\boldsymbol{I}_{u}\right)\end{array}$ \\
\hline \multirow{2}{*}{$A=1,414 h(b+d)$} & $\begin{array}{l}\bar{x}=b / 2 \\
\bar{y}=d / 2\end{array}$ & $J_{u}=\frac{(b+d)^{3}}{6}$ & $I_{u}=\frac{d^{2}}{6}(3 b+d)$ \\
\hline
\end{tabular}

\subsection{ENSAIO DE FADIGA}

O ensaio de vida à fadiga do presente trabalho baseou-se no realizado por Goes; Batalha e Camarão (2009), sendo alterada a geometria da amostra e o posicionamento do dispositivo de aplicação da carga. Todos os testes de resistência à fadiga foram realizados no Laboratório de Ensaios Mecânicos (LEM) da empresa ArvinMeritor.

As amostras foram submetidas a carregamento combinado de torção e flexão até a trinca ser detectada, quando então o ensaio era parado e as amostras enviadas para análise metalográfica e metalúrgica. 
Através destes ensaios acelerados de fadiga, em laboratório, pode-se avaliar a Integridade da junta soldada, calibrar as curvas de fadiga e propor melhorias, quando aplicável.

Os dispositivos, parâmetros e calibração do ensaio são descritos abaixo, bem como a determinação da tensão hot spot.

\subsubsection{Dispositivos e parâmetros do ensaio de Fadiga}

Para aplicação da carga combinada de torção e flexão foi necessário desenvolver um dispositivo e um sistema de fixação para as amostras. A Figura 48 apresenta a configuração do ensaio (set up) com a montagem dos dispositivos utilizados e a Figura 49 o desenho dos dispositivos (dimensões em $\mathrm{mm}$ ). Um incerto foi utilizado no interior do tubo para minimizar o efeito local que o tensionamento do dispositivo provoca na parede do tubo, fazendo com que a trinca ocorresse na interface tuboplaca.

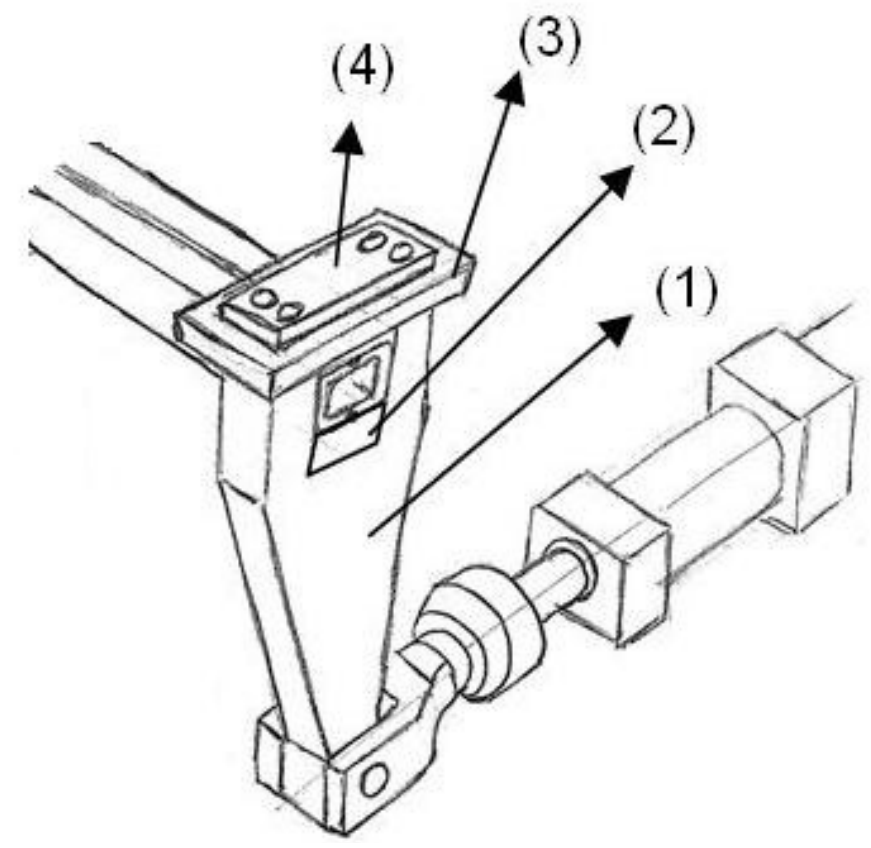

\begin{tabular}{|l|l|}
\hline 1 & Braço de aplicação da carga \\
\hline 2 & Suporte recartilhado \\
\hline 3 & Fechamento recartilhado \\
\hline 4 & Fechamento do braço \\
\hline
\end{tabular}

Figura 48 - Montagem dos dispositivos (set up) 

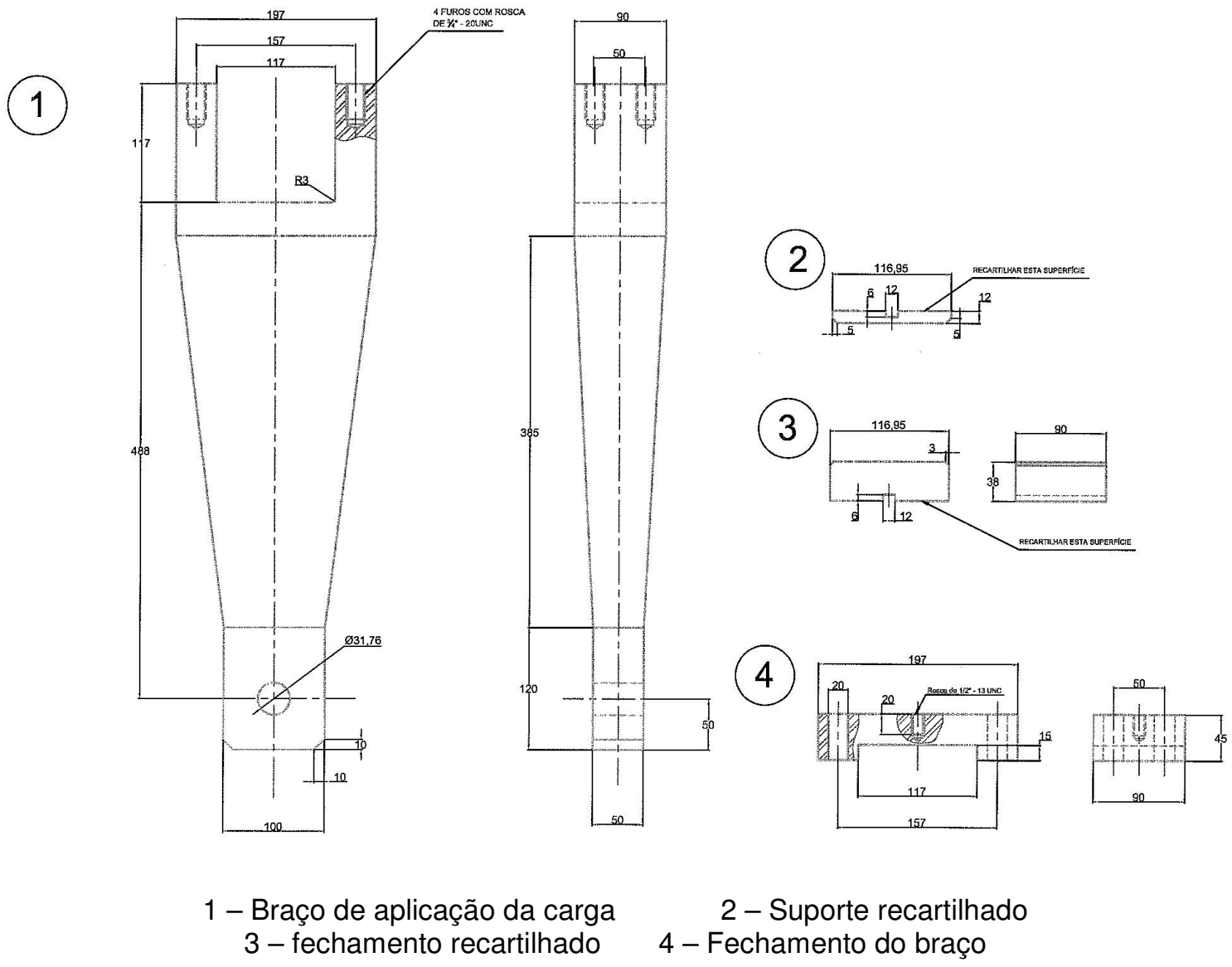

Figura 49 - Dispositivos utilizados no Ensaio de Fadiga

Foi utilizado um atuador linear pneumático MTS com um braço de alavanca aplicando o carregamento completamente reverso $(R=-1)$ sob uma freqüência de 2,0Hz, controlada pelo dispositivo Controller 407 da MTS. A Figura 50 apresenta o ensaio de fadiga realizado.

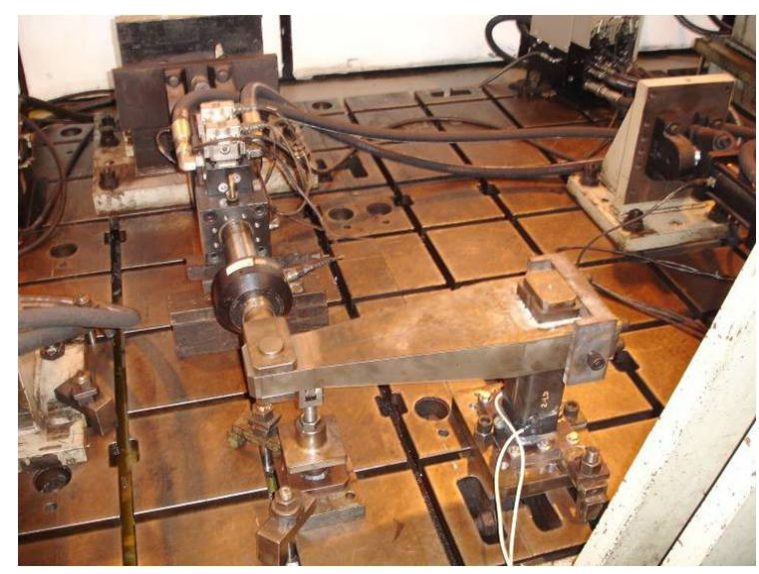

(a)

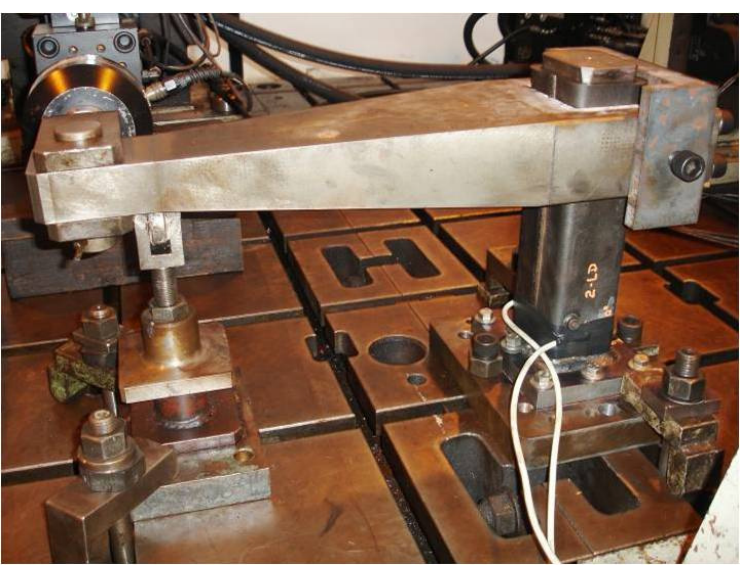

(b)

Figura 50 - Ensaio de fadiga (a) e detalhe do dispositivo utilizado (b) 
Duas amostras foram submetidas ao ensaio de durabilidade acelerada, cujo carregamento de $18 \mathrm{kN}$ foi simulado anteriormente através do $\mathrm{EF}$, utilizando o programa ANSYS.

A instrumentação foi realizada na primeira com o objetivo de calibrar o ensaio e comparar o valor da tensão na região crítica (tensão de hot spot) com o obtido através de EF.

A calibração do ensaio e a tensão de hot spot foram obtidas através de extensometria, utilizando extensômetros do tipo roseta especificado abaixo:

- Roseta retangular Kyowa - KFG-2-120-D17-11

A localização da roseta foi determinada através do MEF, obedecendo ao critério de maior tensão, foram utilizadas duas rosetas por amostras, dispostas opostamente.

A Figura 51a apresenta a localização da Roseta, que foi fixada com Loctite 496 (éster de cianoacrilato) e a Figura 51 b com a fiação e a proteção de Araldite finalizadas.

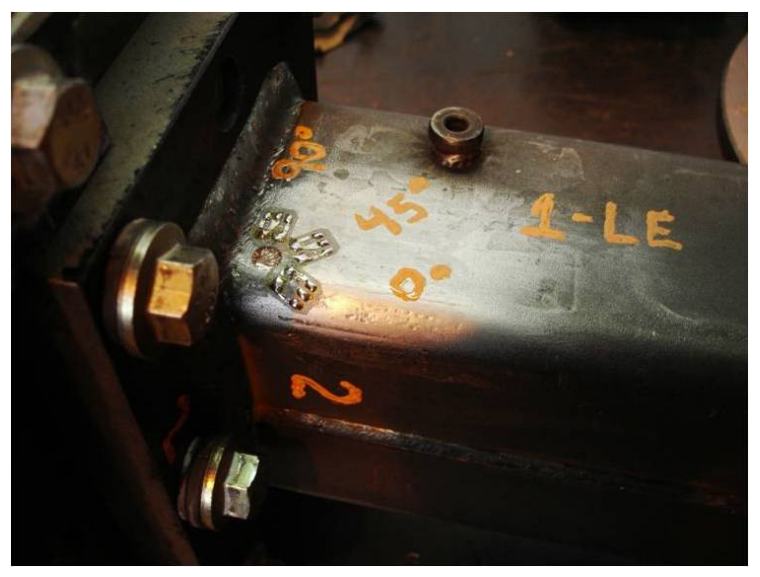

(a)

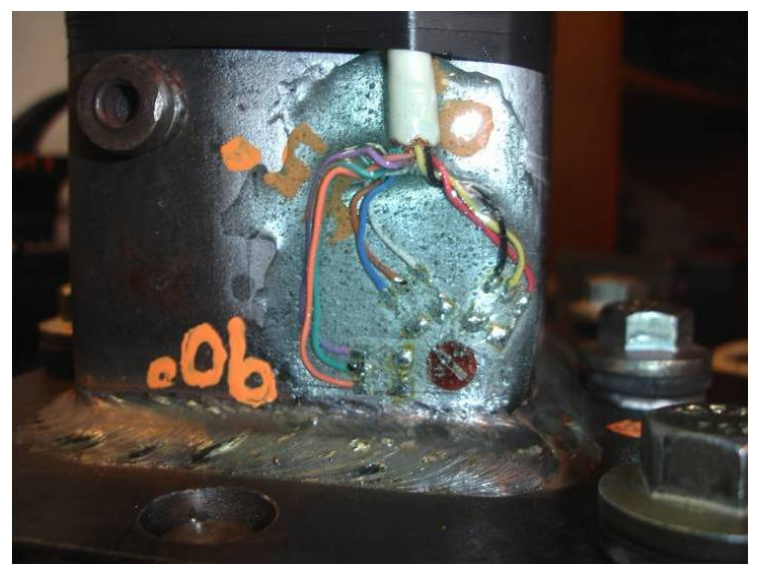

(b)

Figura 51 - Posicionamento da Roseta (a) juntamente com a fiação e a proteção (b)

\subsubsection{Calibração do ensaio de Fadiga}

A calibração da curva das rosetas foi determinada aplicando incrementos de carregamento, através do atuador hidráulico linear, até obter $20 \mathrm{kN}$.

O dispositivo MGCPlus da HBM foi utilizado para capturar as deformações em cada 
direção. A resposta de cada canal $\left(0^{\circ}, 45^{\circ}\right.$ e $\left.90^{\circ}\right)$ foi gravada a uma taxa de $60 \mathrm{~Hz} \mathrm{e}$, utilizando o programa Catman 5.0 da HBM, construído o gráfico de deformaçãocarregamento. A curva de calibração do extensômetro localizado do lado esquerdo (LE) da seção retangular é apresentada Figura 52a e para o localizado no lado direito (LD) a curva é apresentada na Figura 52b. A calibração foi feita no sentido positivo da aplicação da carga, considerando como positivo quando o pistão está saindo. A Figura 53 apresenta o posicionamento das rosetas e o sentido do carregamento aplicado.

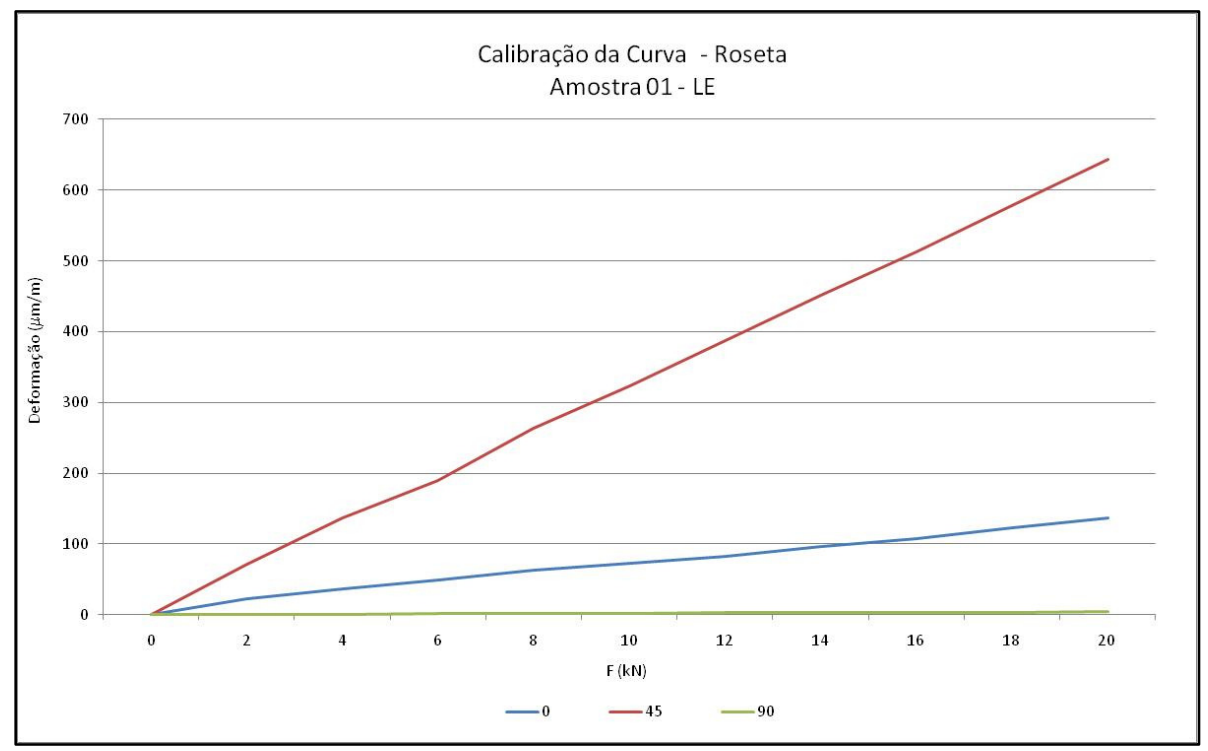

(a)

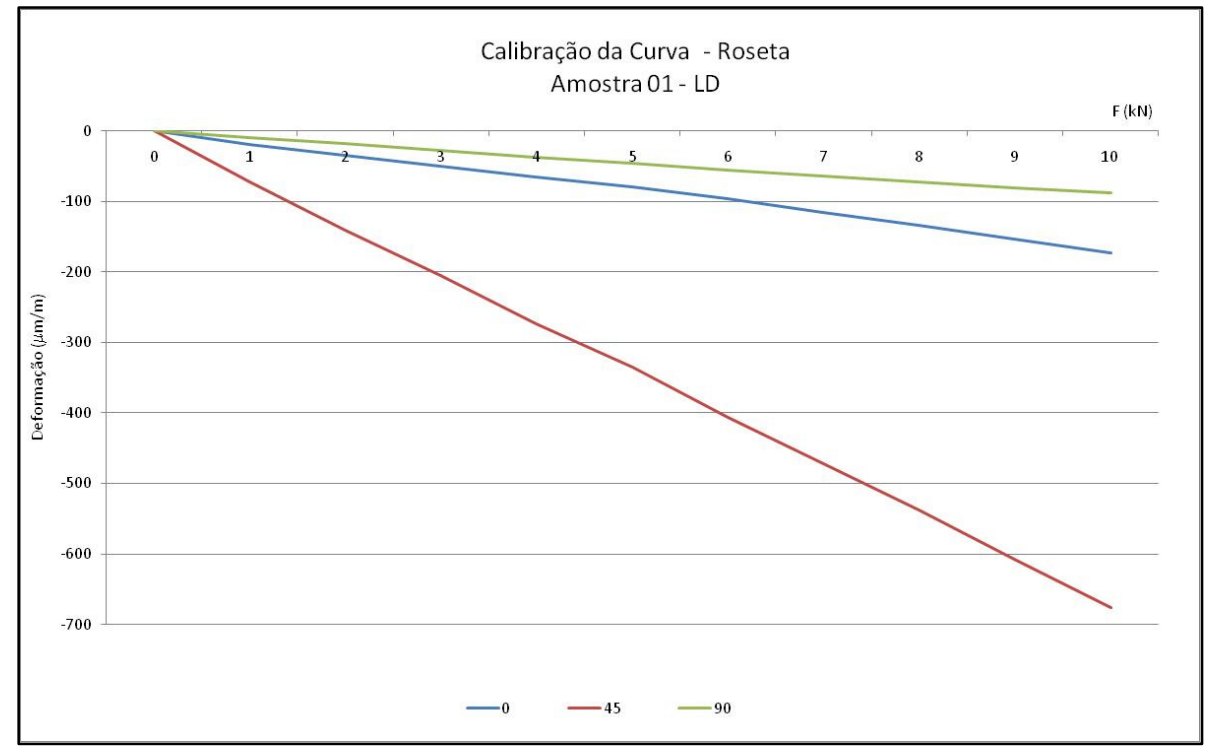

(b)

Figura 52 - Curva de calibração da roseta localizada no LE (a) e no LD (b) da seção retangular 


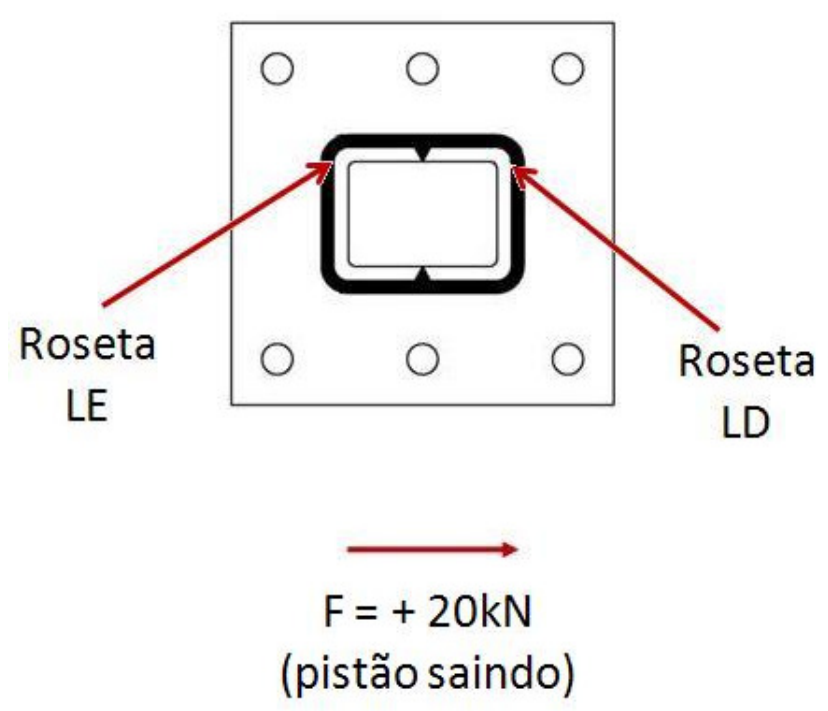

Figura 53 - Posicionamento das rosetas e força aplicada

\subsubsection{Determinação da tensão hot spot}

A tensão hot spot pode ser determinada experimentalmente através de extensômetros, como apresentado na Figura 26, ou através do MEF.

Niemi (1995) desenvolveu uma metodologia para o cálculo da tensão de hot spot através de extensômetros, que propõe a utilização de dois extensômetros de $90^{\circ}$ dispostos a 0,4t e 1,0t do pé da solda, onde t é a espessura da placa. Os dados obtidos são então utilizados na equação 33.

$$
\sigma_{h s}=1,67 \sigma(0,4 . t)-0,67 \sigma(1 . t)
$$

No presente trabalho, a quantidade de extensômetros disponíveis não era suficiente, então optou-se por utilizar apenas um localizado a aproximadamente $4 \mathrm{~mm}$ do pé da solda, abordagem esta proposta por alguns autores. Tal escolha é possível por se tratar de curva de tensão nominal, ou seja, ao utilizar uma tensão maior que a nominal opta-se pela segurança do resultado. A aproximação utilizada será avaliada e se o resultado for adequado, será validada. 


\section{RESULTADOS E DISCUSSÕES}

O presente capítulo visa apresentar os resultados obtidos e discutir os mesmos. Primeiramente são apresentados os resultados da tensão equivalente através do MEF, utilizando o programa ANSYS, em contrapartida o cálculo analítico da tensão no pé da solda é realizado e ambos os resultados são comparados com o resultado da tensão hot spot obtida em laboratório, através da instrumentação da primeira amostra.

Os resultados de fadiga através do FE-Fatigue também são apresentados, juntamente com os resultados de durabilidade acelerada realizados em laboratório.

\subsection{TENSÃO}

\subsubsection{Tensões através do MEF - ANSYS}

Dentre as diversas metodologias de cálculo de tensões, a tensão equivalente é a mais utilizada para juntas soldada, por considerar a torção, flexão e o esforço cortante ao qual a junta está submetida.

A distribuição de tensões equivalentes para o carregamento de $18 \mathrm{kN}$ é apresentada na Figura 54a e a Figura 54b apresenta o detalhe na região crítica. 


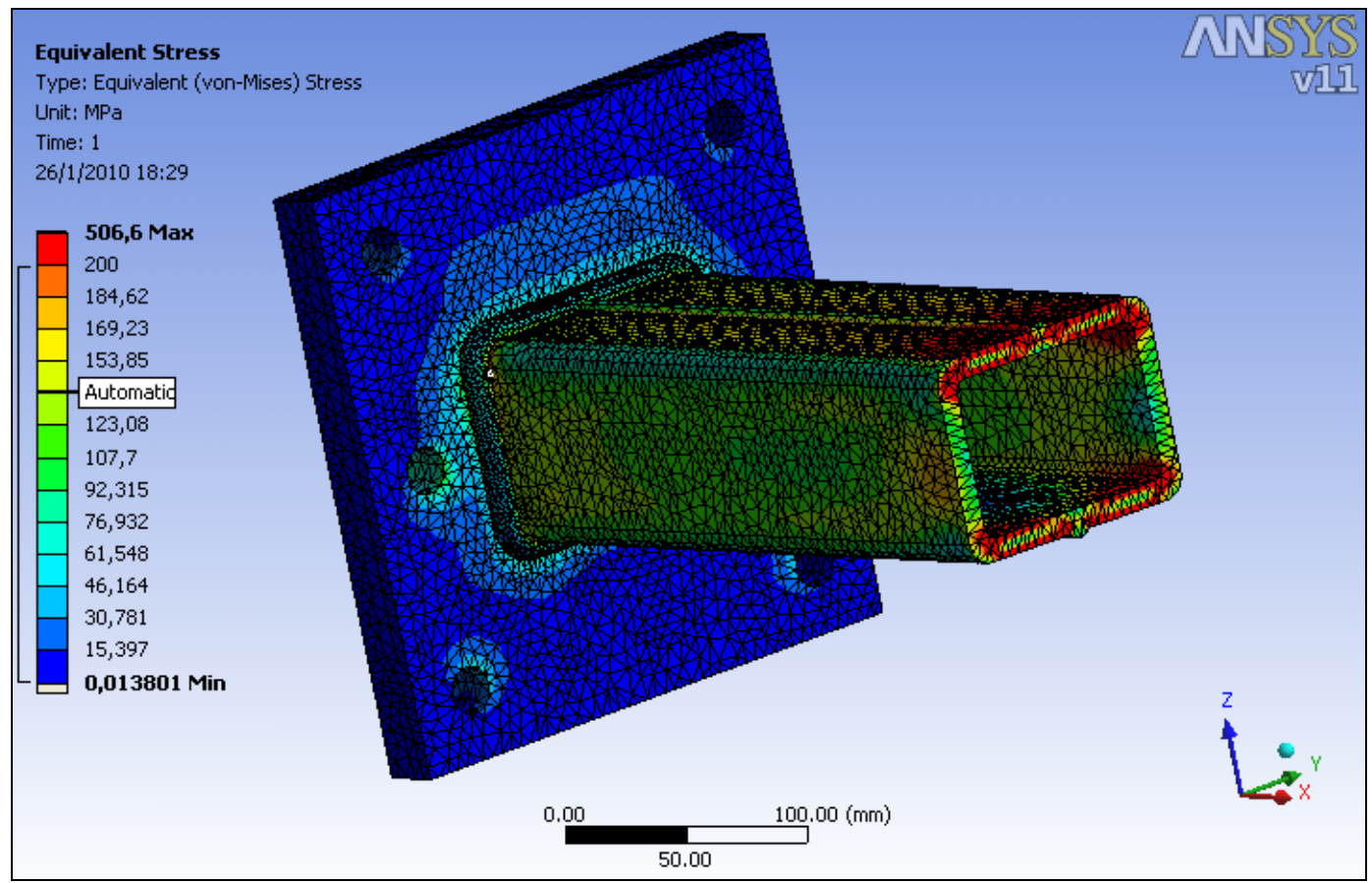

(a)

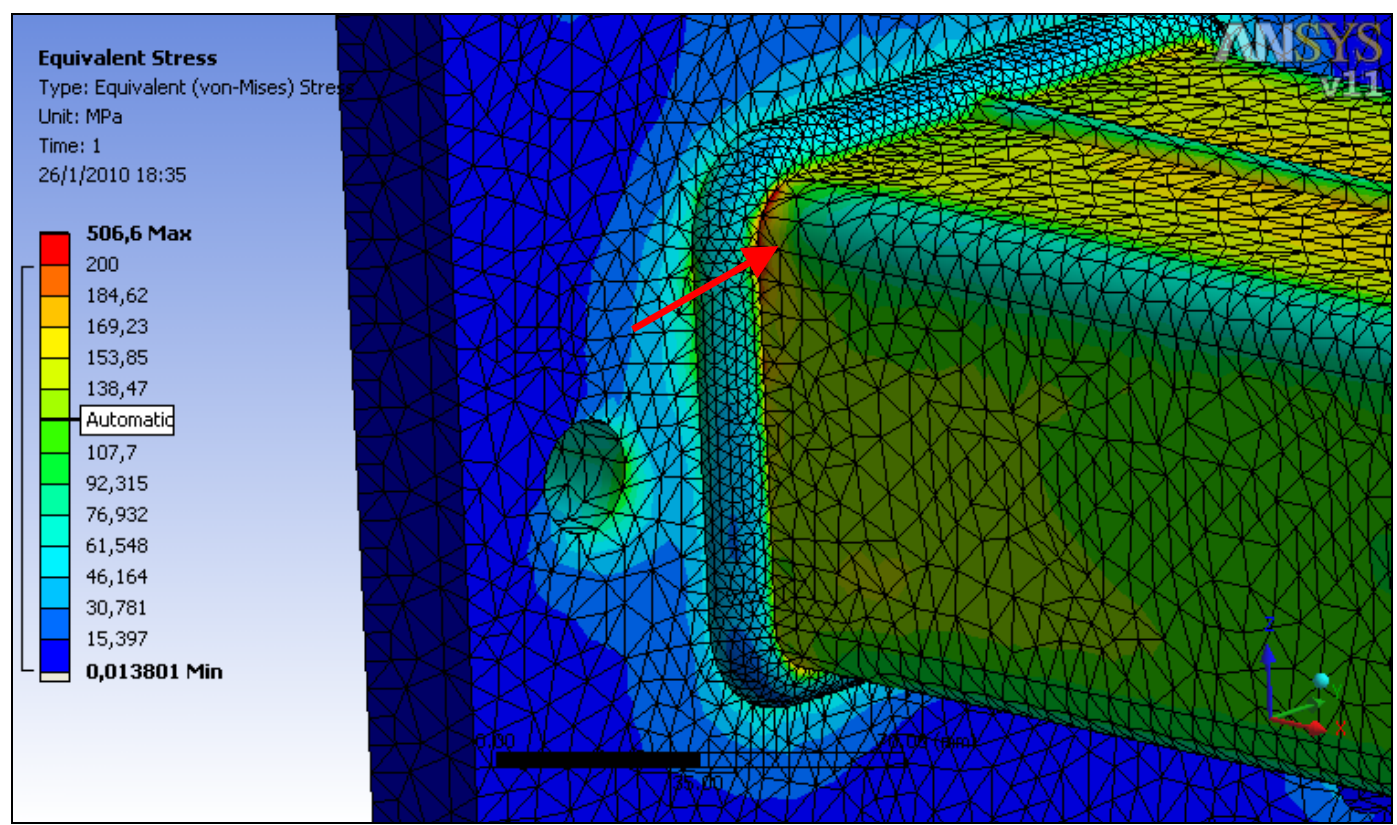

(b)

Figura 54 - Distribuição de tensões equivalentes no modelo de Elementos Finitos para o carregamento de $18 \mathrm{kN}$ (a) e detalhe na região crítica com indicação do ponto onde foi medida a tensão (b)

Bäckström (2003) indica a utilização da tensão máxima principal para o cálculo da vida à fadiga de juntas soldadas, quando submetidas a carregamento proporcional. Com o objetivo de comparar os resultados obtidos através do cálculo pela tensão equivalente e pela máxima principal, a Figura 55a apresenta o resultado da 
distribuição das tensões máximas principais para o carregamento de $18 \mathrm{kN}$ e a Figura 55b o detalhe na região crítica.

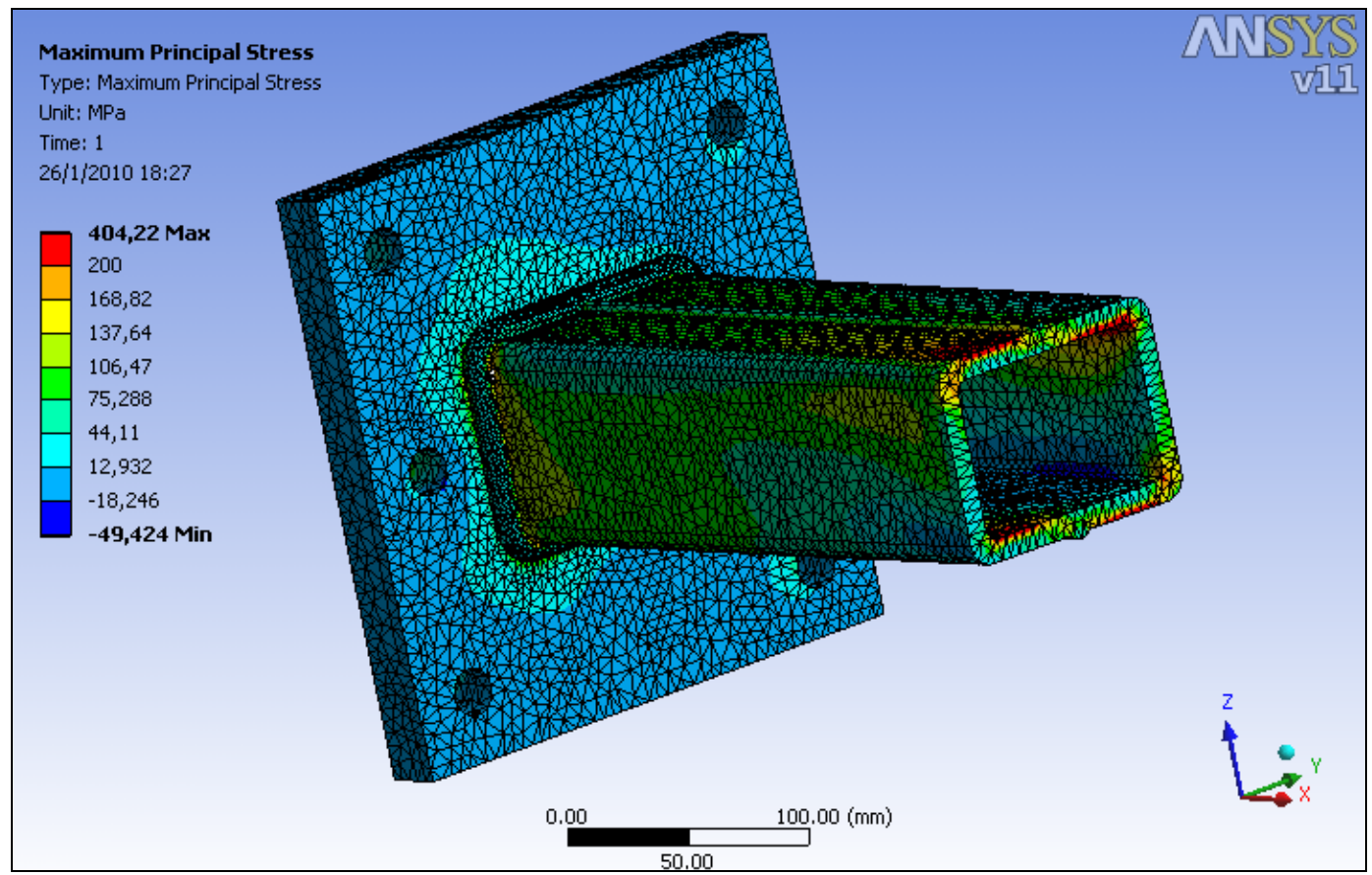

(a)

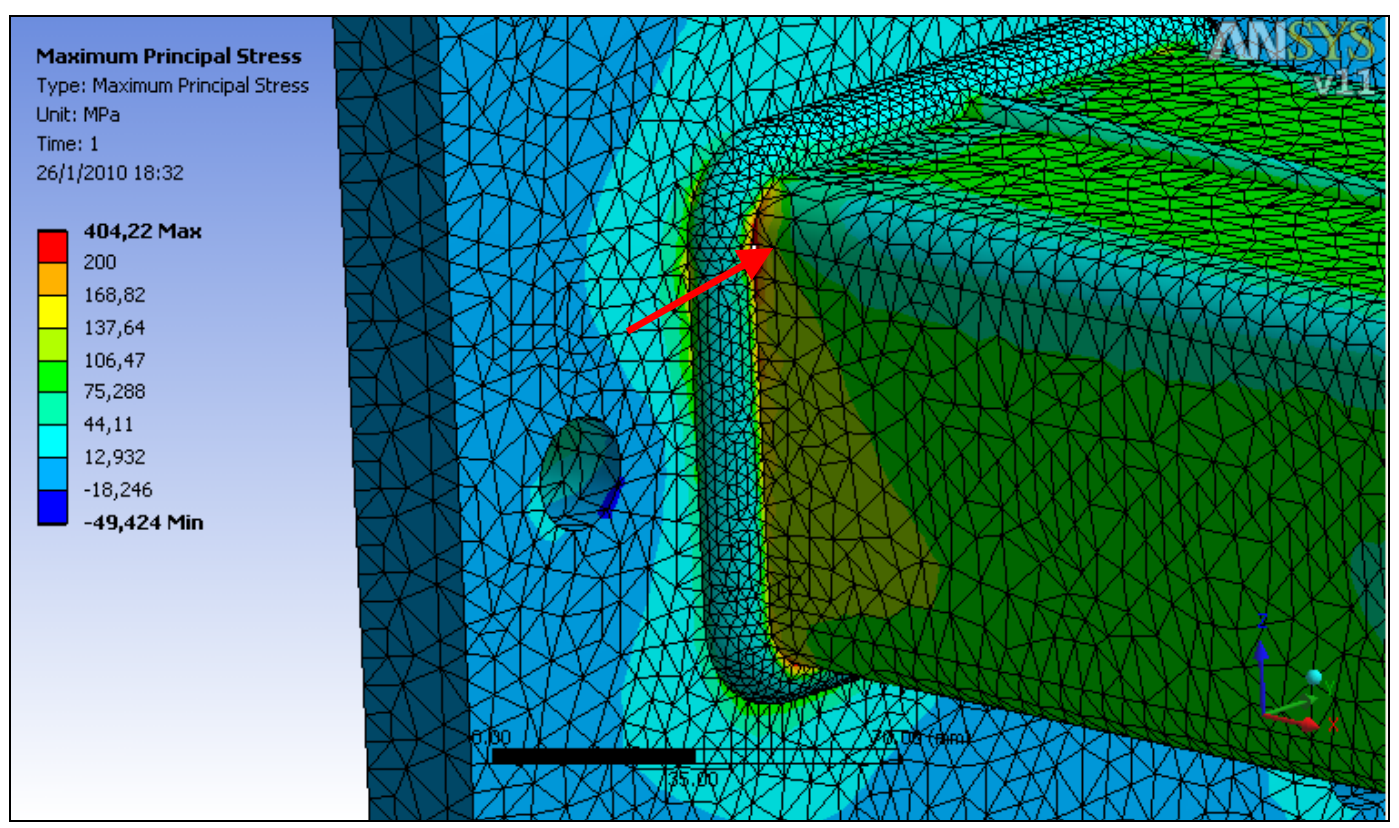

(b)

Figura 55 - Distribuição de tensões máximas principais no modelo de Elementos Finitos para o carregamento de $18 \mathrm{kN}$ (a) e detalhe na região crítica com indicação do ponto onde foi medida a tensão (b)

A Tabela 8 apresenta os valores das tensões equivalente e máxima principal para o ponto considerado como hot spot, ou seja, a aproximadamente $4 \mathrm{~mm}$ do pé da solda, com isto são excluídos os efeitos de não linearidade. Tais tensões são originadas 
quando a amostra é submetida a um carregamento de $+18 \mathrm{kN}$ e de $-18 \mathrm{kN}$. O sentido positivo da carga é apresentado na Figura 53, sendo o negativo na mesma direção, mas em sentido oposto.

Tabela 8 - Resultado da tensão hot spot através do ANSYS para o carregamento de $18 \mathrm{kN}$

\begin{tabular}{|c|c|c|c|c||}
\hline \multirow{2}{*}{ Carregamento } & \multicolumn{2}{|c|}{$\begin{array}{c}\text { Tensão Equivalente } \\
\text { (MPa) }\end{array}$} & \multicolumn{2}{|c|}{$\begin{array}{c}\text { Tensão Máxima Principal } \\
\text { (MPa) }\end{array}$} \\
\cline { 2 - 5 } & LE & LD & LE & LD \\
\hline$+18 \mathrm{kN}$ & 154 & 144 & 140 & 34 \\
\hline$-18 \mathrm{kN}$ & 154 & 144 & 32 & 125 \\
\hline
\end{tabular}

O resultado da tensão equivalente através do ANSYS apresentou valores superiores a da tensão máxima principal, o que já era esperado visto que a tensão equivalente considera os efeitos da triaxialidade de tensões.

Através da Tabela 8 pode-se concluir que o modelo analisado apresenta rigidez geométrica simétrica, pois a tensão equivalente apresenta aproximadamente o mesmo valor quando a amostra é sujeita a carregamento positivo (pistão saindo) e a carregamento negativo (pistão entrando), com isto, a metodologia aqui proposta foi desenvolvida para o ponto crítico do lado esquerdo da amostra, que também valida o lado direito da mesma.

\subsubsection{Tensão analítica no pé da solda}

Tendo como base a localização do hot spot utilizado na obtenção das tensões através do ANSYS, foi calculada a tensão analiticamente no mesmo ponto.

No cálculo analítico foram utilizadas as apresentadas no capítulo 4.3, onde o sistema de coordenadas utilizado é apresentado na Figura 44.

O resultado da tensão equivalente no pé da solda é apresentado na Tabela 9. Como a seção transversal é simétrica, o resultado será igual tanto para o LE quanto para o LD. 
Tabela 9 - Resultado da tensão equivalente analítica para o carregamento de $18 \mathrm{kN}$

\begin{tabular}{|c|c|}
\hline Carregamento & $\begin{array}{c}\text { Tensão Equivalente } \\
\text { (MPa) }\end{array}$ \\
\hline $18 \mathrm{kN}$ & 222 \\
\hline
\end{tabular}

O valor da tensão calculada analiticamente apresentou valor superior à obtida através do ANSYS (aproximadamente 44\% superior), o que pode ser explicado pelo método adotado no cálculo analítico considerar apenas a inércia do cordão, não incluindo efeitos de concentração de tensão, ou seja, todo esforço é suportado pelo cordão de solda. Este método se contrapõe ao realizado pelo MEF, onde a geometria foi gerada como um único sólido, ou seja, como se fosse um fundido onde a área resistente à carga aplicada é calculada através da soma entre a área do cordão de solda e a área da seção do tubo (espessura). A comparação entre os valores das tensões seria assertiva se o cálculo analítico considerasse a junta como uma viga engastada.

Visando verificar a influência da forca cortante no resultado da tensão equivalente, a tensão cisalhante foi calculada e obtido o resultado de $7,9 \mathrm{MPa}$ que, quando comparado ao resultado final, pode ser considerado desprezível, mas foi considerada nos cálculos da tensão equivalente.

\subsubsection{Tensão experimental}

O cálculo da tensão experimental utilizou os resultados de deformação a $0^{\circ}, 45^{\circ} \mathrm{e}$ $90^{\circ}$ capturadas pelo MGCPlus e visualizadas através do programa Catman 5.0.

A Tabela 10 apresenta os resultados da tensão equivalente para cada roseta (LE e LD) considerando o carregamento como positivo quando o pistão está saindo.

A tensão experimental foi obtida através de uma aproximação do método proposto por Niemi (1995), onde dois extensômetros devem ser utilizados, dispondo o primeiro a 0,4t do pé da solda e o segundo a 0,6t do primeiro, sendo t a espessura da placa. Os valores de tensão obtidos são então inseridos na equação 33, obtendo assim a tensão hot spot. No presente trabalho a segunda parcela da equação foi desconsiderada, ou seja, apenas um extensômetro foi utilizado e disposto a 
aproximadamente $4 \mathrm{~mm}$ do pé da solda, obtendo assim a tensão de hot spot. Tal aproximação foi possível devido a observação de baixa variação de tensão entre os pontos onde devem ser localizados os extensômetros, ou seja, a 3,8mm e a 9,5mm do pé da solda, utilizando para isto a análise de tensões do MEF. Como a variação de tensões é mínima, a equação 33 reduz-se à tensão obtida a aproximadamente $4,0 \mathrm{~mm}$ do pé da solda.

Tabela 10 - Resultado da tensão equivalente obtida experimentalm
\begin{tabular}{|c|c|c||}
\hline \multirow{2}{*}{ Carregamento } & \multicolumn{2}{|c|}{$\begin{array}{r}\text { Tensão Equivalente } \\
\text { (MPa) }\end{array}$} \\
\cline { 2 - 3 } & Roseta LE & Roseta LD \\
\hline$+18 \mathrm{kN}$ & 144 & 142 \\
\hline$-18 \mathrm{kN}$ & 142 & 140 \\
\hline
\end{tabular}

A tensão principal apresentou ângulo de $45^{\circ}$ o que a caracteriza como predominantemente cisalhante, fato este explicado pelas tensões de torção e de flexão ao qual a junta esta submetida.

A Tabela 11 apresenta um resumo dos resultados de tensão equivalente obtidos em cada abordagem realizada.

Tabela 11 - Comparativo entre os resultados de tensão equivalente no ponto analisado para o carregamento de $18 \mathrm{kN}$

\begin{tabular}{|c|c|c|c|}
\hline \multirow{2}{*}{ Carregamento } & \multicolumn{3}{|c|}{ Tensão Equivalente (MPa) } \\
\cline { 2 - 4 } & ANSYS & Analítico & Experimental \\
\hline $18 \mathrm{kN}$ & 154 & 222 & 144 \\
\hline
\end{tabular}

O resultado da tensão experimental apresentou valor ligeiramente inferior ao obtido através do ANSYS (cerca de 7\%), validando assim o modelo de elementos finitos. 


\subsection{FADIGA}

\subsubsection{Fadiga através do MEF - FE-Fatigue}

Os resultados de tensão e deformação do ANSYS foram utilizados no programa de análise de fadiga FE-Fatigue, juntamente com a curva $\mathrm{S}$ x $\mathrm{N}$ corrigida por Goes et al (2008), obtendo assim a distribuição de vida para a tensão equivalente e para a máxima principal. A correção da tensão média, quando aplicada, é realizada pelo próprio programa, utilizando para isto o critério de Goodmann.

O programa FE-Fatigue gera a distribuição de vida ao longo do modelo 3D, facilitando assim a visualização das regiões onde a trinca provavelmente ocorrerá.

A Figura 56a apresenta a distribuição de vida para o carregamento de $18 \mathrm{~N}$ utilizando a tensão equivalente e a Figura 56b o detalhe na região crítica (menor vida). 


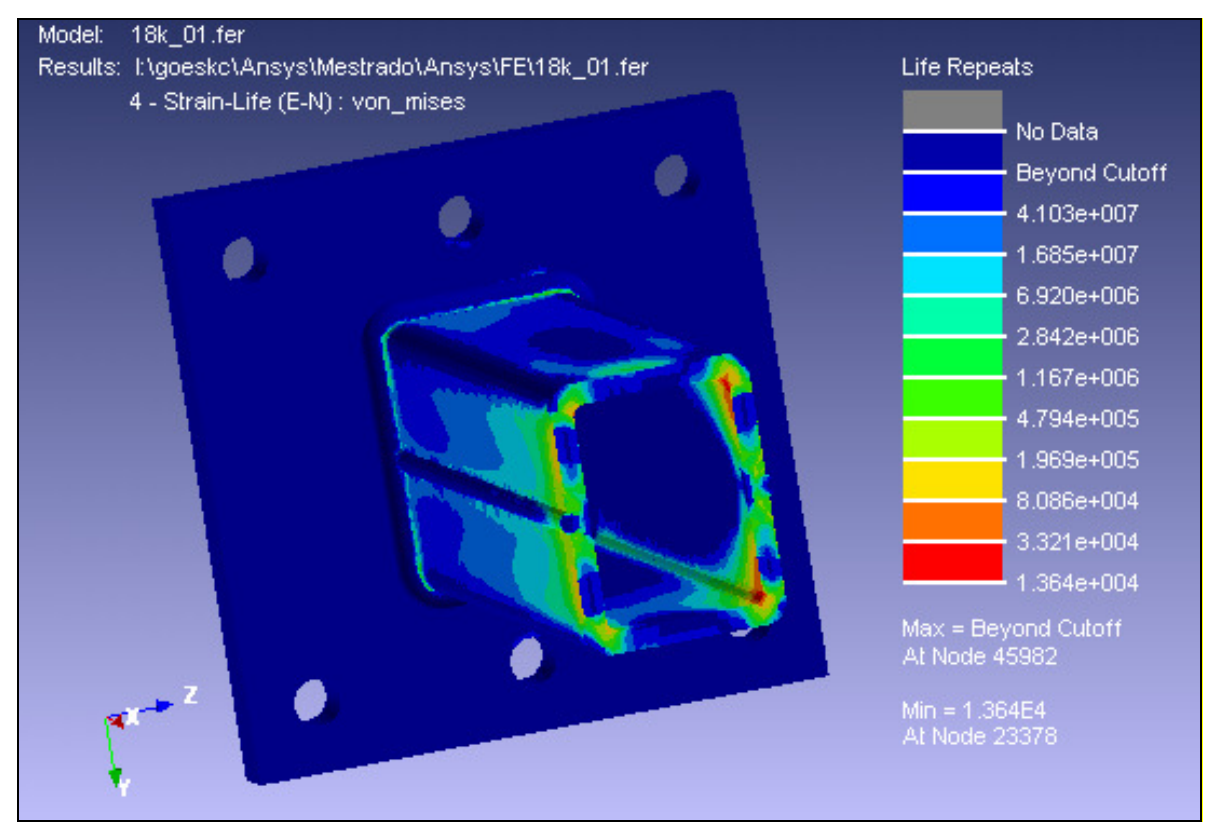

(a)

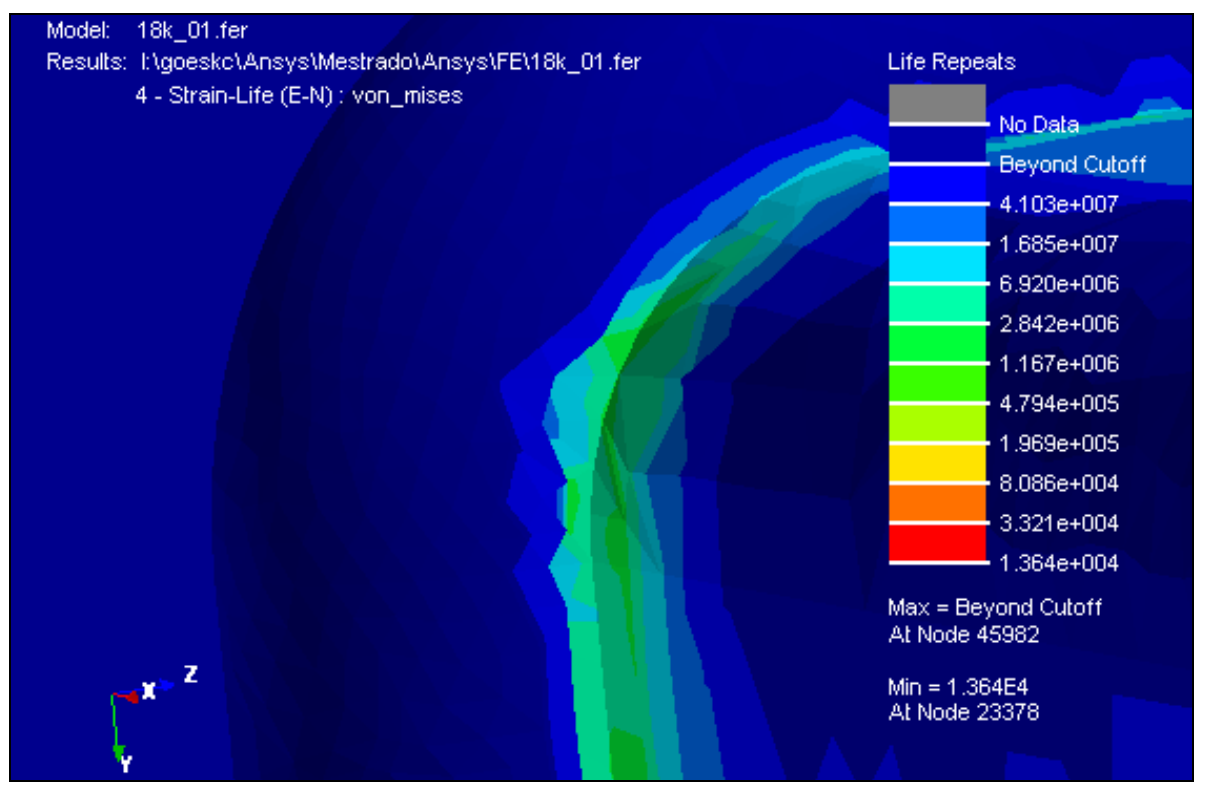

(b)

Figura 56 - Distribuição de vida para a tensão equivalente (a) e detalhe na região crítica (b)

A Figura 57a apresenta a distribuição de vida para o carregamento de $18 \mathrm{kN}$ e a Figura 57b o detalhe na região crítica. 


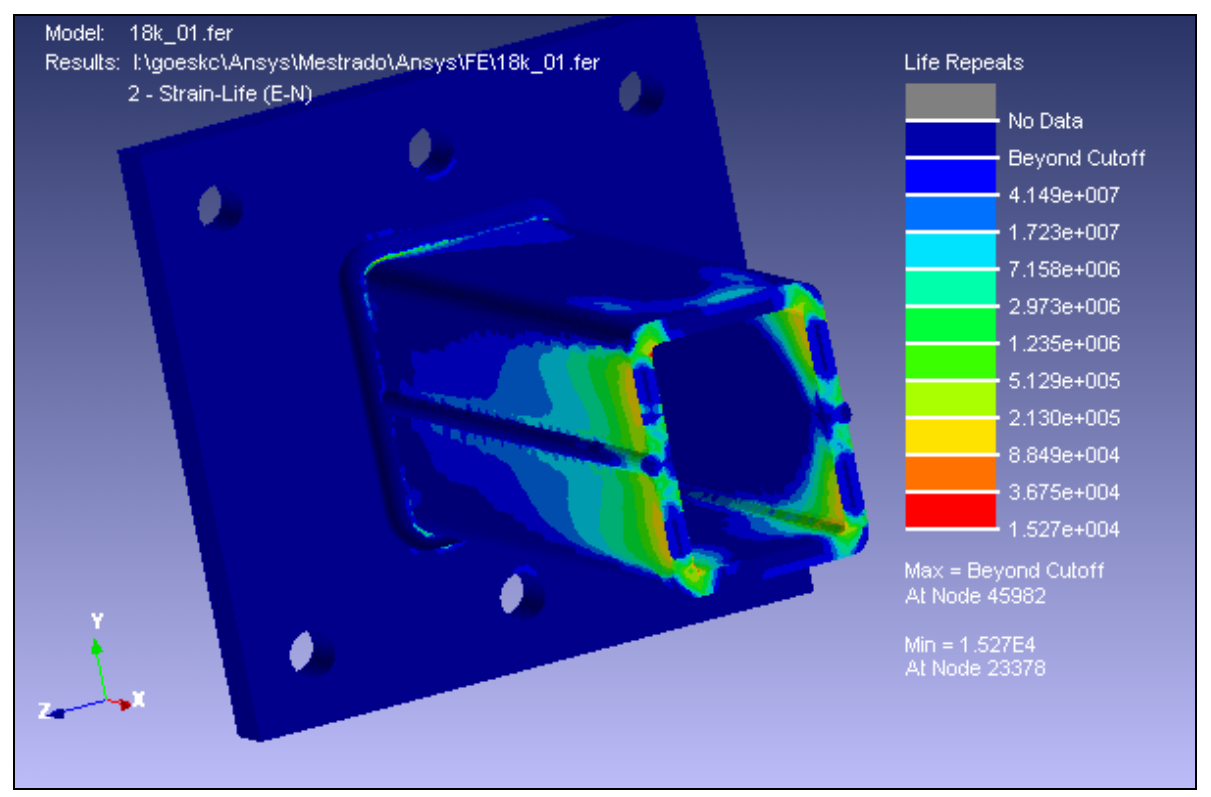

(a)

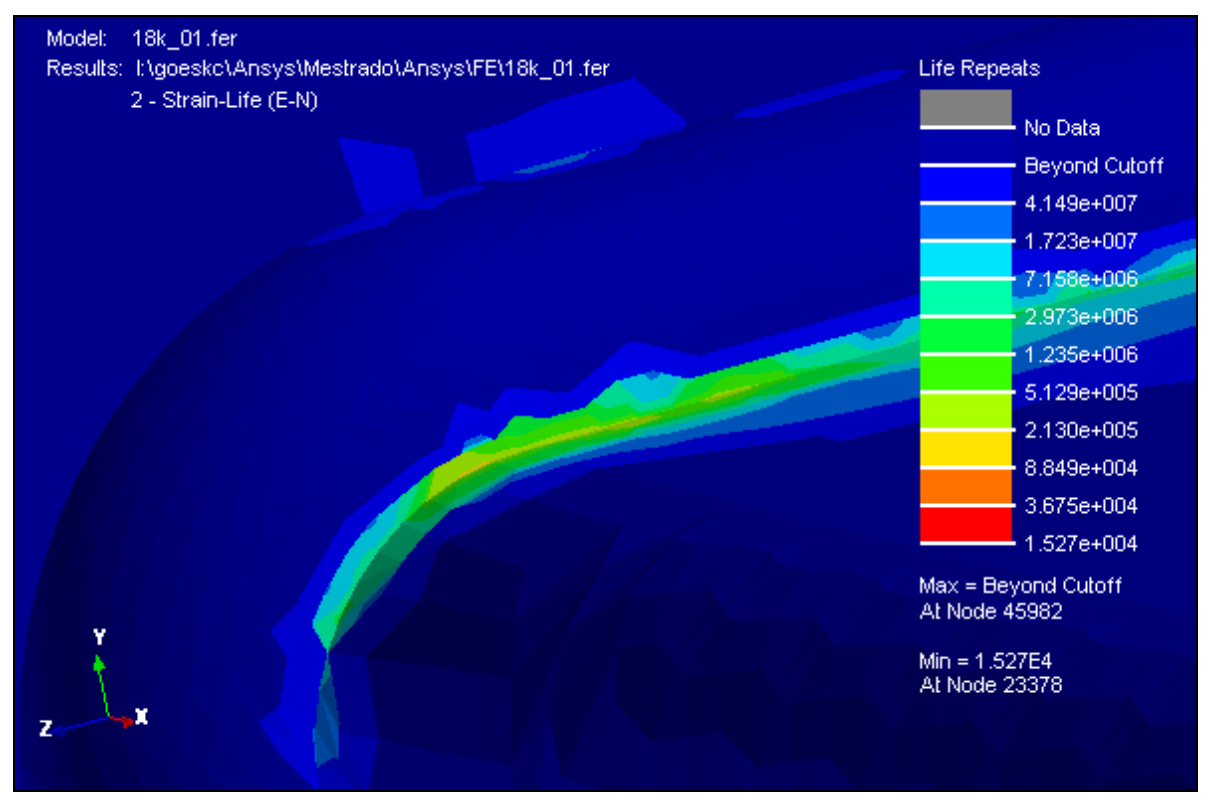

(b)

Figura 57 - Distribuição de vida para a tensão máxima principal (a) e detalhe na região crítica (b)

A Tabela 12 apresenta os valores de vida à fadiga, através do FE-Fatigue, para o ponto considerado como hot spot. 
Tabela 12 - Resultado da vida à fadiga através do FE-Fatigue para o ponto analisado.

\begin{tabular}{|c|c|c||}
\hline \multirow{2}{*}{ Carregamento } & \multicolumn{2}{|c|}{$\begin{array}{c}\text { Vida à fadiga } \\
\text { (x 103 } \text { ciclos) }\end{array}$} \\
\cline { 2 - 3 } & $\begin{array}{l}\text { Pela Tensão } \\
\text { Equivalente }\end{array}$ & $\begin{array}{c}\text { Pela Tensão } \\
\text { Máxima Principal }\end{array}$ \\
\hline \multirow{2}{*}{$18 \mathrm{kN}$} & 235 & 317 \\
\hline
\end{tabular}

A análise de vida à fadiga utilizando tensões equivalentes é a mais indicada para juntas soldadas, mas como critério comparativo, a vida à fadiga também foi obtida para a tensão máxima principal, sendo ambos os resultados apresentados na Tabela 12, onde é possível observar a maior severidade da tensão equivalente, demonstrada através do resultado inferior de vida à fadiga da junta soldada.

Através do ANSYS foi possível localizar o ponto de maior tensão da junta soldada, ocorrendo no pé da solda onde, devido à concentração de tensões geométricas e residuais, ocorre o início da trinca. Como o FE-Fatigue utiliza os resultados de tensões da ANSYS, associado à curva de vida e ao carregamento, é de se esperar que na região de maior tensão ocorra uma menor vida, afirmação esta comprovada pelo resultado de distribuição de vida do FE-Fatigue e confirmada através do ensaio de durabilidade acelerada, onde as amostras falharam na região de maior tensão e menor vida.

\subsubsection{Ensaio de Fadiga}

No presente trabalho foram realizados dois ensaios de durabilidade acelerada.

Após o início da trinca o teste foi interrompido, sendo a trinca identificada com líquido penetrante e a amostra enviada para análise da trinca.

A Figura 58a apresenta a trinca na amostra 01 e a Figura 58b a localização da trinca. 


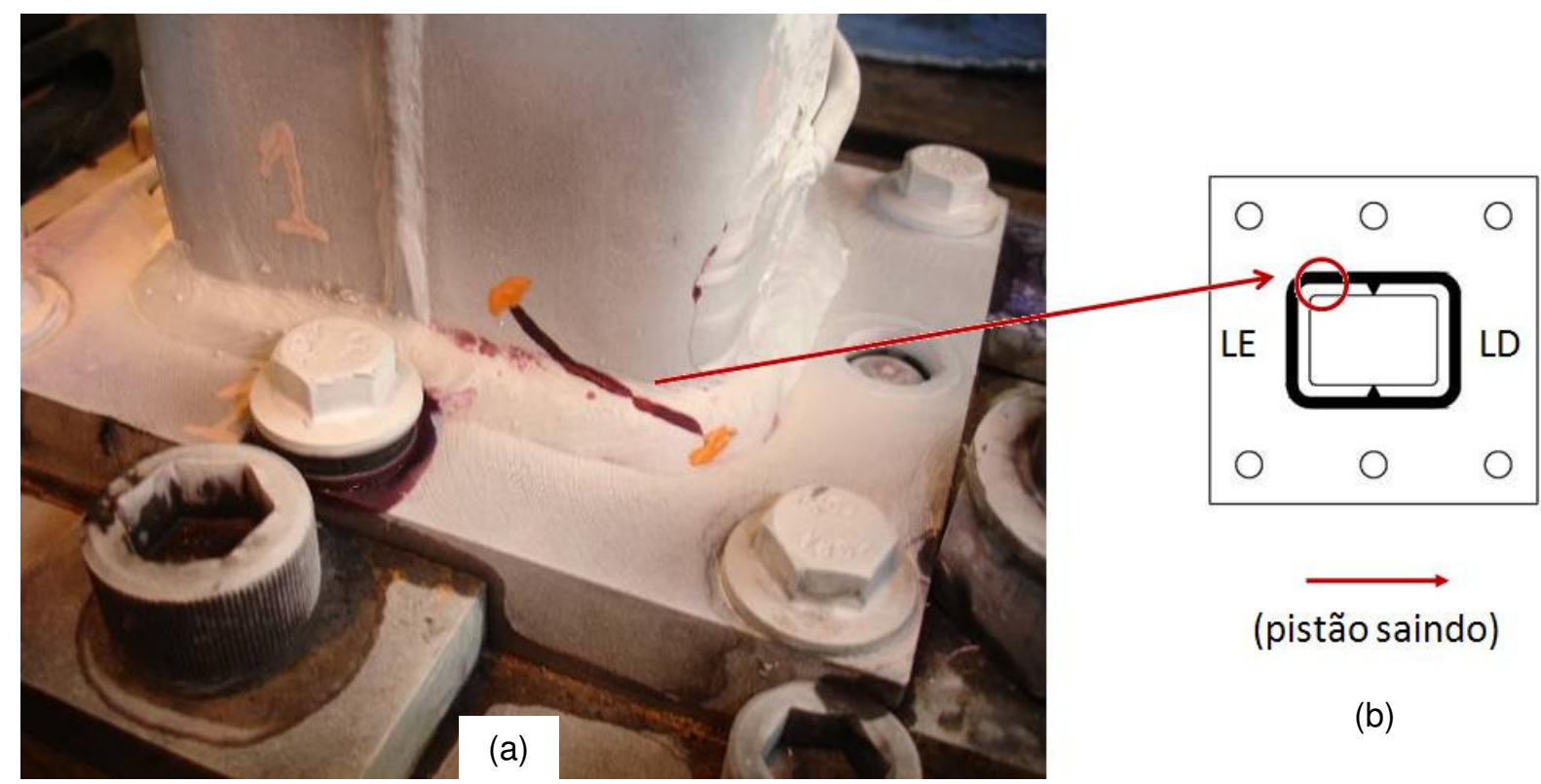

Figura 58 - Trinca após o ensaio de resistência à fadiga sob carregamento de $18 \mathrm{kN}$ (a) e localização da trinca (2) - Amostra 01

A Figura 59a apresenta a trinca na amostra 02 e a Figura 59b a localização da trinca.

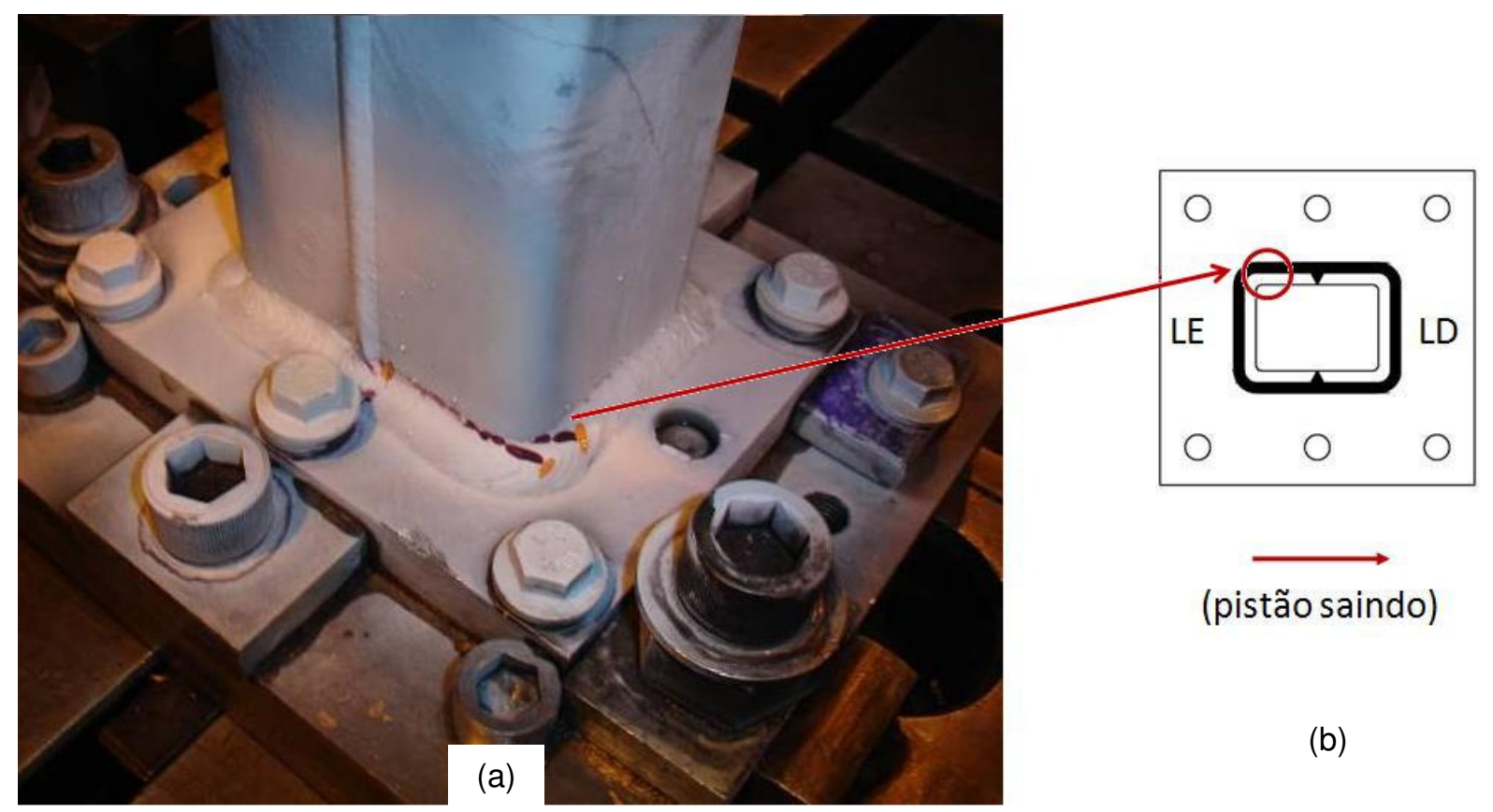

Figura 59 - Trinca após o ensaio de resistência à fadiga sob carregamento de $18 \mathrm{kN}$ (a) e localização da trinca (2) - Amostra 02

A Tabela 13 apresenta os resultados do ensaio de durabilidade acelerada realizado em laboratório. O tamanho da trinca e a vida à fadiga foram obtidos quando o ensaio foi interrompido. 
Tabela 13 - Resultados da vida à fadiga para as amostras ensaiadas em laboratório

\begin{tabular}{|c|c|c|c|}
\hline Amostra & $\begin{array}{c}\text { Carregamento } \\
(\mathbf{k N})\end{array}$ & $\begin{array}{c}\text { Tamanho da trinca } \\
(\mathbf{m m})\end{array}$ & $\begin{array}{c}\text { Vida à fadiga } \\
\left(\mathbf{x 1 0 ^ { 3 }} \text { ciclos }\right)\end{array}$ \\
\hline 01 & 18 & 45 & 309 \\
\hline 02 & 18 & 50 & 100 \\
\hline
\end{tabular}

O resultado da vida à fadiga para as amostras ensaiadas apresentou considerável diferença, que pode ser atribuída ao processo de soldagem (manual), as tensões residuais não consideradas na análise e à própria quantidade de amostras, que não são representativas para um estudo quantitativo. O objetivo dos testes de laboratório foi calibrar o modelo de EF e verificar a repetibilidade da localização da trinca, inicialmente obtida através do FE-Fatigue.

\subsubsection{Fadiga através das normas BS7608 e Eurocode 3}

As curvas de vida à fadiga das normas BS7608 (1993) e Eurocode 3 (2005) foram utilizadas para obter a vida à fadiga da junta estudada no presente trabalho.

Para a norma BS7608 (1993) foi utilizada a curva da junta tipo F e para a norma Eurocode 3 (2005) a tipo 80. A Tabela 14 apresenta os resultados obtidos para a tensão de hot spot, utilizando a distribuição de tensão equivalente das diversas abordagens estudadas.

Tabela 14 - Vida à fadiga utilizando as normas BS7608 e Eurocode 3, para a tensão de hot spot oriunda das diversas abordagens analisadas

\begin{tabular}{|c|c|c|c|}
\hline \multirow{2}{*}{ Abordagem } & \multirow{2}{*}{$\begin{array}{c}\text { Tensão Equivalente } \\
\text { hot spot } \\
\text { (MPa) }\end{array}$} & \multicolumn{2}{|c|}{$\begin{array}{c}\text { Vida à Fadiga } \\
\text { (x10 ciclos) }\end{array}$} \\
\hline & & BS7608 & EUR3 \\
\hline ANSYS & 154,2 & 459 & 429 \\
\hline Analítico & 221,8 & 153 & 126 \\
\hline Experimental & 143,6 & 569 & 545 \\
\hline
\end{tabular}


A tensão alternada apresentada no gráfico das normas considera a tensão média nula, sendo necessário uma correção quando a tensão média é diferente de zero, neste caso utiliza-se a relação de Goodmann (equação 18), por exemplo. Através da Tabela 10 a tensão média foi considerada nula, pois os valores de tensão equivalente para o carregamento de $+18 \mathrm{kN}$ e de $-18 \mathrm{kN}$ apresentam valores muito próximos, não sendo necessário nenhum critério de correção da tensão. $A$ vida é então obtida através do cruzamento entre o valor da tensão alternada e a curva que representa a geometria da junta.

Os resultados da vida à fadiga, utilizando as normas BS7608 (1993) e Eurocode 3 (2005), apresentaram valores muito próximos entre si, quando comparado os resultados de vida para uma mesma tensão alternada, sendo a norma Eurocode 3 um pouco mais conservativa, apresentando menor vida á fadiga.

A menor vida à fadiga, utilizando as normas propostas, foi obtida pela tensão analítica, por esta apresentar a maior tensão equivalente.

Comparando os resultados de vida obtidos através do FE-Fatigue, que utiliza a curva corrigida do material, e das normas BS7608 e Eurocode, pode-se observar que o primeiro apresentou maior severidade e, conseqüentemente, menor vida.

\subsection{ANÁLISE DA TRINCA POR MICROGRAFIA}

A análise do início da trinca foi realizada na amostra 01. A trinca iniciou-se numa região de leve mordedura de solda, próxima a interface do cordão de solda com o tubo, progredindo em um sentido para o tubo em diagonal e no outro sentido para o centro do cordão de solda, tendo aproximadamente $45 \mathrm{~mm}$ de comprimento.

A Figura 60 apresenta uma foto da trinca na junta soldada. A região de origem da trinca e o sentido de propagação são apresentados na Figura 61. 


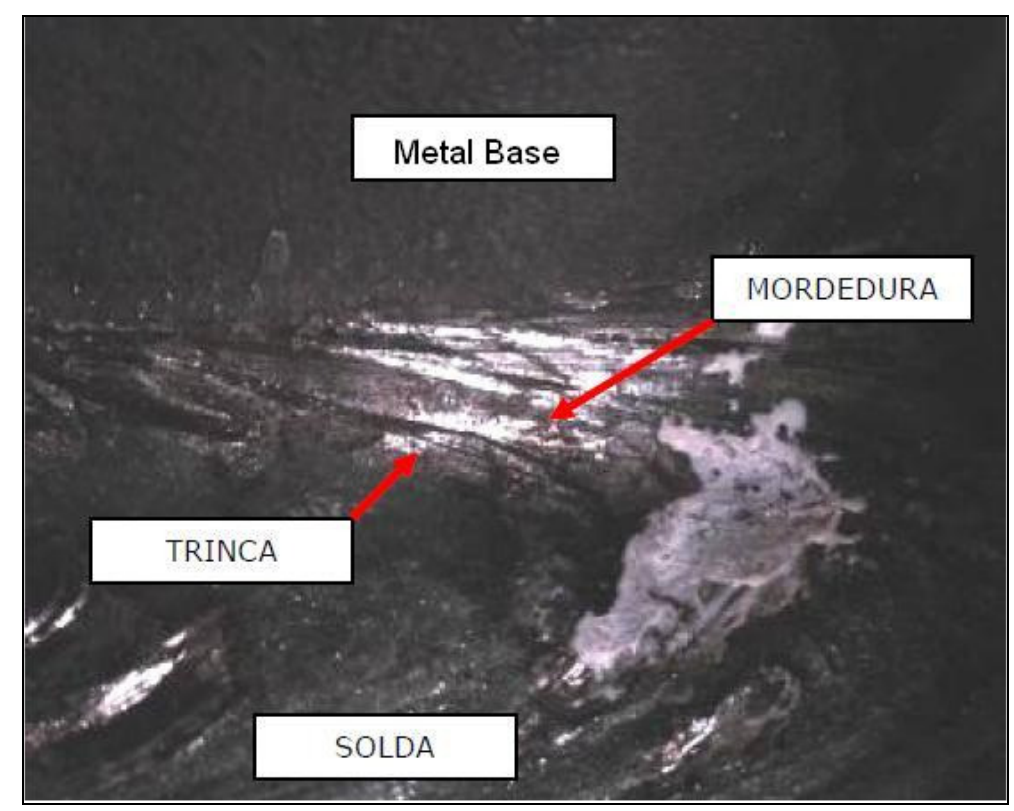

Figura 60 - Foto da trinca e regiões da junta soldada na amostra 01

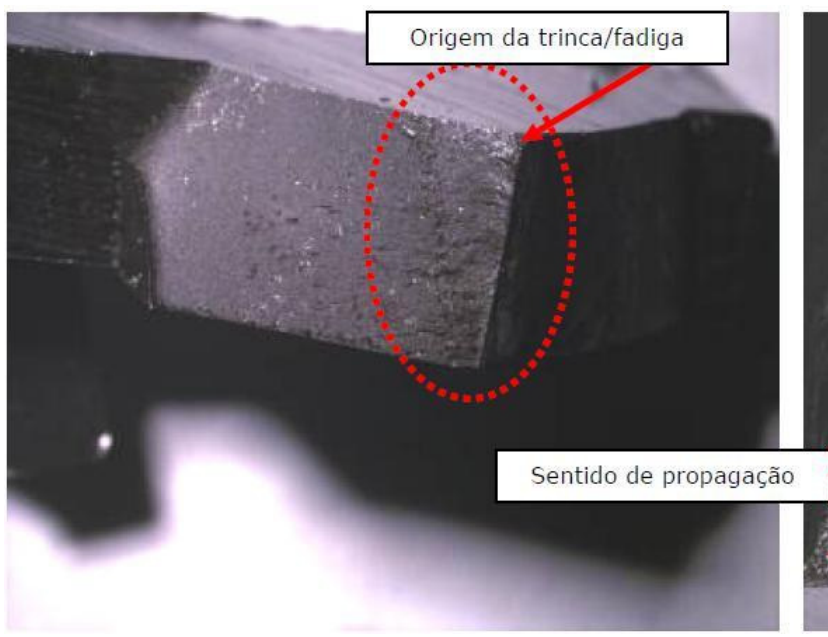

(a)

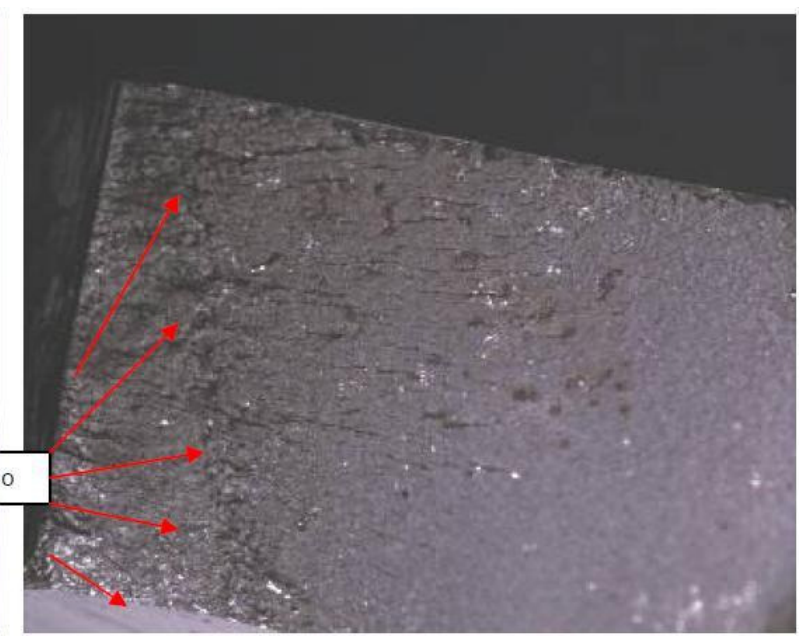

(b)

Figura 61 - Região de origem (a) e sentido de propagação (b) da trinca na amostra 01

As amostras 01 e 02, ambas submetidas a carregamento de $18 \mathrm{kN}$, foram seccionadas na região da junta soldada e atacadas com Nital 2\%. A Figura 62 apresenta a seção transversal na região da trinca para a amostra 01 e a Figura 63 para a amostra 02. 


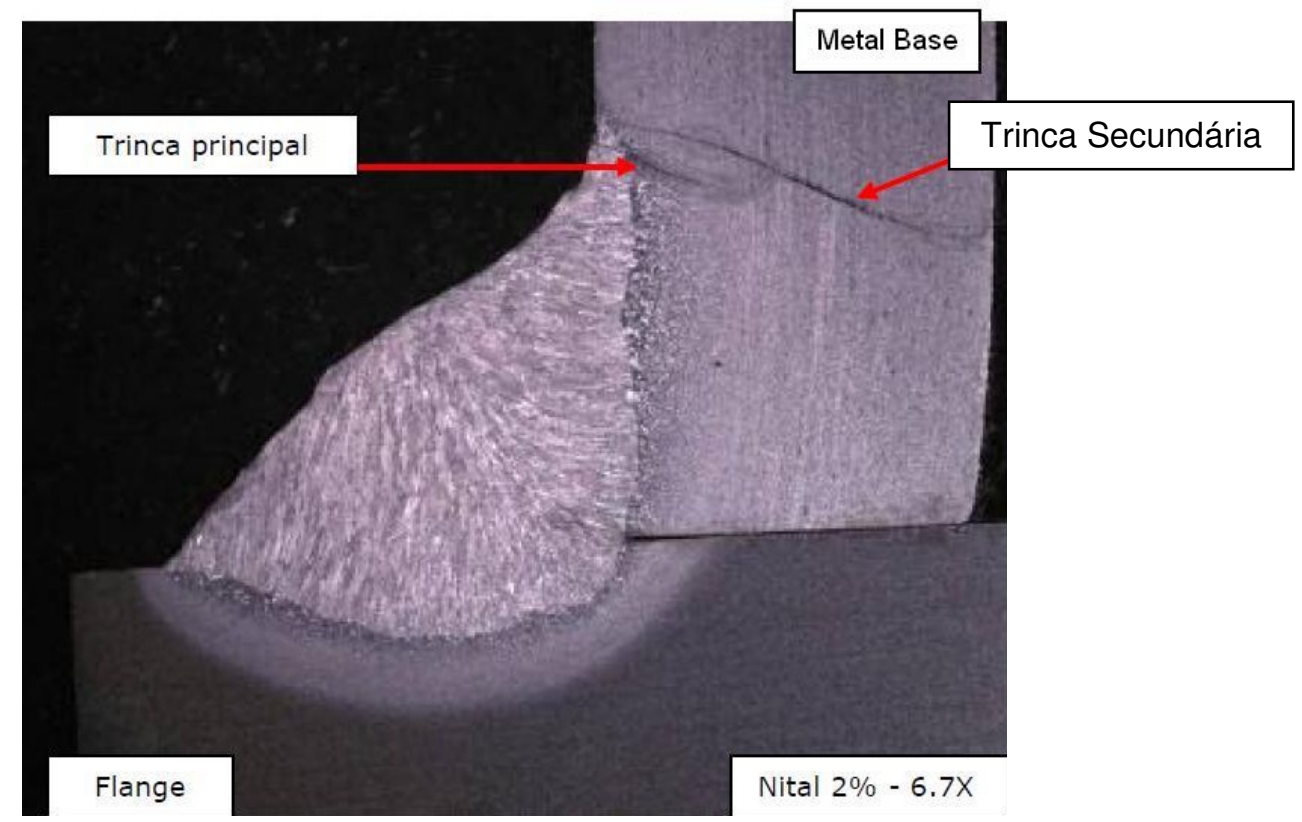

Figura 62 - Micrografia da junta soldada na região da trinca - Amostra 01

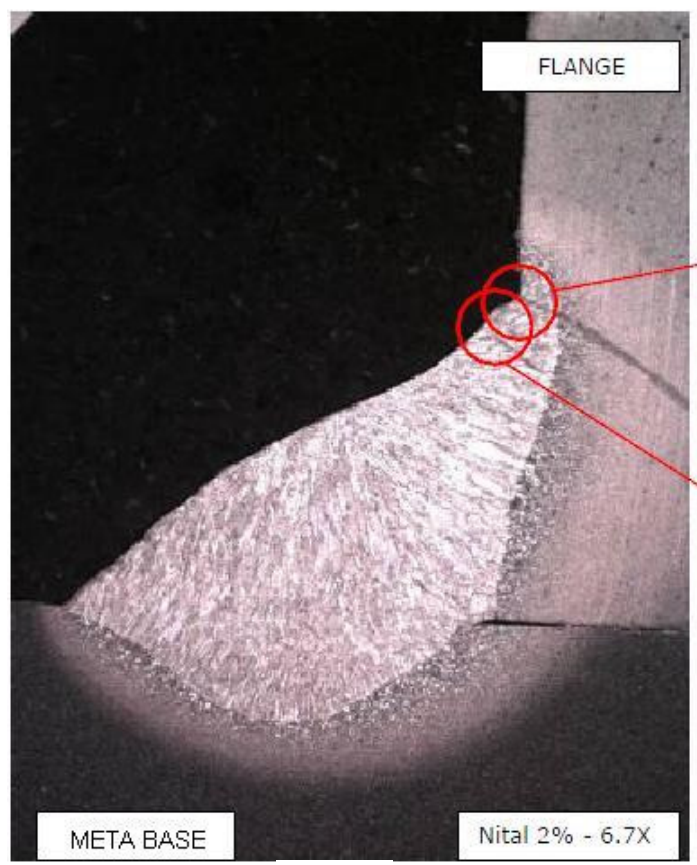

(a)

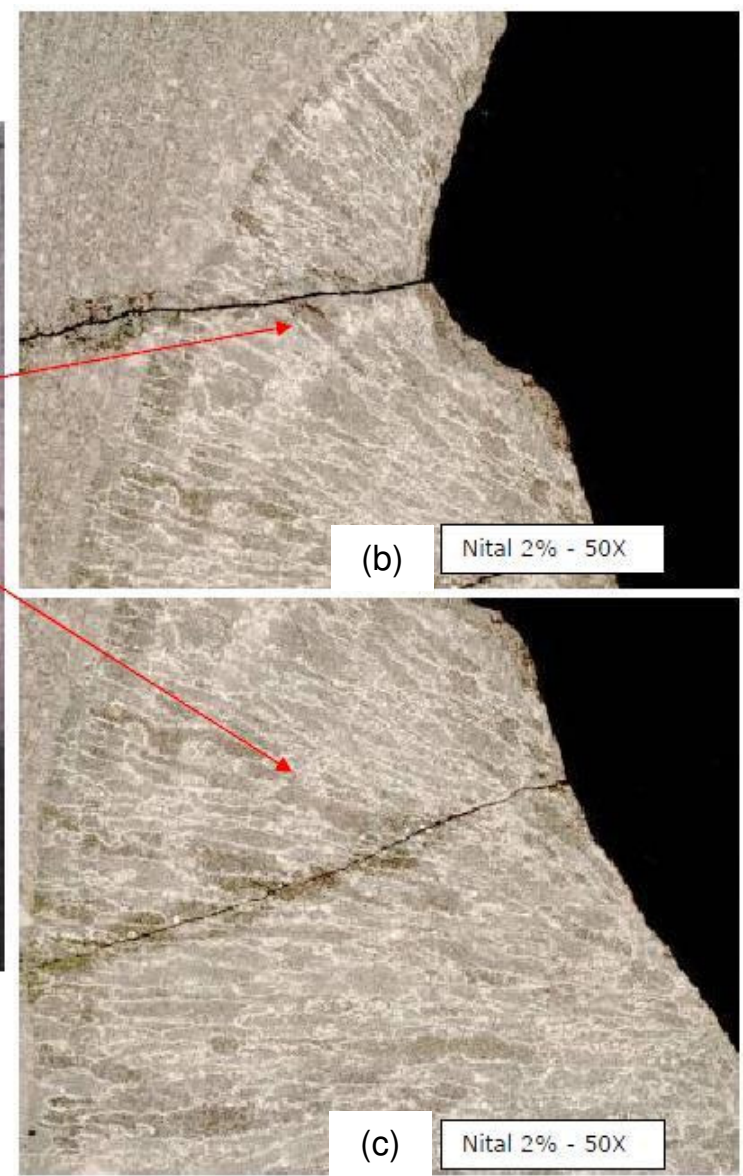

Figura 63 - Micrografia da junta soldada (a) apresentando a trinca principal (b) e secundária (c) Amostra 02 
A micrografia da junta soldada indica o início da trinca no pé da solda, corroborando com o resultado do FE-Fatigue que já indicava o início da trinca nesta localização. Através da micrografia é possível observar um entalhe no pé da solda, provocado pelo próprio processo de soldagem, que no presente trabalho foi manual.

Ambas as amostras foram cicladas até a ocorrência da trinca e apresentaram uma trinca principal e uma secundária, apresentando valores de vida de 309 e 100 mil ciclos. 


\section{CONCLUSÕES}

Os valores obtidos através do MEF foram próximos aos obtidos em laboratório, o que valida o modelo proposto.

A tensão analítica apresentou valor superior devido ao método adotado no cálculo que considera apenas a inércia do cordão de solda, sendo todos os esforços suportados pelo próprio cordão.

O modelo apresentou reprodutividade do local da falha e boa correlação das tensões.

A precisão dos resultados foi obtida através do refinamento do modelo de elementos finitos.

O efeito da tensão residual, concentração de tensão do cordão, influência de defeitos, propriedade do material, rigidez das peças, carregamentos e taxa de propagação de trinca são de extrema importância para otimização da qualidade e integridade da junta.

O Modelo é prático e confiável para desenvolver testes acelerados de fadiga submetidos a carregamentos combinados e reproduzir modos de falha em campo.

Ao integrar a análise da vida à fadiga com a simulação por Elementos Finitos é possível fazer diversas análises de configurações da junta soldada, investigando sua integridade estrutural ainda na fase de projeto, diminuindo assim o tempo e custo de desenvolvimento com o aumento da confiabilidade do projeto. 


\section{TRABALHOS FUTUROS}

- Obtenção das tensões residuais na junta soldada;

- Simulação da carga térmica e tensões residuais oriundas do processo de soldagem;

- Alívio das tensões residuais trativas através de jateamento por microesferas de aço;

- Utilização do FE-Fatigue com as curvas das normas BS7608 e Eurocode 3 inseridas no programa;

- Refinar modelo FEA considerando contato, visando reproduzir com maior precisão a rigidez da junta e seu efeito na distribuição de tensões no pé da solda. 


\section{REFERÊNCIAS BIBLIOGRÁFICAS}

ALEXANDRE S. F.; CAMARÃO, A. F.; FERNANDES, A. O.; BEZERRA, M. A.; ARGENTINO, M. A.; RIPOLI, R. R. A Finite Element Approach for Fatigue Analysis of Welded Components. SAE Brasil - International Fatigue Conference, São Paulo, pp. 229-235, 2001.

ANSYS Inc. Introduction to ANSYS. Release 10, 2006.

ASTM 837-95. Standard Test Method for Determining Residual Stress By the Hole-Drilling Strain-Gage Method. AMERICAN SOCIETY FOR TESTING AND MATERIALS, 1995.

BÄCKSTRÖM, M; SILJANDER, A.; KUITUNEN, R.; ILVONEN, R. Multiaxial Fatigue Experiments of Square Hollow Section Tube-to-Plate Welded Joints. In: Blom, A.F. (ed.). Welded High-Strength Steel Structures. Proceedings of the First North European Engineering and Science Conference (NESCO I), Suécia, Estocolmo, October. London: EMAS Publishing, pag. 163-177, 1997.

BÄCKSTRÖM, M. Multiaxial fatigue life assessment of welds based on nominal and hot spot stresses, VTT technical Research Center of Finland, VTT Publications no 502, Finlandia, 107p, 2003.

BANNANTINE, J.; COMER, J. J.; HANDROCK, J. Fundamentals of Metal Fatigue Analysis. USA: Ed. Prentice Hall, 1990.

BATHE, K. J. Finite Element Procedures in Engineering Analysis. New Jersey: Prentice Hall, 1982.

BORESI, A. P.; SCHMIDT, R.J.; SIDEBOTTOM, O. M. Advanced Mechanics of Material. 5. Ed. EUA: John Wiley \& Sons, 811p. 1993.

BRANCO, C. M.; FERNANDES, A. A.; CASTRO, P. M. S. T. Fadiga de Estruturas Soldadas. Portugal: Ed Fundação Calouste Gulbenkian, 1986.

BS153:Part 3A:1972, Specification for steel girder bridges - Loads. British Standard, EUA, 1972. 
BS7608:1993, Code of practice for Fatigue design and assessment of steel structures. British Standard, London, 1993.

CAMARÃO, A. F. Elementos Finitos: o uso do ANSYS 5.0A na indústria automotiva. Máquinas e Metais no 342, Aranda Editora Técnica, pag 34-49, 1994.

CHIAVERINI, V. Tecnologia Mecânica - Processos de Fabricação e Tratamento. Vol. 2, 2ª edição, Ed. McGraw-Hill, 1986.

Eurocode 3, Design of steel structures. Part 1-9: Fatigue (EN 1993-1-9:2005), Belgica. 2005.

FRICKE, W. Fatigue Analysis of welded joints: state of development. Marine Structures 16. pag 185-200, 2003.

FUCHS, H. O.; STEPHENS, R. I. Metal Fatigue in Engineering. Canada: John Wiley \& Sons, 1980.

GOES, K. C.; BATALHA, G. F.; CAMARÃO, A. F. A Fatigue Analysis model of Welded Joints within Finite Element environment. In IIW INTERNATIONAL CONGRESS, $2^{\circ}$ Latin American Welding Congress e XXXIV CONSOLDA. Maio, 19, 2008. São Paulo: ABS, 2008. Anais.

GOES, K. C ; CORREIA, E. M. G. ; CAMARÃO, A. F. ; BATALHA, G. F. Uma Metodologia Numérico-Experimental Aplicada ao Projeto de Juntas Soldadas em Eixos Automotivos. In V Congresso Nacional de Engenharia Mecânica, Agosto 27, 2008. Salvador: ABCM, 2008. Anais.

GOES, K. C. ; CAMARÃO, A. F. ; SANTOS, A. L. ; BATALHA, G. F. Finite Element Modeling Techniques of 3D Welded Joints - The Structural Hot Spot Approach. In 20th International Congress of Mechanical Engineering, Novembro 15-20, 2009. Gramado. ABCM, 2009. Anais.

GOES, K. C.; BATALHA, G. F.; CAMARÃO. Multiaxial Fatigue of Welded Joints A Method for Fatigue Life Prediction. In 20th International Congress of Mechanical Engineering, Novembro 15-20, 2009. Gramado. ABCM, 2009. Anais.

GOMES, J. F. D. S. Desenvolvimento de um Sistema Computadorizado de Medição de Tensões Residuais, Dissertação de Mestrado, Rio de Janeiro: DEMPUC RIO, 1990. 
GRANT, P. V. ; LORD, J. D. ; WHITEHEAD, P. S. Measurement Good Practice Guide N. 53. Reino Unido: National Physical Laboratory, 53 p. 2002.

GUSTAFSSON, J.; SAARINEN, J. Multi-axial fatigue in welded details - An investigation of existing design approaches. Dissertação de Mestrado, Chalmers University of Technology, Suécia, 117p, 2007.

IIDA, K. Application of hot spot strain concept to fatigue life prediction. Welding in the World, vol. 22, n. 9/10, pag. 222-246, 1984.

LIRA Jr, J. D. Análise de Fadiga em Juntas Soldadas pelo Processo MIG/laser utilizando o Método dos Elementos Finitos. Dissertação de Mestrado, Universidade Federal de Pernambuco, Recife. 69p, 2006.

MASUBUCHI, K. Analysis of Welded Structures. International Series on Material Science and Technology, Vol. 33. MIT. EUA: Ed. Pergamon, 1980.

MESSLER, R. W. Principles of Welding: Processes, Physics, Chemistry and Metallurgy. EUA, Ed. Wiley-Interscience, 1르 edição, 1999.

NASCIMENTO, M. P. Retrabalho em Estruturas Aeronáuticas Soldadas do Aço ABNT4130 - Em Foco: Berços de Motores de Aeronaves. Dissertação de Mestrado. São Paulo: Universidade Estadual Paulista (Unesp), 240p. 2004.

nCode. FE Fatigue Release 7 Worked Examples, 2006.

NIEMI, E. Stress Determination for Fatigue Analysis of Welded Components. Cambridge: Abington Publishing, 69p. 1995.

NITSCHKE-PAGEL, T. e DILGER, K. Eigenspannungen in Schweißverbindungen - Teil 1: Ursachen der Eigenspannungsentstehung beim Schweißein. Schweißen und Schneiden, 58, pag. 466-479, 2006.

NOYAN, L. C. e COHEN, J. B. Residual Stress: Measurements by diffraction and Interpretation. Springer-Verlag, 1987.

OKUMURA T. e TANIGUCHI, C. Engenharia de Soldagem e Aplicações. São Paulo, Editora LTC, 1982. 
RAZMJOO, G.R. Fatigue of load-carrying filled welded joints under multiaxial loading. Reino Unido: Abington Hall, Abington Cambridge. TWI. Pag. 10, 1996.

SAE J784a. Residual Stress Measurement by X-Ray Diffraction. Handbook Supplement, Society of Automotive Engineers - SAE, 1971.

SAE72-0242. Equipment and Methods of X-Ray Stress Analysis. 1972.

SEGERLIND, J. L. Applied Finite Element Analysis. EUA, Ed. Wiley, 1984.

SHIGLEY, J E. Elementos de Máquinas. Vol 2. Brasil, Ed. LTC, pag. 354-362, 1984.

SILJANDER, A.; KURATH, P.; LAWRENCE, F.V. Jr. Nonproportional Fatigue of Welded Structures. In: Mitchell, M.R., Landgraf, R.W. (ed.). Advances in fatigue lifetime predictive techniques. USA: ASTM, pag. 319-338 (ASTM STP 1122), 1992.

SILVA, B. M. Alívio de tensões residuais em juntas soldadas de caixa espiral de turbina hidráulica. Dissertação de Mestrado. São Paulo: Universidade Estadual Paulista (Unesp), 132p, 2005.

SONSINO, C.M. Multiaxial Fatigue of Welded Joints Under in-phase and out-ofphase Local Strains and Stresses. International Journal of Fatigue, Vol. 17, N. 1, pag. 55-70, 1995.

SONSINO, C.M. Schwingfestigkeit von geschweißten Komponenten unter komplexen elasto-plastischen, mehrachsigen Verformungen. Darmstadt: Fraunhofer Institut Betriebsfestigkeit and Luxembourg: Commission of European Communities (LBF-Nr. 6078 and EUR-report No. 16024), 1997.

SONSINO, C. M. Multiaxial fatigue assessment of welded joints Recommendations for design codes. International Journal of Fatigue, Vol. 31. N. 1, pag. 173-187, 2009.

TANALA, E.; BOURSE, G.; FREMIOT, M.; BELLEVAL. J. F. Determination of near surface residual stresses on welded joints using ultrasonic methods. NDT\&E International. Vol. 28, N. 2, pag. 83-88, 1995. 
TIMOSHENKO, S. P. e GOODIER, J. N. Theory of Elasticity. 3. Ed. Singapura: McGraw-Hill, 567p. 1982.

YUNG, J. Y.; LAWRENCE Jr, F. V. Predicting the Fatigue Life of Welds Under Combined Bending and Torsion. Urbana-Champaign: University of Illinois, USA. 27 p. (UILU-ENG 86-3602, Report No. 125), 1986.

ZAHAVI, E. The Finite Element Method in Machine Design. USA: Prentice-Hall, 305p. 1992.

ZIENKIEWICZ, O. C. The Finite Element Method. New York: McGraw-Hill, New York, 1973. 